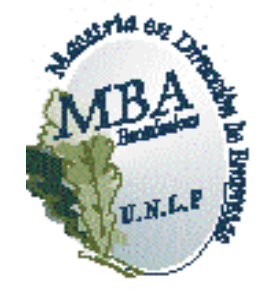

Universidad Nacional de La Plata

Facultad de Ciencias Económicas

MBA - Maestría en Dirección de Empresas

\title{
La Competitividad Empresarial en la región de La Plata, Berisso y Ensenada
}

\section{Trabajo final para optar al título de Magister}

\section{La Plata}

Noviembre 2012 


\section{Índice}

1. Planteo del Problema ................................................................................ 1

2. Objetivos de la Investigación ............................................................ 4

3. Evaluación del Problema ......................................................................... 5

4. Alcance de la Investigación..................................................................... 8

5. Marco Teórico de Referencia .................................................................... 9

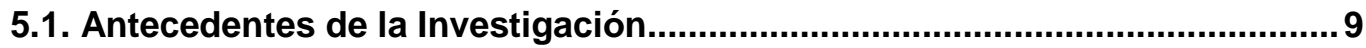

5.2. Bases Teóricas ............................................................................................10

5.2.1. El concepto de la Competitividad.................................................................... 10

5.2.2. La teoría económica moderna: el modelo de la ventaja competitiva de las naciones

5.2.2.1. El diamante de la ventaja competitiva nacional ........................................ 19

5.2 .2 .1 .1 . Las condiciones de los factores.................................................. 21

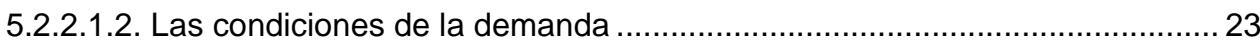

5.2.2.1.3. Los sectores afines y auxiliares........................................................ 25

5.2.2.1.4. La estrategia de la empresa, la estructura y la rivalidad ........................ 27

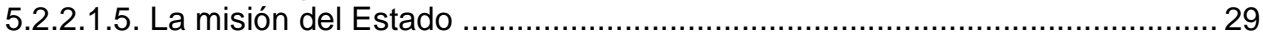

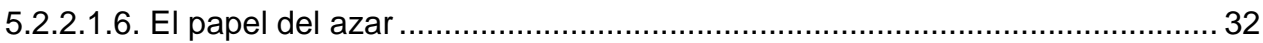

5.2.2.2. El diamante como sistema ................................................................ 33

5.2.2.3. Los cúmulos (clusters) y la competitividad................................................ 35

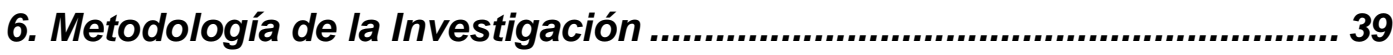

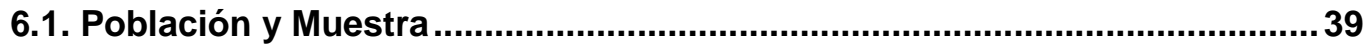

6.2. Tipo de Investigación ................................................................................ 41

6.3. Técnicas de Recolección de Datos ..............................................................41

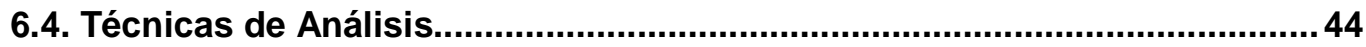

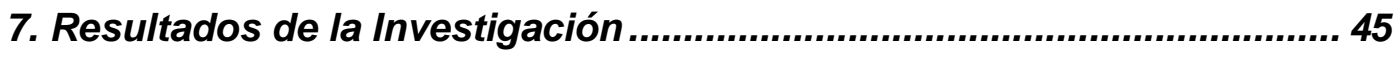

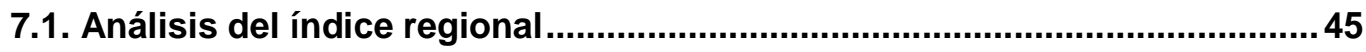

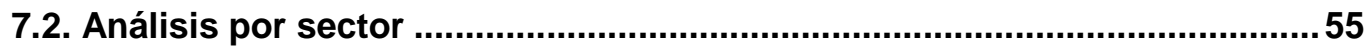

7.3. Análisis comparativo con índices internacionales .................................58

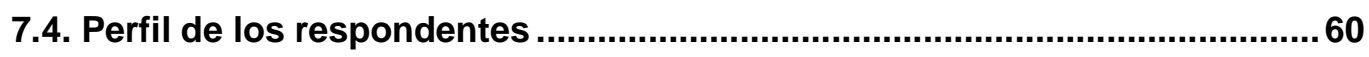

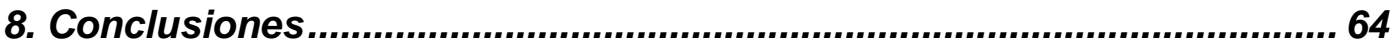

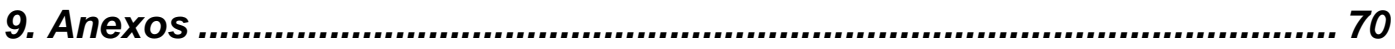

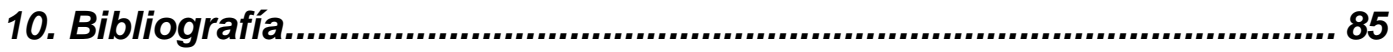




\section{Planteo del Problema}

Según el informe de Standard \& Poor's "América Latina: La esforzada clase media del mundo" de octubre de 2011, que indica que en comparación con muchos países de Asia, en gran parte de América Latina se han hecho escasos progresos en las reformas microeconómicas y otras políticas que aumenten la productividad y el crecimiento del PBI.

El informe argumenta que poco y nada se ha reducido la brecha del ingreso per cápita en las últimas décadas entre los países avanzados y los mercados emergentes, con excepción de los países de rápido crecimiento de Asia oriental y sudoriental. Según estudios recientes, la brecha de ingreso per cápita entre América Latina y los países avanzados, como EE.UU., es más un reflejo de la pobre productividad en general que una brecha en el nivel de insumos, tales como el capital y el trabajo, que están disponibles para la producción. Algunas empresas en América Latina han sido capaces de cerrar la brecha de productividad frente a sus competidores en los países avanzados, pero las ganancias de productividad a nivel de empresas individuales y entre grupos de empresas de sectores en particular en América Latina no se ha traducido en una mejora sustancial en el nivel general de productividad de la economía y del ingreso per cápita.

Se resalta que tanto los países de Asia como América Latina han sido capaces de impulsar el crecimiento de la productividad en sectores individuales de la economía, pero que Asia ha tenido más éxito en lograr un cambio estructural más amplio.

Según el analista de S\&P -Joydeep Mukherji-, América Latina tiene la oportunidad de desarrollar su propia combinación de crecimiento en capacidades y recursos para aprovechar sus talentos y recursos naturales, así como la proximidad geográfica a los mercados de EE.UU. y la UE. Pero "un 
avance lento simplemente mantendrá el perfil histórico de América Latina como la «clase media» del mundo"1.

El informe incorpora cifras del BID, según las cuales entre 1960 y 1980 América Latina comenzó a cerrar su brecha de productividad en comparación con EE.UU., pero en las décadas siguientes se estancó, "con la excepción de Chile”. Este país tiene la mayor productividad de América Latina y el Caribe, alcanzando el $75 \%$ de la productividad total de factores (PTF) de EE.UU., mientras Brasil y México están por debajo del 60\%. Según el documento, "la experiencia de los países asiáticos, así como Chile, señala la importancia de realizar reformas microeconómicas y otras iniciativas para reducir los costos de hacer negocios, incentivar la inversión, la innovación y las nuevas tecnologías, así como el crecimiento de nuevas sectores de la economía".

"En conjunto, América Latina no ha sido tan exitoso como muchos países de Asia en el cambio de los trabajadores de baja a sectores de mayor productividad", según Mukherji.

A una conclusión similar llega el informe del Foro Económico Mundial ${ }^{2}$ del año 2011. En el primer párrafo del apartado dedicado a la Argentina, el informe expresa que el "extraordinario potencial competitivo" se mantiene "incumplido". Según dicho estudio, si Argentina no atiende las dificultades que están obstaculizando la competitividad y no se introducen reformas estructurales, será imposible mantener un crecimiento fuerte, agravado por un contexto mundial desfavorable, la inflación y el deterioro de la estabilidad macroeconómica.

El informe mostró un estancamiento de la Argentina en relación con la escala del año pasado. Pese a haber subido dos escalones, al aumentar la cantidad de países evaluados, quedó en una posición "relativamente estable", según se describe. Desde un punto de vista comparativo, la competitividad local quedó

\footnotetext{
${ }^{1}$ Diario Financiero S\&P - Oc.t, 2011

http://www.df.cl/s-p-chile-tiene-la-mayor-productividad-de-la-region/prontus_df/2011-10-03/215303.html

2 Foro Económico Mundial en http://www.weforum.org/reports
} 
por debajo de la medición de Chile, Brasil, Uruguay y Perú, entre otros países latinoamericanos. Según dicho informe, la competitividad en el país está socavada por "la falta de confianza en las instituciones y la gran ineficiencia en la distribución de los bienes, recursos humanos y recursos financieros".

El Foro Económico Mundial considera que la falta de confianza en el sistema financiero atenta contra la asignación eficiente de sus recursos. Además explica que la Argentina podría sufrir una "vuelta a las fluctuaciones erráticas del pasado, con períodos de larga expansión seguidos de profundas recesiones".

Por otro lado, las estadísticas de comercio exterior ${ }^{3}$ indican que la industria manufacturera argentina carece de competitividad suficiente como para ganar y hasta mantener mercados externos.

Puede afirmarse que la región tomada por objeto se ve inmersa en un contexto internacional donde las reformas llevadas a cabo no han sido capaces aun de mejorar sustancialmente las perspectivas de crecimiento a largo plazo. Es de conocimiento que los tres distritos seleccionados para el estudio lidian con las fluctuaciones del mercado argentino y a su vez, de la perspectiva latinoamericana de competitividad.

3 Instituto Nacional de Estadística y Censos -INDEC- en www.indec.mecon.ar 


\section{Objetivos de la Investigación}

- Identificar las dimensiones y sectores o sub-sectores en los cuales se presentan las mayores oportunidades o debilidades de competitividad en el ámbito regional.

- Evaluar la eficacia con que la economía regional utiliza su stock de recursos.

- Detectar las oportunidades para la mejora de la competitividad. 


\section{Evaluación del Problema}

El nivel de vida de una nación está determinado por la productividad de su economía, la cual es medida por el valor de los bienes y servicios producidos por unidad de recursos humanos, de capital y naturales de una nación. La productividad depende tanto del valor de los productos y servicios de una nación, medido por los precios que pueden merecer en mercados abiertos, como por la eficiencia con que pueden ser producidos.

La verdadera competitividad, entonces, es medida por la productividad. La productividad permite a una nación soportar altos salarios, una moneda fuerte, y una atractiva rentabilidad al capital $-\mathrm{y}$ junto con ello un alto nivel de vida-. La productividad es la meta, no las exportaciones por si mismas. La productividad es la meta, no si las empresas que operan en el país son locales o de propiedad extranjera. Lo que más importa no es la propiedad, sino la naturaleza y la productividad de las actividades de las empresas en un país en particular. A las industrias completamente locales también les importa la competitividad porque su productividad tiene una mayor influencia en el costo de vida y en el costo de hacer negocios, sin mencionar su nivel de salarios. La productividad de toda la economía tiene importancia para el nivel de vida, no sólo para el sector de los bienes transados.

"La economía mundial no es un juego de suma cero. Muchas naciones pueden mejorar su prosperidad si es que pueden mejorar su productividad. El desafío central para el desarrollo económico, entonces, es hallar el camino para crear las condiciones para un rápido y sostenido crecimiento de la productividad» ${ }^{4}$.

\section{Competitividad en el territorio}

La competitividad de una región es la habilidad o capacidad de esta economía para alcanzar una prosperidad sostenida. Esto implica no sólo un aumento de

\footnotetext{
${ }^{4}$ Michael E. Porter, Universidad de Harvard

Septiembre, 2011. Centro Internacional para el Desarrollo de la Competitividad Empresarial.

http://www.amands.net/co0_0.htm
} 
la productividad, del ingreso y de las exportaciones (eso que tradicionalmente se entiende como "crecimiento económico"); la competitividad significa, además, el mejoramiento de la equidad, entendida como la reducción de la pobreza y la desigualdad social y la sustentabilidad ambiental.

En términos económicos, la competitividad puede ser definida como la capacidad de una empresa para producir bienes y servicios que alcancen los estándares de los mercados internacionales, en condiciones de mercado libre, manteniendo o aumentando, al mismo tiempo, su ingreso real. Esta definición supone que las que compiten son las empresas, que lo hacen con niveles de alta calidad y que no deben sostener su éxito en la protección arancelaria o en los bajos salarios.

Ahora bien, la posibilidad de que compitan con éxito depende de factores que escapan a su control directo. Hay condiciones del contexto en el que se desempeñan que son decisivas. Estas no son puramente económicas, sino que incluyen dimensiones sociales -como la reducción de las desigualdades-, culturales -como la existencia de un buen sistema educativo - y políticas como un buen funcionamiento de las instituciones-. Estas dimensiones tienen una localización territorial, sea nacional, provincial o regional. Los gobiernos tienen una responsabilidad básica en la creación y en el mantenimiento de estas condiciones.

De este modo, es factible pasar de un concepto de competitividad centrado en la empresa, a otro focalizado en las capacidades que una región determinada posee o desarrolla para alcanzar una prosperidad económica sostenida. Esas aptitudes se pueden agrupar en distintos aspectos:

- La capacidad para exportar y para atraer inversiones.

- Los recursos humanos y su relación con el progreso técnico.

- La infraestructura -básicamente vial, energética e hídrica- y los recursos naturales -incluyendo la calidad del medio ambiente-.

- Las condiciones institucionales. 
Hacer mención a la competitividad de las regiones es referirse a la capacidad de las mismas para "estar en el mundo", para generar recursos y poder introducirlos en el mercado, para lograr una producción diversificada que pueda satisfacer a los mercados interno y externo. La competitividad no alude a la competencia entre las regiones sino a la necesidad de que todas tengan las capacidades y los recursos necesarios para propiciar el desarrollo integral de sus habitantes.

El desarrollo consiste en lograr un crecimiento equilibrado, con mejoras sustanciales y sostenidas en la calidad de vida de los habitantes. 


\section{Alcance de la Investigación}

Los resultados que se presentan son el producto de un proyecto de investigación del MBA cuyo título es "La competitividad empresarial y su impacto regional", en proceso de acreditación en el marco del Programa de Incentivos de la Secretaría de Ciencia y Técnica de la UNLP, con un tronco común que luego se divide en cada uno de los subsectores industriales de la economía regional.

La Investigación se realizó en la región comprendida por los partidos de La Plata, Berisso, y Ensenada y comprendió el último trimestre 2011. 


\section{Marco Teórico de Referencia}

\subsection{Antecedentes de la Investigación}

La presente investigación reconoce como antecedentes a "The Global Competitiveness Report» del WEF (World Economic Forum) y el "World Competitiveness Yearbook» del IMD (Institute for Management Development). EI WEF es una organización privada, internacional, independiente y sin fines de lucro con base en Ginebra, Suiza, conocida por su asamblea anual en Davos. La misma involucra a líderes empresariales, políticos, intelectuales y sociales, que comprometidos con la mejora, tratan y debaten temas de interés industrial, regional y global.

EI WEF lleva a cabo conferencias en distintas partes del mundo para tratar temas actuales de impacto global, entre las que destaca el Foro de Davos, en Suiza, donde normalmente participan los Gerentes Ejecutivos de las empresas más influyentes del mundo, Jefes de Estado e intelectuales de renombre internacional.

Asimismo, el WEF es responsable de una serie de publicaciones anuales entre las que destaca el Global Competitiveness Report, que analiza la competitividad de 133 naciones, basándose en más de 110 indicadores que incluyen cifras oficiales provenientes de diversas fuentes nacionales e internacionales y la información proveniente de encuestas de opinión realizadas a más de 12 mil líderes empresariales en todos los países.

La columna vertebral del informe es el Índice de Competitividad Global (ICG), que captura el conjunto de instituciones, políticas y factores que determinan el crecimiento económico sostenible y ayudan a explicar por qué algunos países son más exitosos que otros en elevar, de manera sostenible, su productividad, niveles de ingreso y oportunidades para sus respectivas poblaciones. 


\subsection{Bases Teóricas}

\subsubsection{El concepto de la Competitividad}

El concepto de competitividad fue modificándose a lo largo de la historia del pensamiento económico. El primero es el que se basa en la competitividad como ventaja comparativa (teoría clásica), y el segundo es el que toma como precepto la ventaja competitiva.

Las primeras ideas de competitividad surgieron con la teoría del comercio internacional, siendo éste uno de los impulsores de crecimiento de una economía. Para los mercantilistas, el comercio internacional se basaba en un juego de suma cero, dada la presencia de naciones que exportaban y se enriquecían versus naciones importadoras que se empobrecían.

Adam Smith sostenía que todos los países podían obtener beneficios del comercio internacional, basados en una ventaja absoluta que es la producción a costos unitarios menores. La ganancia del comercio en las naciones surgía por la producción más eficiente de algún producto. Sin embargo, esta teoría no admitía el comercio entre naciones cuando una de ellas era eficiente en la producción de varios bienes. Aquí es donde surgió la teoría de la ventaja comparativa que explica David Ricardo. La teoría de la ventaja comparativa explica que la ganancia resulta por la mayor producción en el bien en el que un país tiene una ventaja comparativa. Al exportar el bien en el que tiene ventaja comparativa, un país puede aumentar el consumo de bienes. Así, el comercio podía seguir siendo un juego en el que todos se beneficiaban, aunque en este caso se permitía que los países se especializaran en la producción de más de un bien. De esta manera, el patrón de producción de un país es determinado por la ventaja comparativa. Según este modelo, no solo son los países los que ganan con el comercio, sino que también los individuos se ven beneficiados como consecuencia del mismo.

Posteriormente, apareció el modelo de Heckscher y Ohlin basado en dotaciones factoriales. El modelo establecía que un país tendrá una ventaja 
comparativa en aquellos bienes que requieran una mayor cantidad del factor del cual tiene una abundancia relativa.

Hasta aquí, todas las teorías identifican el concepto de competitividad con la ventaja de costos relativos o precios, donde no se requiere la presencia del Estado ni tampoco existe ausencia de fallas en los mercados.

A finales de los noventa surge el modelo de la ventaja competitiva de las naciones de la mano de Michael Porter $^{5}$, quien pretendía dar respuestas teóricas a una realidad mucho más compleja que la asumida por los teóricos clásicos, puesto que la teoría de la ventaja comparativa ya no explicaba suficientemente la competitividad de las naciones. Además, y a pesar de que el comercio seguía siendo un factor esencial en el éxito competitivo de un país, existían otras cuestiones que iban más allá de la compraventa de productos y las dotaciones naturales de factores.

Los cambios en la naturaleza de la competencia internacional, entre ellos el surgimiento de las multinacionales, que no sólo exportan sino que también compiten en el extranjero por medio de sucursales extranjeras, han restado validez a las explicaciones tradicionales de por qué y dónde exporta una nación (Porter) $^{6}$. Muchos son los interrogantes que la teoría clásica no logra responder:

- Cuáles son las naciones pueden conseguir economías de escala y en qué industrias,

- Por qué determinadas empresas de una nación establecen liderazgos en industrias emergentes,

- Por qué naciones menos desarrolladas o con un mercado doméstico más pequeño surgen como líderes mundiales.

- Por qué la innovación es un aspecto continuo en muchas industrias a diferencia del concepto de la teoría del ciclo del

\footnotetext{
${ }^{5}$ Capitulo 1: “La competitividad Internacional de las Naciones”. De: "La Ventaja Competitiva de las Naciones" 1990 Michael Porter

${ }^{6}$ Curiosamente, más tarde Porter sería criticado por no incorporar propiamente en su modelo la actividad de las multinacionales (e.g., Rugman (1991); Moon, Rugman y Verbeke (1995)).
} 
producto que consideraba que era una aspecto puntual y concreto.

- Por qué algunas empresas son capaces de obtener ventajas en determinadas industrias y en otras no.

Todas estas cuestiones empezaban a suscitar dudas a muchos académicos sobre la viabilidad de los modelos clásicos para analizar apropiadamente la realidad de entonces.

Krugman, en un artículo titulado "Competitividad: una obsesión peligrosa", menciona su desconfianza sobre muchas cuestiones básicas tomadas de la teoría clásica y que estaban ampliamente difundidas entre académicos, empresarios y políticos. El autor consideró que el término competitividad se estaba utilizando con poca rigurosidad. Además, destacó que no se establecía diferencia alguna entre la competitividad de una empresa y la competitividad de una nación, cuando las naciones no compiten de la misma forma que las empresas, ni el comercio es un juego de suma cero. Para ello, se centra en el punto límite, de forma que si la empresa no puede pagar a sus empleados, accionistas y proveedores, ésta dejará de existir. Sin embargo, los países no dejarán de existir por no ser competitivos, en realidad no tienen bien definido su punto límite.

A su vez, el déficit en la balanza comercial de un país puede ser síntoma de fortaleza, mientras que el superávit podría ser un indicador de debilidad. No obstante, el autor entiende que políticamente es más correcto y resulta más fácil transmitir a empresarios y directivos el hecho de que la competitividad de una nación sea similar a la de una empresa. También advierte que la obsesión por el término de competitividad presenta tres peligros importantes:

a) los esfuerzos por incrementar la competitividad podrían resultar un gasto inútil de dinero público;

b) podría conducir a políticas proteccionistas;

c) implicaría la toma de decisiones políticas en cuanto a una amplia variedad de temas claves para las naciones. 
Por otro lado, como argumenta Porter, la teoría clásica no asume el papel de la estrategia empresarial como, por ejemplo, mejorar la tecnología o diferenciar los productos.

Además, el autor describe que en la época de vigor de la teoría clásica las industrias estaban fragmentadas, la producción era más intensiva en trabajo y menos en capacidades-habilidades y el comercio demarcaba las diferencias en los recursos naturales de los países.

No obstante, aunque Ricardo ya señalaba que el comercio se basaba en las diferencias en la productividad de la mano de obra entre naciones, el centro de atención se estaba corriendo hacia otras direcciones. Así, los gobiernos, acertada o desacertadamente habían establecido políticas diseñadas para mejorar la ventaja comparativa en los costos de los factores ${ }^{7}$. Pero el autor indica que gran parte del comercio mundial se efectúa entre naciones industrializadas avanzadas con dotaciones de factores similares.

Adicionalmente, un importante volumen del comercio se basa en exportaciones e importaciones entre las distintas sucursales nacionales de empresas multinacionales, una forma de comercio que no contempla la teoría convencional. Los costos de los factores siguen siendo significativos en industrias que dependen de los recursos naturales, en aquellas donde el trabajo no especializado es una gran porción del costo total, y en aquellas otras donde la tecnología está ampliamente disponible. Por otro lado, las economías de escala y otras imperfecciones del mercado son importantes para la ventaja competitiva en muchas industrias.

El informe del Foro Económico Mundial indica que la competitividad puede ser definida como un juego de instituciones, políticas y factores que determinan el nivel de productividad de una nación. Por otro lado, el nivel de productividad establece el nivel de prosperidad que se puede alcanzar en una economía. Lo

\footnotetext{
${ }^{7}$ Como por ejemplo reducción de los tipos de interés, mantenimiento de los bajos niveles de los costos salariales, devaluaciones que buscan afectar a los precios comparativos o subvenciones a determinados sectores para promover las exportaciones, etc.
} 
cual también determina las tasas de retorno de las inversiones, lo cual se vuelve un indicador fundamental en las tasas de crecimiento de una economía.

En el siguiente apartado se presenta el modelo de Porter $^{8}$ del diamante de la ventaja nacional, el cual pretende ofrecer una respuesta adecuada a la pregunta de por qué las empresas con base en determinadas naciones tienen éxito a escala internacional en segmentos e industrias diferentes.

\subsubsection{La teoría económica moderna: el modelo de la ventaja competitiva de las naciones}

La teoría económica moderna surge como respuesta a una economía cada vez más globalizada, donde existe un mayor grado de concentración empresarial, un mayor número de multinacionales que operan en diversos países, una creciente y cada vez más variada demanda y una oferta más diferenciada.

Como argumenta Porter, la presencia de empresas multinacionales que no sólo exportan sino que también compiten en el extranjero a través de sucursales ha dejado sin respuesta a las explicaciones tradicionales de por qué y dónde exporta una nación. Además, puede afirmarse que la competencia se ha intensificado, forzando así, a los países, a tener un mayor conocimiento y control de la competitividad, independientemente de su nivel de desarrollo.

Por otro lado, la estructura de la competencia, unida a la influencia de la cultura asiática en América y Europa, ha motivado un mayor dinamismo en la economía internacional. Así lo explican Porter, Takeuchi y Sakakibara cuando dicen que Japón, la segunda potencia mundial, ha tenido una influencia significativa en el crecimiento económico y la toma de decisión política en Asia y en el extranjero, afectando a las relaciones de EE.UU. con otros países.

\footnotetext{
8 Capitulo: La Teoría Económica Moderna - El Modelo de la ventaja competitiva de las Naciones. De: Evolución de la Teoría Económica de la competitividad internacional, Michael Porter
} 
Además, técnicas como la gestión de la calidad total, la mejora continua y el just-in-time, procedentes de la forma de actuar de las empresas japonesas, han sido ya difundidas por todo el mundo.

Varios investigadores han explicado que la competitividad de los territorios se ha convertido en una de las principales preocupaciones de los gobiernos e industrias de cada nación. Por otro lado, la teoría clásica de la ventaja comparativa resultaban más apropiada cuando las industrias estaban fragmentadas, la producción era más intensiva en trabajo y menos en capacidades, y el comercio destacaba las diferencias en las dotaciones de factores. También durante las últimas décadas han establecido una etapa de globalización, donde surgieron importantes consecuencias para las naciones que no han sido capaces de alcanzar un cierto nivel de desarrollo.

Las diferencias económicas entre países desarrollados y no desarrollados son cada vez más importantes, las tasas de natalidad y mortalidad mundial se disparan, las presiones por ser competitivos son cada vez mayores $\mathrm{y}$, como resultado, existe un mayor interés por conocer los factores determinantes de la competitividad internacional.

Tal como se mencionó anteriormente, una de las fuentes más importantes de error con relación al comercio internacional ha sido confundir la ventaja absoluta de Adam Smith con el modelo de David Ricardo de ventaja comparativa (Krugman y Obstfeld). Así, mientras que para Smith una nación exporta un producto sólo si es el fabricante de menor costo del mundo, el paradigma de ventaja comparativa de Ricardo admite que un país podría importar un producto del que puede ser el productor de menor costo si es incluso más productivo en la producción de otros bienes. De esta forma, el país en cuestión se especializará más en la producción de un bien que ofrece, con relación a otros bienes, un menor costo de oportunidad, es decir, una ventaja comparativa.

Curiosamente, otro aspecto significativo de la literatura ha sido la confusión existente entre ventaja comparativa de la teoría económica tradicional y ventaja 
competitiva de la teoría económica moderna. En tal sentido, Porter describe por qué las industrias de las naciones son las que determinan el éxito de estas últimas; por consiguiente, las ventajas de una nación con respecto a otra no está dada en las dotaciones de factores y en los costos comparativos, sino en la selección estrategias claves y en la capacidad de innovación de las industrias.

El libro de Porter "La ventaja competitiva de las naciones"9 fue resultado de un estudio, de cuatro años de duración, sobre diez de las naciones más importantes del mundo ${ }^{10}$, en el que se investigó acerca de las fuentes del éxito competitivo internacional de una amplia variedad de industrias. Las conclusiones de este estudio contradicen la sabiduría convencional que hasta ese momento había orientado el modo de pensar y de actuar de muchas empresas y gobiernos nacionales, afirmando que el éxito de una nación se debe a sus ventajas competitivas y no a las ventajas comparativas que ostenta.

En dicho libro Porter afirma que "la prosperidad nacional se crea, no se hereda. No surge de los dones naturales de un país, del conjunto de su mano de obra, de sus tipos de interés o del valor de su moneda, como afirma con insistencia la economía clásica. La competitividad de una nación depende de la capacidad de su industria para innovar y mejorar".

Este autor fue uno de los primeros en defender que se debía abandonar la idea de "una nación competitiva" y, en su lugar, estudiar los determinantes de la productividad, entendida como el valor del output generado por cada unidad de capital y trabajo, con la que los recursos de una nación son utilizados. Así no se contemplaba a la economía como un todo, sino que se estudian aquellos sectores en los que las empresas de un país tenían éxito internacionalmente, es decir, poseían ventaja competitiva con relación a los mejores competidores mundiales.

\footnotetext{
9 "La Ventaja Competitiva de las Naciones" 1990, Michael Porter

${ }^{10}$ Alemania, Corea, Dinamarca, EE.UU., Italia, Japón, Reino Unido, Singapur, Suecia y Suiza.
} 
Porter define a la productividad como único concepto de competitividad en el ámbito nacional o regional. El comercio permite a una nación incrementar su nivel medio de productividad, especializándose en aquellas industrias y segmentos en los que sus empresas son relativamente más productivas, e importando aquellos productos y servicios donde lo son menos. Como consecuencia, la competitividad de una nación depende de la capacidad de sus industrias para innovar y mejorar.

Las empresas logran ventaja frente a los mejores competidores del mundo a causa de la presión y el reto. Se benefician de tener fuertes competidores nacionales, proveedores agresivos radicados en el país y clientes nacionales exigentes.

El libro "La ventaja competitiva de las naciones" primeramente explica por qué algunos países tenían éxito en determinadas industrias, según Porter son las empresas y no las naciones los principales actores. La competitividad internacional de empresas se ve impulsada al éxito por el entorno cercano de las naciones en las cuales se encuentran inmersas. Considerando que las empresas normalmente crecen en un contexto doméstico antes de expandirse internacionalmente, la nación en la que se ubican juega un papel fundamental en la formación de la empresa, las decisiones de sus altos directivos, su estrategia, y la existencia de recursos disponibles. Como explica Porter:

La base doméstica es la nación en la que las ventajas competitivas esenciales de la empresa son creadas y mantenidas. Es donde la estrategia de una empresa se establece y el producto principal y la tecnología de proceso (ampliamente definida) son creados y mantenidos. Normalmente, aunque no siempre, gran parte de la producción sofisticada tiene lugar allí. La base doméstica será la localización de la mayoría de los trabajos productivos, tecnologías puntas y las más avanzadas capacidades. 
Grant ${ }^{11}$ afirma que considerar a la nación como un conjunto de variables de contexto que afectan a la ventaja competitiva de las empresas y de las industrias tiene varias ventajas. Primero, permite recurrir a la definición del comercio internacional que se basa en la diferencia en los costos nacionales como pilar para el comercio internacional. También, el reconocimiento de que la ventaja en diferenciación de los productos (calidad, diseño y tecnología) es tan importante como determinante del comercio y de la inversión en el extranjero. Segundo, permite un enfoque sistémico para el análisis de la actuación competitiva en el ámbito nacional. El dinamismo implica innovación en la creación de una ventaja competitiva. La ventaja competitiva internacional se alcanza con exportaciones abundantes y continuas hacia una serie de naciones y/o por la inversión directa en otros países..

Para otros académicos, las multinacionales están fuera de las bases domésticas y entonces se oponen a la idea de la importancia del entorno nacional en el éxito de las empresas. Pero considerando que las multinacionales tienen acceso a economías de escala globales y a recursos en los diferentes países en los que operan, esto se encuentra de acuerdo con la proposición básica de Porter de que los entornos nacionales generan un efecto significativo en la ventaja competitiva de las empresas e industrias.

Además, Grant señala que al estudiar multinacionales líderes a nivel mundial, puede observarse que estas empresas se encuentran muy influidas por la nacionalidad de la empresa matriz.

El modelo del diamante de Michael Porter se encuentra basado en el estudio de las características del entorno nacional. Así se quería dar respuesta a por qué empresas ubicadas en ciertos territorios eran capaces de mejorar y otras no, así como a por qué dichas empresas logran innovar, buscando nuevas fuentes, cada vez más perfeccionadas. La respuesta a estos interrogantes se halla en cuatro grupos de variables que influyen en la habilidad de una empresa para obtener y mantener la ventaja competitiva en los mercados

11 GRANT, R. (1991) "Porter's Competitive Advantage of Nations': An Assessment".Strategic Management Journal 
internacionales. Estos factores claves se relacionan entre sí creando lo que Porter denomina el diamante de la ventaja nacional.

\subsubsection{El diamante de la ventaja competitiva nacional}

La teoría de la ventaja competitiva nacional de Porter se basa en el análisis y estudio de las características del contexto doméstico que identifica cuatro grupos de variables que afectan la capacidad de las empresas para lograr y mantener una ventaja competitiva en los mercados internacionales:

1. Condiciones de los factores: Establece como se encuentra una nación en cuanto a los factores de producción.

2. Condiciones de la demanda: Naturaleza de la demanda del producto o servicio del sector.

3. Sectores afines y auxiliares: Existencia o no de grupos afines que sean internacionalmente competitivos.

4. Estrategia, estructura y rivalidad en las empresas: cuestiones que rigen el modo en una nación en que las empresas se crean, organizan y gestionan.

Existen otros dos factores que, conjuntamente con los anteriores, forman "el diamante nacional" y se corresponden con el azar y el Gobierno. 


\section{Los determinantes de la ventaja competitiva nacional}

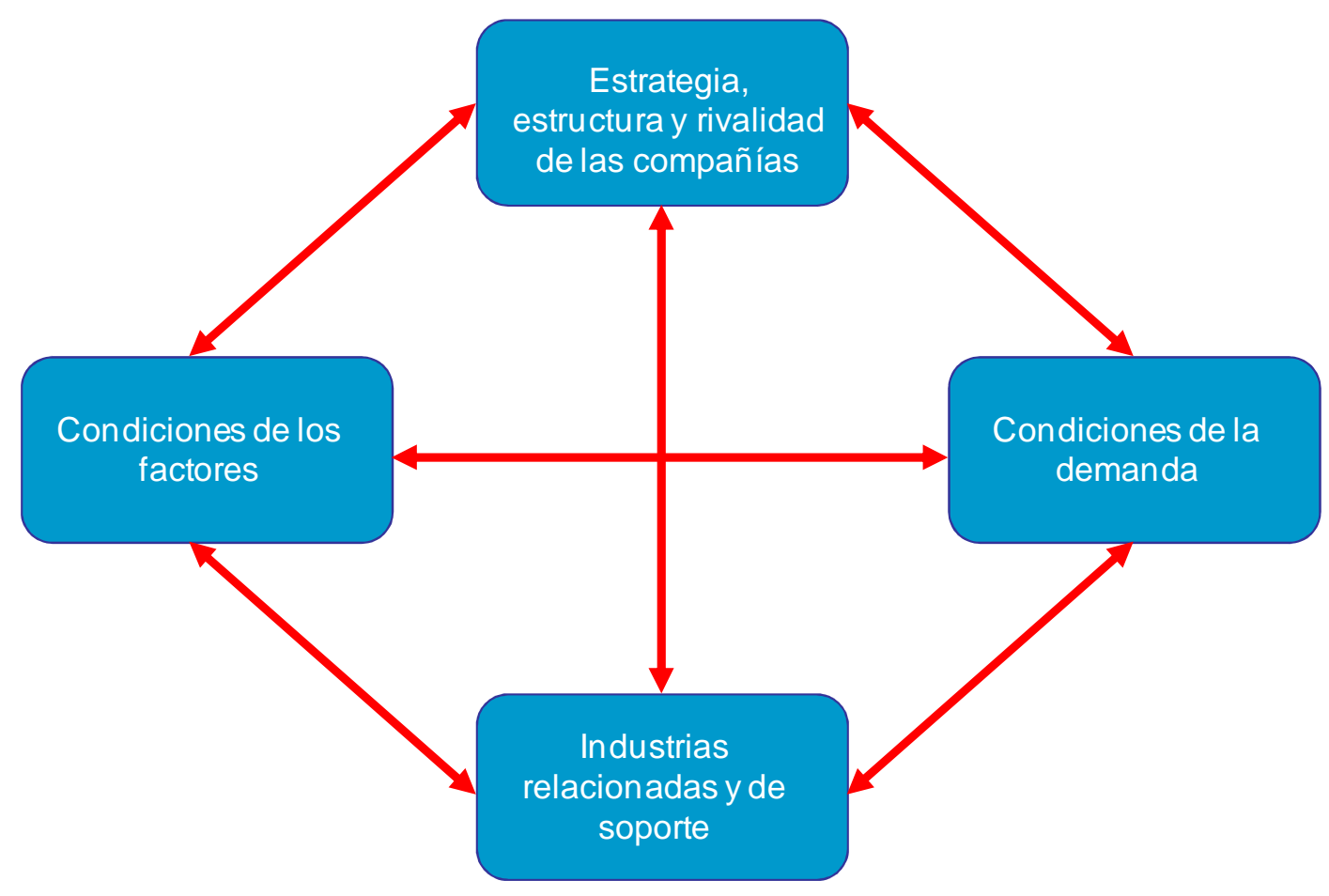

Fuente: Porter ${ }^{12}$

El diamante es un sistema que se ve afectado por cada vértice, de forma que el efecto de un determinante es dependiente del estado de Estrategia, estructura y rivalidad de las empresas, de la Condiciones de los factores, de la Condiciones de la demanda y de los Sectores afines y auxiliares otros. El diamante como un todo afecta a los factores esenciales para lograr el éxito competitivo internacional: la disponibilidad de recursos y habilidades necesarios para tener ventaja competitiva en un sector; la información que da forma a las oportunidades que las empresas perciben y las direcciones en que despliegan sus recursos y destrezas; los objetivos de los propietarios, directivos y personal de las empresas; y lo que es más importante, las presiones sobre las empresas para invertir e innovar.

12 PORTER, "Ser Competitivo", Edición Deusto, 1999. 
Cuando la situación nacional facilita la acumulación más rápida de recursos y habilidades especializadas, las empresas logran una ventaja competitiva. Cuando el contexto doméstico permite obtener información continua y mejorada sobre las necesidades de producto y de proceso, las empresas logran igualmente ventaja competitiva.

Finalmente, cuando el contexto nacional presiona a las empresas para desarrollar e innovar, las empresas logran una ventaja competitiva y la mejoran con el tiempo. La ventaja competitiva en un solo factor no sería sostenible y posible, dada la posible imitación por parte de los competidores globales. Tampoco es necesario una ventaja en cada uno de los vértices del diamante para que sea exitosa.

A continuación se describen brevemente los factores o vértices del diamante.

\subsubsection{Las condiciones de los factores}

Como se mencionó anteriormente para la teoría económica clásica, los factores de producción -el trabajo, la tierra, los recursos naturales, el capital y la infraestructura- establecen el flujo del comercio, de manera que una nación exportará las mercancías que hacen el máximo uso de los factores en los que está relativamente mejor dotada. En un sentido opuesto, la teoría de la ventaja competitiva de las naciones defiende que una nación no hereda, sino que crea sus factores de producción más importantes. Considera también que la velocidad y eficacia en su creación y correcta utilización es mucho más importante que la mera existencia de los mismos.

Porter, a diferencia de la teoría clásica, realizó un análisis más detallado de los factores de producción. Es decir, identifica sus características, los procesos sobre los que fueron creados y su relación con la competitividad de las empresas. El autor distingue entre dos tipos de factores: los factores básicos y los factores avanzados. Los factores básicos son aquellos factores tales como los recursos naturales, el clima, la localización y la demografía. Los segundos (factores avanzados) se refiere a los factores especializados, como las 
infraestructuras de comunicaciones, la investigación y las capacidades avanzadas, entre otros.

Según Porter, los factores avanzados son los más importantes para la ventaja competitiva, puesto que al ser especializados son más difíciles de imitar y provienen de inversiones llevadas a cabo por individuos, empresas y gobiernos. Contrariamente a lo que dice la teoría clásica, el disponer simplemente de una población activa formada en las escuelas secundarias o incluso en la universidad no representa una ventaja competitiva a nivel internacional. En principio, la competencia tendrá acceso a estos factores sin inconvenientes a través de una estrategia mundial. En cambio, los factores especializados son más escasos, más difíciles de imitar por futuros competidores y su creación requiere una inversión a largo plazo que no todos están dispuestos a afrontar. A pesar de ello, los factores básicos también son importantes ya que permiten ventajas en la etapa inicial, para luego ser apoyados por factores avanzados y especializados.

Mientras tanto, Grant describe cómo los factores avanzados, que conforman la base de la ventaja competitiva. Esto permite la existencia de una relación más estrecha entre el éxito de una industria y la creación de factores de producción especializados necesarios para el éxito.

Los factores de producción pueden ser diferenciados en cinco categorías:

1. Recursos humanos. Representa la cantidad, la capacidad y el costo del personal.

2. Recursos físicos. Incluye los factores tierra y agua. Teniendo en cuenta la calidad, cantidad, su accesibilidad, las condiciones climática, el tamaño y la localización se incluyen dentro de este grupo de factores. Afectando este último al costo del transporte y a la facilidad en los intercambios culturales y empresariales. 
3. Recursos del conocimiento. Incluye el stock de conocimiento científico, técnico y de mercado sobre bienes y servicios que tiene una nación. Estos recursos proceden de las universidades y centros de investigación públicos o privados, instituciones estadísticas públicas, asociaciones comerciales, bases de datos.

4. Recursos de capital. Incluye el costo, calidad y cantidad de capital disponibles para realizar inversiones en la industria.

5. Infraestructura. Incluye el tipo, la calidad y el costo de uso de la infraestructura disponible, el sistema de transportes, el sistema de comunicaciones, el correo, el envío de paquetes postales, los pagos o transferencias de fondos, los servicios sanitarios y otros.

Los factores mencionados anteriormente difieren entre industrias y naciones. Por ejemplo, tal como menciona Porter, la localización de Singapur en la ruta comercial entre Japón y el Oriente Medio lo ha convertido en el centro de reparaciones de barcos. También la habilidad de Suiza para tratar con idiomas y culturas diferentes le ha permitido la obtención de ventajas en sectores de servicios como la banca, el comercio y la gestión logística. Por otro lado, los recursos humanos, el conocimiento y los factores de capital pueden ser movibles entre naciones debido al incremento de la movilidad internacional y de las comunicaciones. Adicionalmente, una región no tendría ventaja en estos factores si no dispone de ellos.

\subsection{Las condiciones de la demanda}

Resulta importante entender las características de la demanda que conducen a las inversiones de las empresas.

Porter explica que este segundo vértice del diamante es importante, ya que la demanda interna presiona a las empresas para que se desarrollen, innoven y mejoren. Las naciones alcanzan ventajas competitivas en los sectores cuya demanda interior informa anticipadamente a las empresas de nuevas 
necesidades que es necesario cubrir, ejerciendo presión para que éstas innoven con mayor rapidez y logrando así ventajas competitivas y más desarrolladas que las de sus rivales extranjeros.

Al igual que sucede con el primer vértice (los factores de producción), el tamaño de la demanda interior es mucho menos importante que el calidad de dicha demanda. Entonces, el lograr una ventaja competitiva va a depender no de la cantidad de la demanda interior, sino de lo exigente que ésta sea.

Si los compradores son refinados y sofisticados, las empresas deberán responder a retos difíciles de afrontar, aunque también una demanda con dichas características los ayuda a prever tendencias mundiales. Brouthers y Brouthers explican cómo este factor podría permitir a las empresas que alcancen ventajas en costo y ventajas en diferenciación, posibilitándole desarrollar economías de escala e introducir nuevas tecnologías en sus procesos de producción.

Porter describe la demanda local a través de tres amplios atributos:

1. La composición de la demanda. La segmentación de la demanda significa que los segmentos domésticos más pequeños influyen en la formación de la ventaja competitiva. La exigencia de los compradores que forman la demanda local juega un papel clave en la ventaja de las empresas. Además, anticiparse a las necesidades de la demanda local y extranjera puede también ayudar a las empresas a obtener ventajas. Esta situación permite a las empresas adelantarse a ofrecer nuevos productos y a participar en segmentos emergentes, y fomentando una mejora continua en sus productos.

2. El tamaño de la demanda y el patrón de crecimiento. El tamaño del mercado local es uno de los aspectos a tener en cuenta al momento de generar una ventaja competitiva en aquellas empresas donde existan economías de escala, provocando que las empresas locales inviertan de forma agresiva en productos a gran escala. Asimismo, el patrón de 
crecimiento de la demanda local ayuda a las empresas a tomar tecnologías nuevas, desarrollarse de forma más rápida y les da seguridad en las proyecciones de sus inversiones.

3. La internacionalización de la demanda. Cuanto más internacionalizada esté la demanda, más ventajas otorgará a las empresas locales. En el caso de empresas que operan en varios mercados, la demanda doméstica se transforma en demanda internacional. También, podría ofrecer ventajas a las empresas locales para establecerse en el extranjero y reducir el riesgo percibido. La confianza en los proveedores del país natal de su empresa matriz les permite reducir riesgos y tener una comunicación fluida con sus proveedores. Por otro lado, la movilidad de la demanda requiere estudios en otro país e implica conocer de cerca la cultura empresarial extranjera y también, importar tendencias extranjeras a su regreso.

La mezcla de las características de la demanda local resulta esencial como fuente de ventaja competitiva para las empresas de una nación.

Sin dudas, la influencia de este vértice del diamante en la ventaja competitiva depende también de otros vértices. Una baja competencia local, un crecimiento lento y un tamaño pequeño de la demanda no estimularán la inversión de las empresas. Además, sin la presencia de industrias proveedoras competitivas a escala internacional, las empresas no serían capaces de responder rápida y anticipadamente a la demanda de los compradores locales. Por consiguiente, no resulta factible pensar sólo en uno de los atributos de la demanda, ni tampoco en que las empresas se centren únicamente en este factor para conseguir ventajas competitivas a escala mundial.

\subsection{Los sectores afines y auxiliares}

Este vértice del diamante contiene todos los sectores afines, es decir, que ofrecen productos y servicios complementarios, y adicionales, proveedores que sean internacionalmente competitivos. La presencia de sectores afines cuyas 
empresas relacionan sus actividades de marketing, distribución, servicios o tecnología en la cadena de valor, o de sectores de productos complementarios, genera a menudo la aparición de nuevos sectores competitivos.

Por otro lado, Porter explica que resulta puede resultar negativo para una empresa o un país crear proveedores "cautivos", es decir, totalmente dependientes de la industria nacional y negados a una demanda extranjera. Por el mismo motivo, si una empresa es exitosa, no es necesario que el país sea competitivo en todas las industrias proveedoras. No obstante, la ubicación estratégica de los proveedores y usuarios finales posibilita a las empresas y proveedores a tener una comunicación más fluida, un flujo de información más rápido y constante y un intercambio permanente de ideas e innovaciones.

Adicionalmente, las empresas pueden influir en el desarrollo tecnológico de sus proveedores y promover lugares de ensayo para la labor de Investigación y Desarrollo, acelerando así el ritmo de la innovación. Este factor puede ser una fuente de nuevas tecnologías y ofrecer un incentivo competitivo hacia desarrollos futuros (Brouthers y Brouthers).

Este vértice del diamante crea un efecto de cadena, ya que permite a otras industrias proveedoras locales obtener productos y tecnologías que pueden ser utilizados en sus cadenas de valor.

Porter destaca la menor importancia de la disponibilidad de inputs en comparación con la eficiencia y coordinación de los mismos. Así, las empresas locales se benefician de los procesos de innovación y mejora de los proveedores locales, al permitirles la identificación de nuevos métodos y oportunidades para sus empresas. A su vez, las empresas locales tienen la posibilidad de dar respuesta a sus proveedores cooperando en el diseño de nuevos productos.

Adicionalmente, el proveedor local es más fácilmente accesible que los proveedores extranjeros, ya que en la nación los suministradores locales son más visibles, su cultura empresarial es similar, suponen que los costos del 
transporte sean menores y ofrecen a las empresas información anticipada sobre el desarrollo de nuevos productos.

El aprovechamiento máximo se logra cuando los proveedores de las empresas locales son proveedores globales. Por ejemplo, los flujos de información domésticos generados cuando una industria proveedora local es internacionalmente competitiva incrementan la ventaja de las empresas.

Concretamente, la ventaja competitiva en algunas industrias proveedoras confiere ventajas potenciales a las empresas de una nación en muchas otras industrias, porque producen inputs que son ampliamente utilizados, además de ser importantes para la innovación o la internacionalización. La industria del software es un ejemplo de las industrias que tienen impactos significativos en otras empresas.

Por su parte, un grupo de sectores auxiliares, ubicados estratégicamente unos de otros, crean ventajas competitivas en una serie de sectores interrelacionados que son todos internacionalmente competitivos.

La interrelación no surge automáticamente. Las empresas proveedoras que están cerca deben estar dispuestas a interrelacionarse, sino esta ventaja no podrá darse.

\subsection{La estrategia de la empresa, la estructura y la rivalidad}

Por último, este vértice del diamante ayuda a descifrar las condiciones nacionales y el contexto originan fuertes tendencias en el modo en que se crean, organizan y gestionan las empresas, así como en la definición de la naturaleza de la competencia interna.

Así un sistema de gestión no necesariamente es universalmente apropiado, sino que la competitividad de un determinado sector es consecuencia de la convergencia de los modos de dirección y de organización prevalecientes en cada país y de las fuentes de ventaja competitiva existentes en cada sector. 
De esta manera, las estrategias de las empresas deben responder y estar basadas en los intereses de la demanda local o extranjera. Generalmente, las estrategias de las empresas locales se ven influenciadas por las estrategías de los líderes internacionales.

También, la existencia de competidores nacionales fuertes es un importante estímulo para la ventaja competitiva, pues impulsa a las empresas a innovar y mejorar. La teoría tradicional argumentaba que la competencia local era muy dañina porque generaba la duplicación de esfuerzos e no permitía a las empresas obtener economías de escala. Además, la competencia en el mercado doméstico crea presión en las empresas para que reinviertan, mejoren sus costos, sus procesos y calidad de productos y servicios.

Además, a diferencia de la competencia extranjera, que suele ser analítica y distante, el mercado local suele ser más pequeño y personalizado, aquí la competencia no sólo busca alcanzar un porcentaje del mercado, sino que las empresas pelean por atraer recursos humanos, por lograr una mejora técnica, por la calidad superior del servicio y por la captación de la clientela, entre otros aspectos. La concentración geográfica magnifica el poder de la rivalidad interior, ya que cuanto más localizada esté la rivalidad, ésta será más intensa y beneficiosa para las empresas que se ven forzadas a innovar y perciben una presión orientada a la mejora constante de las fuentes de ventaja competitiva.

Al contrario de la teoría tradicional, los competidores del mercado doméstico anulan automáticamente los tipos de ventaja que proceden simplemente de estar en una nación determinada. También, la rivalidad local presiona a las empresas para abordar mercados mundiales y las fortalece para tener éxito en los mismos.

Como ya se ha comentado, las estrategias, las estructuras, las metas, las prácticas directivas, las actitudes individuales y la intensidad de la rivalidad en el sector empresarial son todos aspectos específicos de las industrias de una nación que constituyen determinantes de la ventaja competitiva internacional. 


\subsection{La misión del Estado}

Según menciona Porter, "el papel correcto del Estado es el de catalizador y estimulador"13, alentando a las empresas a que eleven sus aspiraciones y niveles de competitividad. El Gobierno juega un papel secundario, aunque fundamental como estimulador de los vértices del diamante. Una política de gobierno exitosa es aquella que genera un ambiente en el que las empresas puedan lograr ventajas competitivas, y no aquella que presiona al gobierno a intervenir directamente en el proceso.

Para una región que quiera conseguir una ventaja competitiva, la misión del Gobierno debería consistir en:

- Centrarse en la creación de factores especializados:

- No intervenir en los mercados de factores y de dinero:

- Imponer estrictas normas sobre los productos, la seguridad y el medio ambiente: Esto presionará a las empresas para que mejoren la calidad, la tecnología y la satisfacción de las exigencias de los consumidores y las demandas sociales. Y si estas normas no se han extendido aún en el ámbito internacional, las empresas disfrutarán de una ventaja inicial para desarrollar productos y servicios que serán valiosos en otros países.

- Limitar claramente la cooperación directa entre sectores rivales: Una cierta cooperación indirecta puede resultar beneficiosa si no se corresponde con temas no directamente relacionados con las fuentes de la ventaja de las empresas.

- Promover objetivos que originen una inversión continuada

- Liberalizar la competencia

- Adoptar una decidida política interior antimonopolista

- Rechazar el comercio exterior regulado

El Gobierno debería también intervenir propiciando la reducción de los costos de ciertos factores o un tipo de cambio favorable que ayude a las empresas a

${ }_{13}$ PORTER, "Ser Competitivo", Edición Deusto,1999. 
competir más eficazmente en los mercados internacionales, particularmente cuando las fuerzas del mercado no actúan a favor de las empresas locales.

El cuadro siguiente contrasta algunas implicaciones políticas que surgen del análisis de la ventaja competitiva de Porter con aquellas del pensamiento tradicional.

Tabla 1 - Medidas políticas: Pensamiento Tradicional vs Modelo de Porter

\begin{tabular}{|c|c|c|}
\hline Medida de política & $\begin{array}{c}\text { Pensamiento } \\
\text { tradicional }\end{array}$ & Modelo de Porter \\
\hline Devaluación & $\begin{array}{l}\text { Mejora la competitividad } \\
\text { de las industrias locales } \\
\text { otorgándoles ventaja en } \\
\text { costos sobre otros } \\
\text { competidores } \\
\text { extranjeros. }\end{array}$ & $\begin{array}{l}\text { Está en detrimento de la } \\
\text { mejora del proceso: estimula } \\
\text { la dependencia en la } \\
\text { competencia en precios y } \\
\text { una concentración en } \\
\text { industrias y segmentos } \\
\text { sensibles al precio. No apoya } \\
\text { la inversión en la innovación } \\
\text { y la automatización. }\end{array}$ \\
\hline $\begin{array}{l}\text { Política } \\
\text { Investigación } \\
\text { Desarrollo }\end{array}$ & $\begin{array}{l}\text { La inversión del Gobierno } \\
\text { en I+D estimula la } \\
\text { innovación dentro del } \\
\text { país. La investigación } \\
\text { basada en la defensa } \\
\text { ofrece efectos indirectos } \\
\text { comerciales. } \\
\text { investigación cooperativa } \\
\text { aúna esfuerzos y evita la } \\
\text { duplicación. }\end{array}$ & $\begin{array}{l}\text { La importancia de la difusión } \\
\text { de la tecnología significa que } \\
\text { la investigación en las } \\
\text { universidades es más } \\
\text { efectiva que la investigación } \\
\text { en los laboratorios públicos. } \\
\text { El Gobierno debería apoyar } \\
\text { la investigación relacionada } \\
\text { con la defensa y el desarrollo } \\
\text { de institutos de investigación } \\
\text { que se centran en } \\
\text { tecnologías de punta. }\end{array}$ \\
\hline
\end{tabular}




\begin{tabular}{|c|c|c|}
\hline $\begin{array}{l}\text { Aprovisionamiento del } \\
\text { Gobierno }\end{array}$ & $\begin{array}{l}\text { Facilita una demanda } \\
\text { local segura para las } \\
\text { empresas locales; así } \\
\text { pues, promueve la } \\
\text { inversión y las } \\
\text { economías } \\
\text { aprendizaje y de escala. } \\
\text { El aprovisionamiento } \\
\text { para la defensa, en } \\
\text { particular, ofrece un } \\
\text { mercado anticipado para } \\
\text { productos técnicamente } \\
\text { sofisticados. }\end{array}$ & $\begin{array}{l}\text { Mientras que el Gobierno } \\
\text { puede comportarse como } \\
\text { comprador temprano } \\
\text { sofisticado, la adquisición } \\
\text { puede actuar fácilmente para } \\
\text { proteger a los campeones } \\
\text { nacionales débiles de la } \\
\text { rivalidad local e internacional } \\
\text { y distorsiona el desarrollo de } \\
\text { productos de las necesidades } \\
\text { globales del mercado. }\end{array}$ \\
\hline $\begin{array}{l}\text { Estándares de } \\
\text { regulación del } \\
\text { producto y el proceso }\end{array}$ & $\begin{array}{l}\text { Las regulaciones } \\
\text { rigurosas imponen costos } \\
\text { que entorpecen la } \\
\text { competitividad en los } \\
\text { mercados locales y } \\
\text { extranjeros. }\end{array}$ & $\begin{array}{l}\text { El rendimiento riguroso y los } \\
\text { estándares de seguridad y } \\
\text { medio ambiente pueden } \\
\text { presionar a las empresas } \\
\text { para que mejoren la calidad y } \\
\text { la tecnología, y ofrezcan } \\
\text { productos con características } \\
\text { superiores. Particularmente } \\
\text { beneficiosas son las } \\
\text { regulaciones que anticipan } \\
\text { los estándares que se } \\
\text { extenderán } \\
\text { internacionalmente. }\end{array}$ \\
\hline $\begin{array}{l}\text { Política antimonopolio } \\
\text { y regulación de la } \\
\text { competencia. }\end{array}$ & $\begin{array}{l}\text { La presencia de la } \\
\text { competencia } \\
\text { internacional implica que } \\
\text { los monopolios locales y } \\
\text { las fusiones no son } \\
\text { efectivas. Se podrían } \\
\text { requerir }\end{array}$ & $\begin{array}{l}\text { La política antimonopolio } \\
\text { juega un papel importante en } \\
\text { lo que se refiere a mantener } \\
\text { la fortaleza de la rivalidad } \\
\text { local. Pero no debe actuar } \\
\text { como una barrera para la } \\
\text { colaboración vertical entre }\end{array}$ \\
\hline
\end{tabular}




\begin{tabular}{|c|c|c|}
\hline & $\begin{array}{llr}\text { antimonopolios } & & \text { para } \\
\text { mejorar las } & \text { alianzas } \\
\text { estratégicas } & \text { y } & \text { el } \\
\text { desarrollo } & & \text { de } \\
\text { competidores de } & \text { clase } \\
\text { mundial. } & & \end{array}$ & $\begin{array}{l}\text { proveedores y clientes, que } \\
\text { es integral para la } \\
\text { innovación. La regulación de } \\
\text { la competencia, por otro lado, } \\
\text { es probable que se lleve a } \\
\text { cabo en detrimento de la } \\
\text { rivalidad y la creación de } \\
\text { nuevas empresas. }\end{array}$ \\
\hline
\end{tabular}

Fuente: Adaptado de Grant

\subsubsection{El papel del azar}

Según menciona Porter, eventos del azar juegan un rol principal en la ventaja competitiva internacional. Estas cuestiones representan acontecimientos que están fuera del dominio de las empresas o del Gobierno. El autor identificaba como cambios significativos en los mercados financieros mundiales o en los tipos de cambio, guerras, terrorismo ${ }^{14}$, decisiones políticas de gobiernos extranjeros, incrementos inesperados en precios de determinados y necesarios bienes como el petróleo. Todos estos hechos crean una discontinuidad y permiten además alteraciones en las posiciones competitivas, pudiendo anular las ventajas de competidores establecidos y dar oportunidades para nuevos competidores.

El azar ofrece, entonces, posibilidades que no pueden proyectarse ni ser planificadas pero que pueden dar lugar una mejora de la situación para alcanzar una ventaja competitiva.

También, estos eventos modifican las condiciones del diamante, ya que producen una discontinuidad que permite innovar y crear nuevos diamantes que sustituyan a los anteriores.

\footnotetext{
14 Todavía se está especulando a cuánto asciende la carga económica y financiera que ha supuesto el ataque terrorista sobre las torres gemelas de Nueva York, si bien existe el acuerdo generalizado de que después del 11 de septiembre, el balance entre los sectores privados y públicos cambiará (Business Week, 1/10/01, p. 35).
} 
Puede mencionarse también que los eventos del azar tienen impactos asimétricos en diferentes naciones. Las guerras, por ejemplo, provocan efectos diferentes en los ganadores y en los perdedores. Sin embargo, estos resultados no actúan independientemente y son propensos a su explotación. De esta manera los diamantes con ventajas nacionales estarán más predispuestas a transformar estos eventos de azar en ventajas competitivas. Por tanto, los cambios y las discontinuidades muestran ventajas sobe las naciones que están en disponibilidad de adelantarse en su explotación.

\subsubsection{El diamante como sistema}

Cada uno de los vértices del diamante definen el rombo de la ventaja competitiva. El efecto de un determinante de la competitividad incluido en el diamante es dependiente del estado de los demás. Por ejemplo, los compradores más exigentes no generarán productos avanzados con sus demandas a menos que la calidad de los recursos humanos permita a las empresas satisfacer las necesidades de estos compradores. Por otro lado, las desventajas de ciertos factores de producción no motivarán la innovación a no ser que la rivalidad sea vigorosa y los objetivos de las empresas respalden una inversión continuada.

A continuación se destacan alguno de los efectos de la naturaleza sistémica del diamante:

- Los vértices se refuerzan unos con otros: dos cuestiones que lo facilitan: la rivalidad interior y la concentración geográfica.

Asimismo, como el rombo es un sistema que se refuerza mutuamente, factores como la concentración geográfica elevan y magnifican la interacción de los cuatro vértices. Que tengan una localización próxima tanto los clientes como las empresas, las industrias proveedoras y los competidores, permite a las empresas:

a) conocer anticipadamente las necesidades de los clientes;

b) establecer una relación más estrecha con sus industrias proveedoras;

c) tener la posibilidad de compartir factores de producción avanzados, como desarrollos e investigaciones en nueva tecnologías; y 
d) conocer de cerca las estrategias de sus competidores y sentirse presionadas para innovar.

Además, los sectores competitivos no suelen estar dispersos geográficamente, sino concentrados en determinadas áreas y relacionados verticalmente (comprador, vendedor) u horizontalmente (clientes, tecnología o canales de distribución). Teniendo en cuenta la concentración de las empresas y sectores, la rivalidad interior se extiende a otras empresas o sectores del grupo a través de la creación de nuevas empresas, la diversificación y el poder de negociación.

- Rara vez existe un solo sector competitivo; de hecho, el diamante promueve la existencia de más sectores. El diamante crea una situación que promueve la formación de sectores afines.

\section{El diamante como sistema}

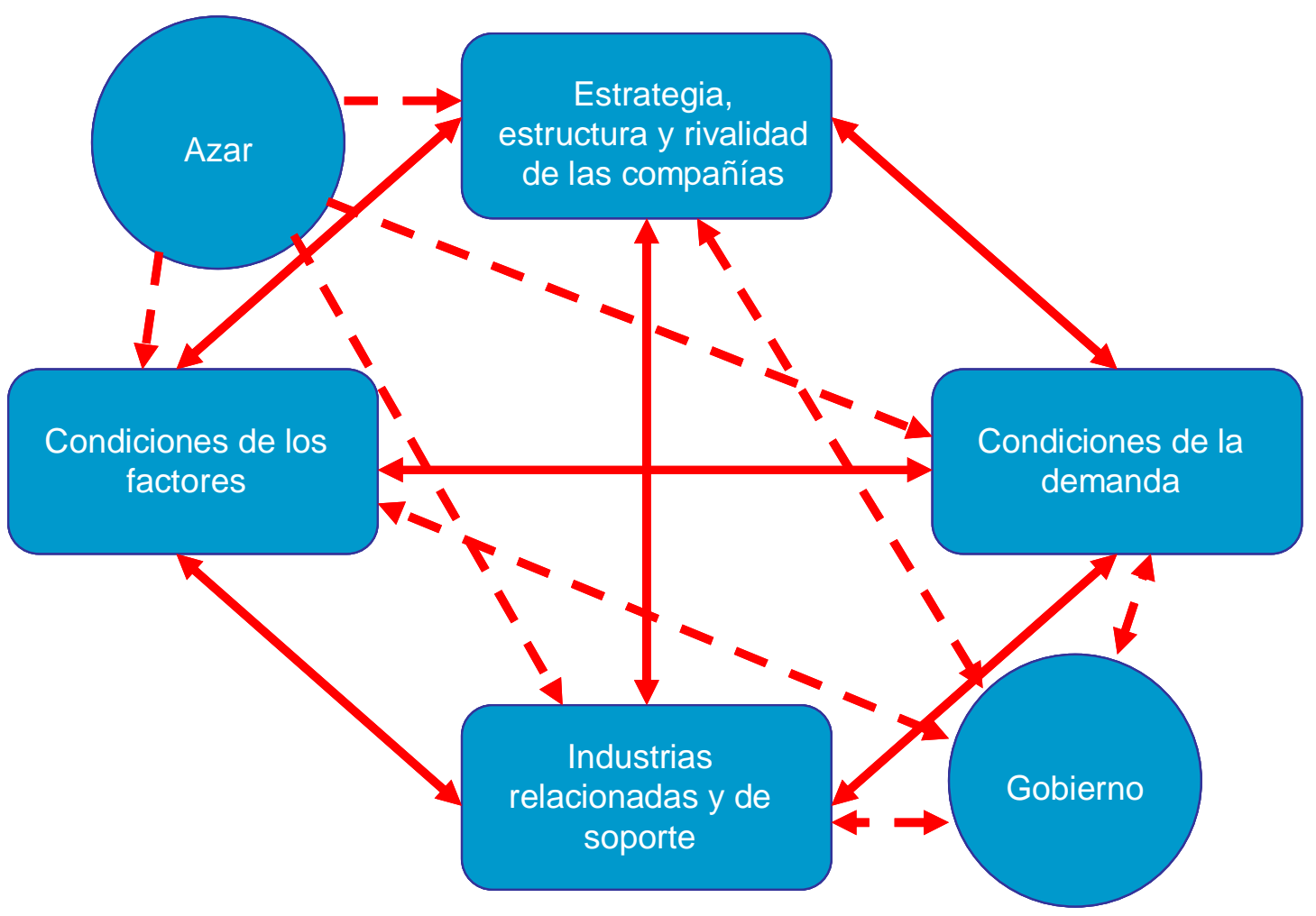

Fuente: Porter 
La figura anterior muestra el modelo del diamante como un sistema donde se puede observar que, junto a los cuatro atributos o determinantes básicos de la competitividad, se encuentra también la misión del Gobierno y el factor del azar. Puede verse que el gobierno puede influir (y estar influido por) cada uno de los cuatro determinantes positiva o negativamente. Por su lado, determinados eventos juegan su papel en parte alterando las condiciones en el diamante y afectando a cada uno de sus vértices. La nación que cuente con el diamante más eficiente podrá modificar los hechos positivos en ventajas competitivas.

\subsubsection{Los cúmulos (clusters) y la competitividad}

Los cluster o cúmulos constituyen uno de los vértices del rombo. Es el tercer vértice del diamante -industrias afines y auxiliares- que muestra que las industrias locales competitivas en el entorno internacional están en realidad concentradas geográficamente, es por eso que se considera importante mencionar como afecta a la competitividad. Según Porter "un cúmulo es un grupo geográficamente denso de empresas e instituciones conexas, pertenecientes a un campo concreto, unidas por rasgos comunes y complementarias entre sí.”. Por su dimensión geográfica, un cluster puede ser urbano, regional, nacional o incluso internacional.

Los clusters determinan a la competitividad en tres aspectos:

- Aumentan la productividad de las empresas que lo integran.

- Incrementa la capacidad de innovación

- Promueven la creación de nuevas empresas.

La presencia de los cúmulos muestra que gran parte de la ventaja competitiva se crea fuera de la empresa, incluso fuera del sector, en las ubicaciones de sus unidades de explotación. Los clusters son un motor de las exportaciones y un imán de la inversión extranjera, genera un círculo virtuoso para el crecimiento y el desarrollo regional, a través de su fuerza de atracción de inversiones, mano de obra especializada, tecnología e infraestructura. Constituyen un foro en el cual se pueden establecer nuevas formas de diálogo entre las empresas, los 
organismos públicos y las instituciones (escuelas, universidades, empresas de suministros públicos).

La fuerza de estas relaciones y la importancia que tienen para la productividad y la innovación son los factores que determinan los límites definitivos. A continuación se detallan las ventajas de los clusters sobre la productividad:

- Acceso a recursos materiales y humanos especializados

- Acceso a la información

- Complementariedad

- Acceso a las instituciones y bienes públicos

- Incentivos y medición del rendimiento

En los clusters pueden captar importantes relaciones, complementariedades e influencias indirectas en cuestión de tecnología, conocimientos prácticos, información, marketing y necesidades de los clientes, que se extienden entre diversas empresas y sectores. Tal como se mencionó anteriormente, estas relaciones son esenciales para la competencia, la productividad, la innovación y, sobre todo, la orientación y el ritmo de formación de nuevas empresas. La mayoría de los integrantes del cluster no compiten directamente entre sí, sino que atienden a diferentes segmentos. Sin embargo, comparten muchas necesidades y oportunidades y han de hacer frente a amenazas y problemas comunes a todos.

Un cluster puede entonces definirse como un sistema de empresas e instituciones interconectadas cuyo valor global es mayor que la suma de sus partes. Los tres efectos positivos que ejercen los clusters sobre la competencia dependen, en cierta medida, de que haya relaciones y comunicaciones personales y existan interacciones entre redes de personas e instituciones.

También, las empresas que forman parte de un cúmulo pueden percibir más rápida y claramente las nuevas necesidades de los clientes. Los integrantes de un cluster, por otro lado, se ven beneficiados por la concentración de empresas que tienen conocimiento sobre los compradores y se relacionan con ellos, de las relaciones entre empresas de sectores afines, de la concentración de 
entidades que generan información especializada y de la experiencia y refinamiento de los compradores.

Asimismo, las empresas que conforman los clusters pueden captar mejor las tendencias de los compradores más rápidamente que los competidores aislados. Además, los participantes en el cluster están informados sobre la aparición de nuevas tecnologías y la disponibilidad de nuevos componentes y máquinas o de nuevos sistemas de ventas y servicios, todo esto como resultado de estar relacionado en un cluster. Los cluster también permite establecer contactos personales y visitas con otras empresas. Así, una empresa perteneciente a un cluster puede hacerse más rápidamente con los nuevos componentes, servicios, máquinas y demás elementos necesarios para poner en práctica las innovaciones, ya sea una nueva línea de producto, un nuevo proceso o un nuevo modelo logístico.

Siguiendo esta línea, los proveedores locales colaboran con el proceso de innovación y, de esta forma, los recursos que ellos proporcionan pueden satisfacer mejor las necesidades de la empresa.

En la próxima figura, Porter representa gráficamente un modelo del efecto que tiene la ubicación en la competencia, considerando cuatro vértices del sistema. Los factores diagramados incluyen los activos tangibles (como la infraestructura material), la información, el sistema jurídico y los institutos de investigación universitaria a los que recurren las empresas para competir. Para aumentar la productividad, los factores han de mejorar en eficiencia, calidad y, en última instancia, especialización para determinadas áreas del cluster. Los factores especializados, sobre todo los que resultan esenciales para la innovación y la mejora (por ejemplo., un instituto universitario de investigación especializada), no sólo fomentan un nivel elevado de productividad, sino que suelen también ser más difíciles de obtener o adquirir en otros lugares. 


\section{Fuentes de la ventaja competitiva de una ubicación}

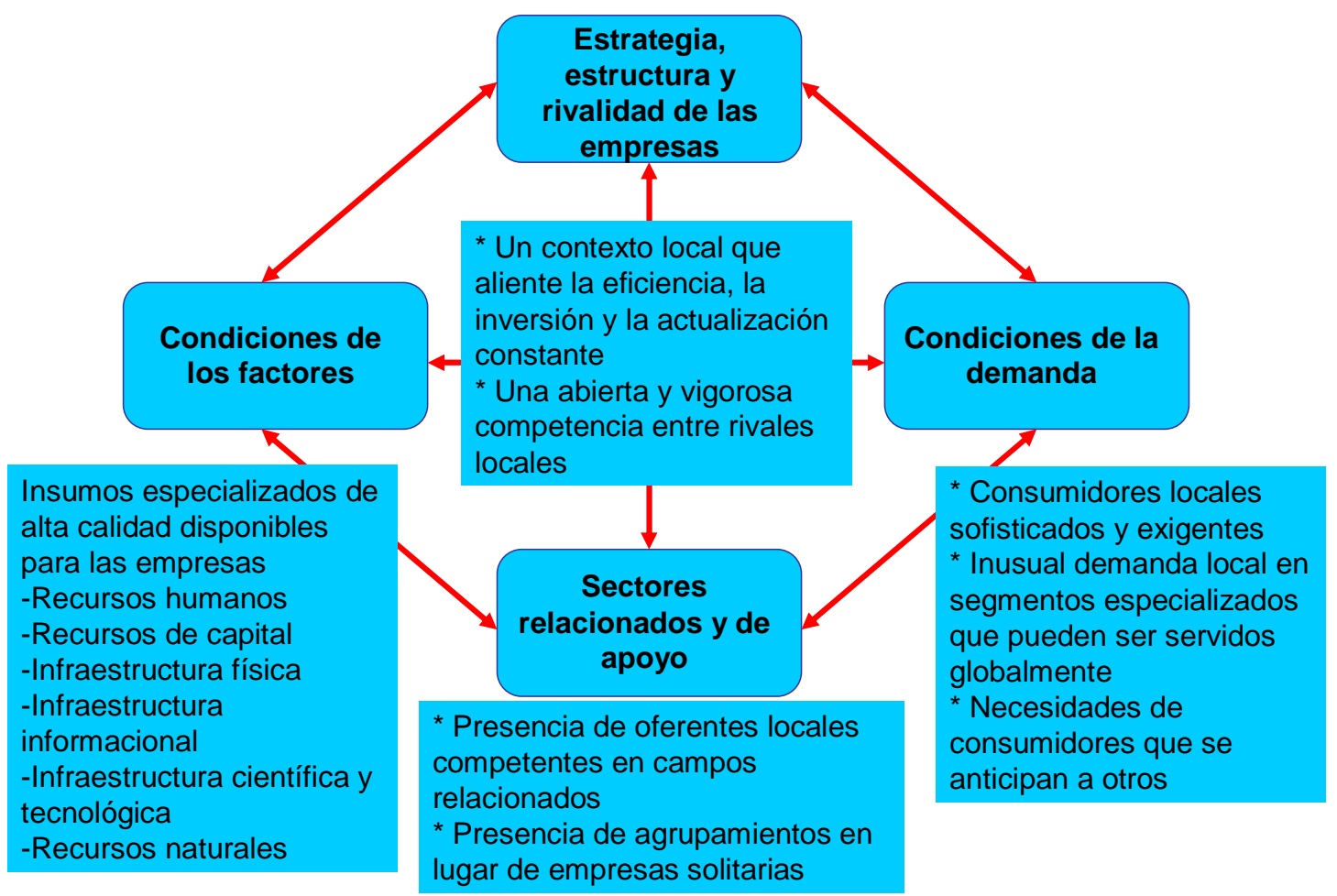

Fuente: Porter

\section{Resumen Final}

Con basamento en estos conceptos, los modelos del World Economic Forum y del International Institute for Management Development explican que el éxito consiste en crear una serie de condiciones microeconómicas y un entorno en el que las empresas puedan competir con éxito.

Por tanto, mientras que en la teoría económica tradicional la riqueza de las naciones se basaba en la dotación de factores, en la teoría economía moderna son las elecciones estratégicas las que conforman el entorno competitivo de una nación. 


\section{Metodología de la Investigación}

\subsection{Población y Muestra}

Debido al amplio conocimiento que los empresarios tienen acerca de su contexto económico, social y político, la población definida para esta investigación estuvo conformada por los directivos de medianas y grandes industrias de La Plata, Berisso y Ensenada.

A su vez, y acorde con el Código Internacional Industrial Uniforme (CIIU), se han tomado los siguientes sub-sectores:

- Productos Alimenticios, bebidas y tabaco

- Textiles y Cueros

- Industria de la Madera

- Imprentas y Editoriales

- Sustancias Químicas

- Productos Minerales No Metálicos

- Metálicas Básicas

- Productos Metálicos, Maquinarias y Equipos

El tamaño de la población $(\mathrm{N})$ surgió de los padrones de contribuyentes de la Tasa de Seguridad e Higiene de los municipios de La Plata, Berisso y Ensenada.

De acuerdo con las características de la población, se realizó un muestreo estratificado o proporcional. Una vez definido el tamaño de la muestra, ésta se asignó en forma proporcional a cada uno de los subsectores económicos según la participación de cada uno, acorde con las siguientes variables: "Cantidad de empresas", "Cantidad de empleados por empleador" y "Facturación anual promedio por empleado" en su calidad de indicadores de eficiencia ${ }^{15}$.

\footnotetext{
15 Lauría, Daniel y otros (2011) "Caracterización Productiva Regional La Plata - Berisso - Ensenada 2010”, La Plata, MBA - FCE - UNLP en http://www.mba.econo.unlp.edu.ar
} 
Finalmente, dentro de cada uno de esos sub-sectores, se realizó una selección al azar de empresas, utilizando una tabla de números aleatorios creada a través de Microsoft Excel (adicionalmente se seleccionaron de la misma manera empresas de reemplazo para cubrir errores y duplicaciones de los padrones).

El tamaño de la muestra se calculó mediante la siguiente expresión, la cual corresponde al tamaño muestral para proporciones con población conocida:

$$
n=\frac{Z_{\alpha}^{2} \cdot N \cdot p \cdot q}{e^{2} \cdot(N-1)+Z_{\alpha}^{2} \cdot p \cdot q}
$$

Donde:

$\mathrm{N}=318$ empresas (tamaño de la población)

$\mathrm{p}$ = prevalencia esperada del parámetro a evaluar, que en caso de desconocerse, se aplica la opción más desfavorable $(p=0,5)$, que hace mayor el tamaño muestral

q = complemento de la prevalencia esperada del parámetro a evaluar, es decir $1-p=0,5$

$Z=1,96$ para $\alpha=5 \%$, o sea un nivel de confianza del $95 \%$

e $=8,95 \%$ error de muestreo

$n=67$ empresas a encuestar (tamaño de la muestra)

Como se indicó anteriormente, el tamaño muestral se repartió proporcionalmente. 
Tabla N² - Distribución del tamaño muestral

\begin{tabular}{|c|c|c|c|c|c|c|}
\hline Sub.sector & $\begin{array}{l}\text { Cantidad } \\
\text { de } \\
\text { empresas }\end{array}$ & $\begin{array}{l}\text { Cantidad de } \\
\text { Empleados } \\
\text { por } \\
\text { Empleador }\end{array}$ & $\begin{array}{l}\text { Facturación } \\
\text { Anual } \\
\text { promedio } \\
\text { por } \\
\text { empleado }\end{array}$ & $\begin{array}{l}\text { Encuestas } \\
\text { a realizar }\end{array}$ & $\begin{array}{l}\text { Encuestas } \\
\text { logradas }\end{array}$ & Diferencias \\
\hline $\begin{array}{l}\text { Productos Alimenticios, bebidas y } \\
\text { tabaco }\end{array}$ & 143 & 17,1 & $34.284,4$ & 23 & 22 & -1 \\
\hline Textiles y Cueros & 14 & 17,2 & $12.399,2$ & 4 & 6 & 2 \\
\hline Industria de la Madera & 9 & 7,6 & $8.792,7$ & 2 & 2 & 0 \\
\hline Imprentas y Editoriales & 27 & 15,9 & $21.693,2$ & 6 & 6 & 0 \\
\hline Sustancias Químicas & 29 & 23,4 & $40.796,6$ & 9 & 11 & 2 \\
\hline Productos Minerales No Metálicos & 25 & 24,0 & $38.193,1$ & 8 & 9 & 1 \\
\hline Metálicas Básicas & 3 & 10,8 & $19.600,0$ & 3 & 1 & -2 \\
\hline $\begin{array}{l}\text { Productos Metálicos, Maquinarias } \\
\text { y Equipos }\end{array}$ & 68 & 11,1 & $20.853,6$ & 12 & 10 & -2 \\
\hline Totales & 318 & & & 67 & 67 & 0 \\
\hline $\begin{array}{l}\text { Coeficientes de correlación con } \\
\text { "Empresas" }\end{array}$ & 1 & 0,10517542 & 0,40151238 & & & \\
\hline $\begin{array}{l}\text { Proporción por coeficiente de } \\
\text { correlación }\end{array}$ & $66,4 \%$ & $7,0 \%$ & $26,6 \%$ & & & \\
\hline
\end{tabular}

Cabe destacar que las diferencias entre "Encuestas a realizar" y "encuestas logradas" -en los casos "en menos"- ha obedecido a la negativa de algunas empresas (con posterior agotamiento de la instancia de suplentes prevista). Lo que hizo que se procediera a una reasignación por sub-sectores durante el "operativo de campo".

\subsection{Tipo de Investigación}

Se trató de una investigación explicativa de control de desempeño toda vez que los resultados generaron un sentido de entendimiento del fenómeno bajo estudio y de los fundamentos y causas de los aspectos en que se falla o se cumple con los preceptos de competitividad.

\subsection{Técnicas de Recolección de Datos}

Los datos fueron relevados en base a la encuesta original del Índice de Competitividad de los Negocios del Foro Económico Mundial (Executive Opinion Survey), que se entregó personalmente al entrevistado. Éste consistió 
en 57 preguntas más 4 de caracterización de la empresa, evaluadas en su mayoría a través de una escala de 1 a 7 puntos (de lo peor a lo mejor para cada aspecto).

En el Anexo 9.1 se puede acceder a la encuesta completa que se realizó. La misma comprende dos grandes categorías, que se subdividen a su vez en numerosos indicadores.

I) Operaciones y Estrategias de las Empresas: sofisticación del proceso de producción, naturaleza de la ventaja competitiva, grado de capacitación del personal, grado de enfoque hacia el mercado, disposición a delegar autoridad, capacidad de innovación, presencia de la cadena de valor, amplitud de los mercados internacionales, grado de orientación al consumidor, control de la distribución internacional, extensión de la política de marcas, confianza en la administración profesional, grado de compensación por incentivos y nivel de ventas a países de la región.

\section{II) Ambiente de Negocios.}

A) Condiciones de Factores.

1) Infraestructura física: calidad de la infraestructura en general; calidad de la infraestructura de las rutas, desarrollo de la infraestructura férrea, calidad de la infraestructura de los puertos, del transporte aéreo y de las comunicaciones; velocidad y costo de acceso a Internet.

2) Infraestructura Administrativa: protección de la propiedad intelectual, independencia judicial, trámites administrativos para iniciar un negocio y burocracia gubernamental.

3) Recursos humanos: calidad de las escuelas públicas y de las escuelas de negocios.

4) Infraestructura tecnológica: disponibilidad de científicos e ingenieros, calidad de los institutos de investigación científica y colaboración para la investigación entre la universidad y las empresas. 
5) Mercados de capital: facilidad en el acceso a préstamos, sofisticación del mercado financiero, acceso al mercado accionario interno y disponibilidad de capitales de riesgo.

B) Condiciones de la demanda: sofisticación de los compradores, presencia de Normas regulatorias de la demanda, rigurosidad de las regulaciones medioambientales, adquisición gubernamental de productos de tecnología de avanzada y leyes relacionadas al uso de las TIC's (tecnologías de la información y comunicación).

C) Industrias Relacionadas y de Apoyo: calidad de los proveedores locales, cantidad de proveedores locales, estado de desarrollo de agrupamientos, grado de colaboración en los productos y procesos, disponibilidad local de componentes y partes, disponibilidad local de servicios de tecnología de la información, disponibilidad local de los procesos de producción, y disponibilidad local de servicios especializados de búsqueda y capacitación.

D) Contexto para la Estrategia y Competencia de las Empresas:

1) Incentivos: favoritismo en las decisiones de los funcionarios gubernamentales, grado de distorsión de los subsidios gubernamentales, eficacia de la junta directiva y cooperación en las relaciones empleadorempleado.

2) Competencia: barreras de comercio encubiertas, intensidad de la competencia local, alcance de los competidores locales, efectividad de las políticas antimonopólicas y descentralización de la actividad empresarial.

Por otra parte, también se recurrió a una fuente de información secundaria, el cual fue el Informe de Competitividad Global 2011-2012. A efectos de realizar la comparación entre los valores obtenidos en la región respecto de Argentina y el mundo se buscaron las preguntas coincidentes y se recalcularon los índices de competitividad. En el Anexo 9.3 se listaron todas las preguntas coincidentes que se tomaron para recalcular el índice de competitividad. 


\subsection{Técnicas de Análisis}

La competitividad fue medida por el «Índice de Competitividad de los Negocios» ( $\mathrm{BCl}$ o Business Competitiveness Index por su sigla en inglés), el cual evalúa la eficacia con la que la economía utiliza su stock de recursos, basándose en dos grupos de variables: las operaciones y estrategias de la empresa y la calidad del ambiente de negocios.

En consecuencia, el índice mide un conjunto de instituciones, políticas y factores que definen los niveles de prosperidad económica sostenible hoy y a mediano plazo.

El índice fue calculado utilizando información de las empresas a través de la Encuesta de Opinión Ejecutiva y siguiendo la metodología de cálculo del WEF. La encuesta contiene un diseño que permite capturar un amplio rango de factores, como son la Habilidad, Recursos, Conocimientos y Atributos.

El cálculo del indicador se determinó de la siguiente manera ${ }^{16}$ :

1. Las variables que fueron preguntadas a los entrevistados para expresar sus opiniones, oscilaban en una escala de 1 (lo de menor nivel) a 7 (lo de mayor nivel).

2. Seguidamente se calculó el promedio de estas variables transformadas para construir cada uno de los sub-índices.

3. En el paso final se calculó el promedio de todos los subíndices, para obtener el índice general.

\footnotetext{
16“"The Global Competitiveness Report 2011-2012", World Economic Forum, Geneva, Switzerland 2011, Professor Klaus Schwab, World Economic Forum, Editor y Professor Xavier Sala-i-Martin, Columbia University, Chief Advisor of the Centre for Global Competitiveness and Performance, Chapter 1.3 "The Executive Opinion Survey: An Indispensable Tool in the Assessment of National Competitiveness", Ciara Browne, Thierry Geiger, World Economic Forum, «Data treatment and score computation», página 77, http://reports.weforum.org/global-competitiveness2011-2012/\#=
} 


\section{Resultados de la Investigación}

En este apartado se incluyen los resultados que emergen de la información relevada, conforme la metodología utilizada y que fue descripta en el acápite anterior. En el Anexo 9.2 se pueden observar los puntajes obtenidos en cada ítem de la encuesta realizada a cada empresa, así como también los subíndices e índices generales.

La exposición que se realizará a continuación se divide en las siguientes secciones:

1. Análisis del índice regional;

2. Análisis por sector;

3. Análisis comparativo con índices internacionales;

4. Perfil de los respondentes.

En todas las secciones la información se expone principalmente en forma de gráficos, acompañados de una somera explicación.

\subsection{Análisis del índice regional}

El índice global de competitividad de la región obtenido fue 3,57 puntos. Puede subrayarse que el puntaje del índice general $(3,57)$ se encuentra dentro de un rango de valores relativamente cercano tanto con el índice de las "Operaciones y estrategias de las empresas" $(3,75)$, como el índice del "Ambiente de negocios" dentro del cual se encuentran inmersas $(3,51)$. A continuación se observa gráficamente los resultados mencionados: 


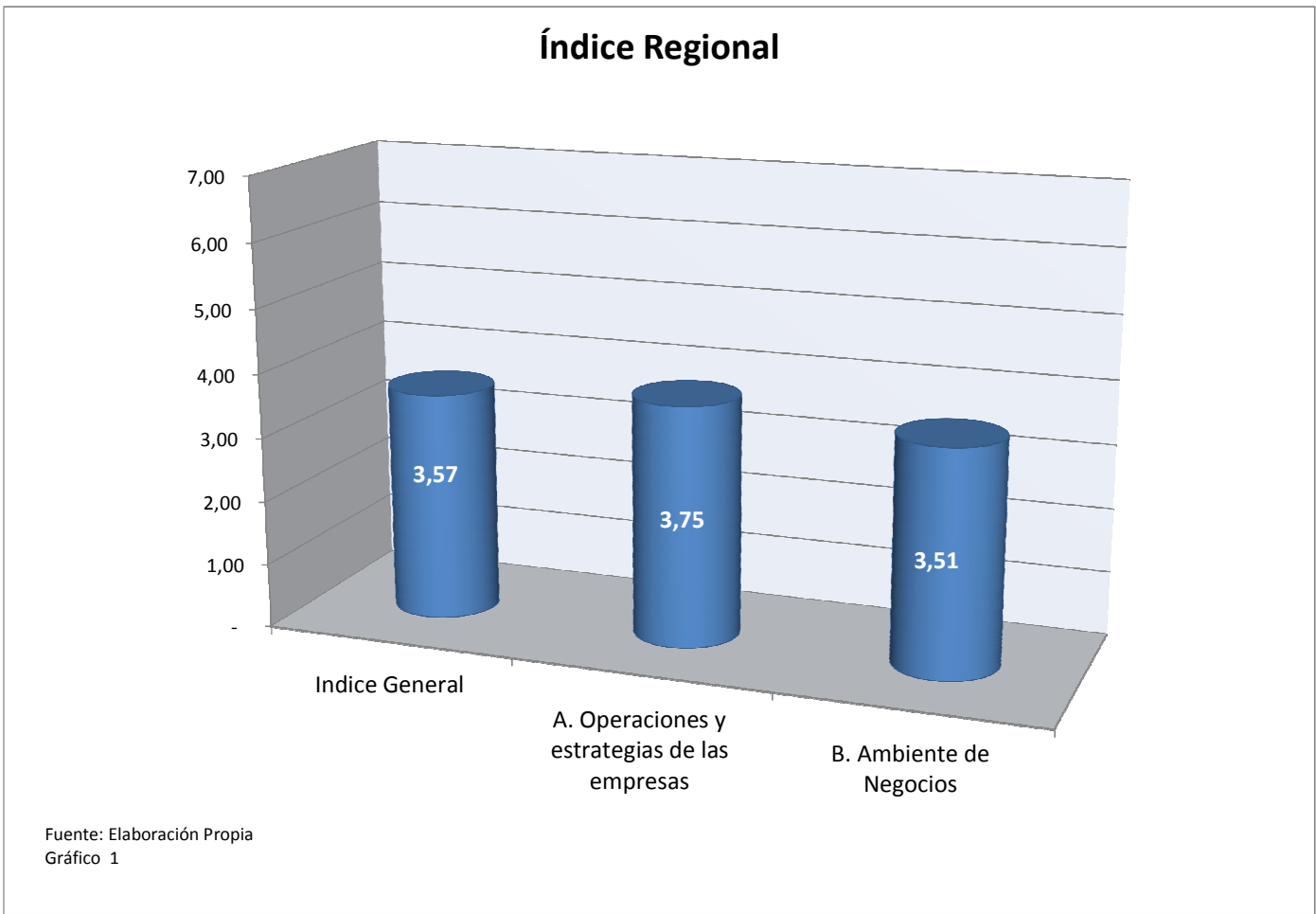

En el gráfico 2 se observan los puntajes alcanzados en cada uno de los ítems del apartado "A. Operaciones y estrategias de las empresas":

\section{A. Operaciones y estrategias de las empresas}

1. Sofisticación del proceso de

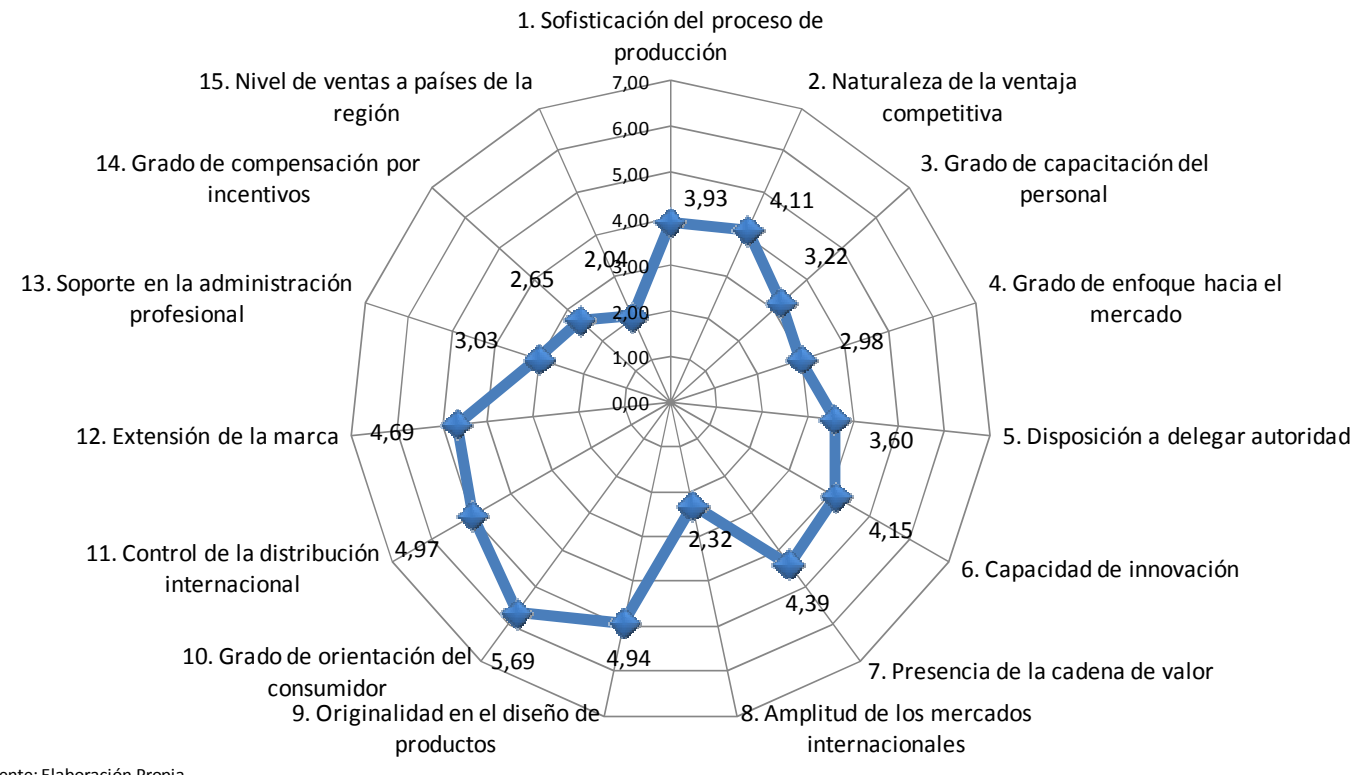

Fuente: Elaboración Propia 
Los aspectos con mayor puntaje dentro de la estrategia son: " Grado de orientación del consumidor", "Control de la distribución internacional", "Originalidad en el diseño de los productos", "Extensión de la marca". Por otro lado, "Nivel de ventas a países de la región" y "Amplitud de los mercados internacionales" son las dos cuestiones con puntaje más bajo.

El apartado "B. Ambiente de negocios" se evalúa a través de la medición de las condiciones de los factores, de la demanda, del Contexto para la estrategia y competencia, y de las industrias relacionadas y de apoyo, siendo los resultados obtenidos los siguientes:

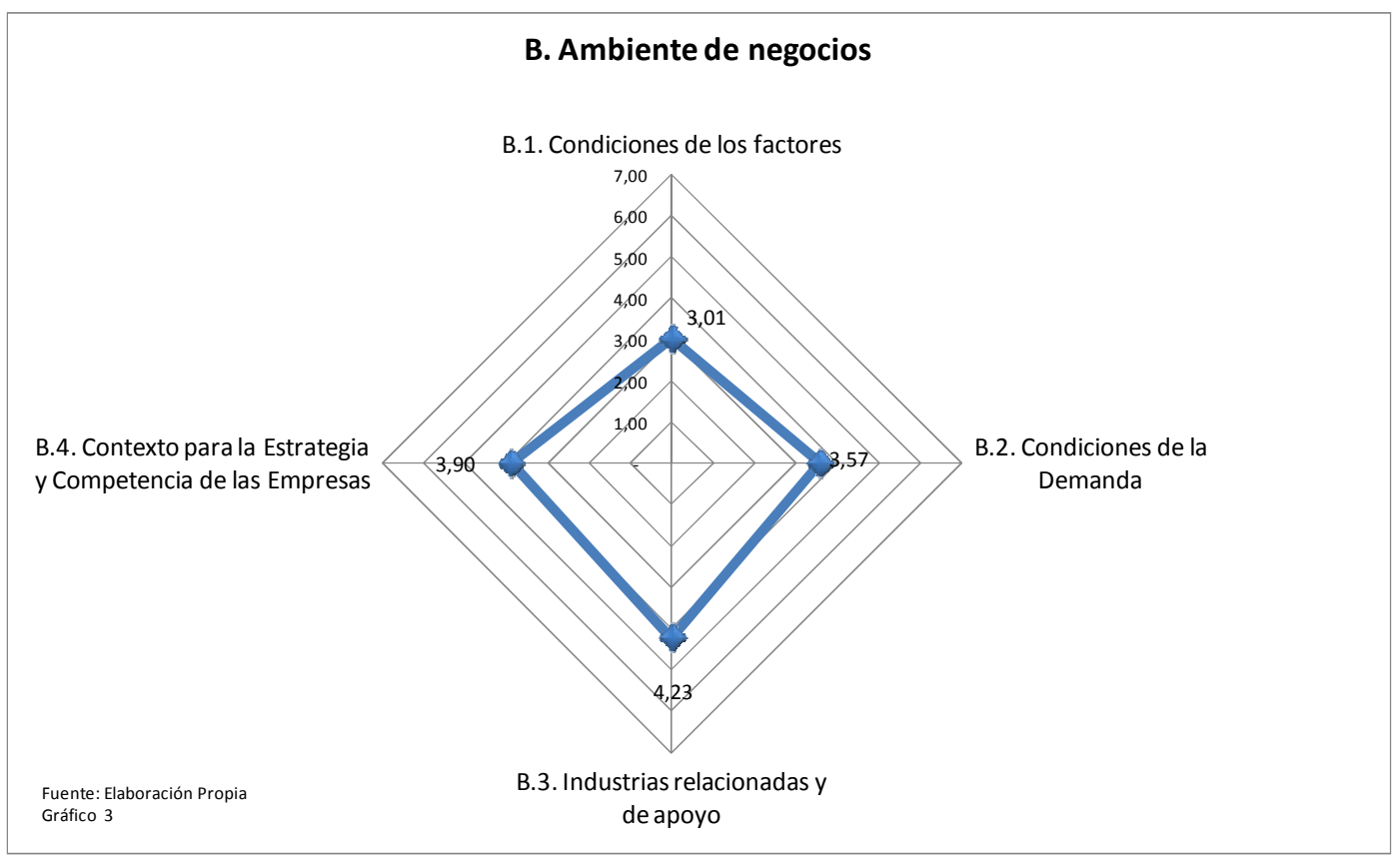

Para entender mejor los resultados obtenidos en cada uno de los ítems de la sección $B$, se muestran los valores alcanzados en los aspectos que conforman los índices de "Condiciones de los factores", "Condiciones de la demanda", "Industrias relacionadas y de apoyo", y "Contexto para la estrategia y competencia".

Como se observa en el gráfico 3, los cuatro vértices que conforman el Ambiente de Negocios obtuvieron un puntaje bajo. 


\section{B1. Condiciones de los Factores}

El gráfico 4 muestra los valores logrados en cada uno de los aspectos que conforman las condiciones de los factores de acuerdo con la encuesta realizada:

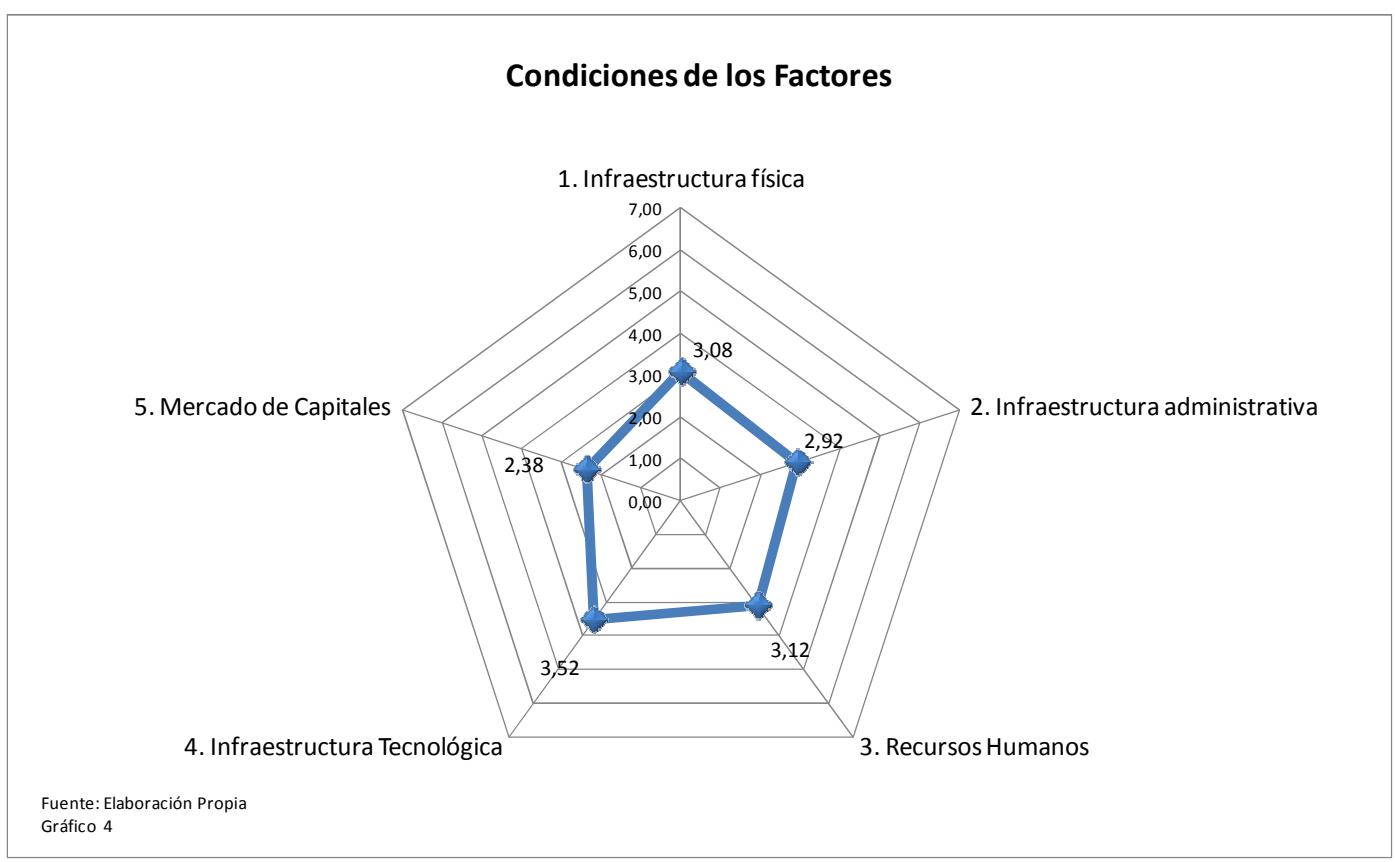

Los recursos de las empresas pueden medirse a través de la infraestructura física que utilizan, la infraestructura administrativa y tecnológica, los recursos humanos y los recursos financieros con que cuentan. Estos últimos resultaron ser los menos calificados.

A continuación puede visualizarse los índices alcanzados para cada uno de los factores que se detallaron:

\section{B1. 1. Infraestructura física}

La evaluación de la infraestructura física se realizó considerando los siguientes aspectos: 


\section{Infraestructura física}

7. Velocidad y costo de acceso a Internet

6. Calidad de la infraestructura de las comunicaciones 5. Calidad de la infraestructura del transporte aéreo

4. Calidad de la infraestructura de los puertos

3. Desarrollo de la infraestructura férrea

2. Calidad de la infraestructura de las rutas

1. Calidad de la infraestructura en genera

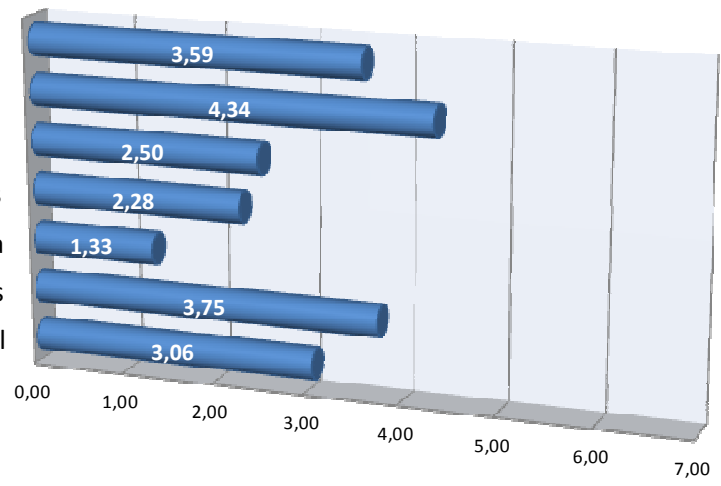

Fuente: Elaboración Propia

Gráfico 5

Es importante destacar del gráfico 5, que la infraestructura de las comunicaciones y de las rutas resultaron los factores mejor calificados, siendo la infraestructura férrea la menos desarrollada.

\section{B1. 2. Infraestructura administrativa}

Los resultados obtenidos en la medición de la infraestructura administrativa se pueden visualizar en el siguiente gráfico:

\section{Infraestructura administrativa}

4. Burocracia gubernamental

3. Trámites administrativos para iniciar un negocio

2. Independencia Judicial

1. Protección de la propiedad intelectual

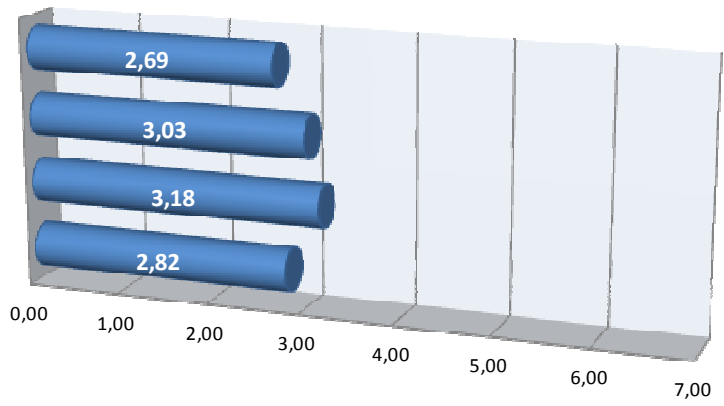

Fuente: Elaboración Propia Gráfico 6 


\section{B1. 3. Mercado de Capitales}

Los recursos de capital fueron evaluados midiendo la cantidad y el costo de capital disponibles para realizar inversiones en la industria, que se expresan de la siguiente manera:

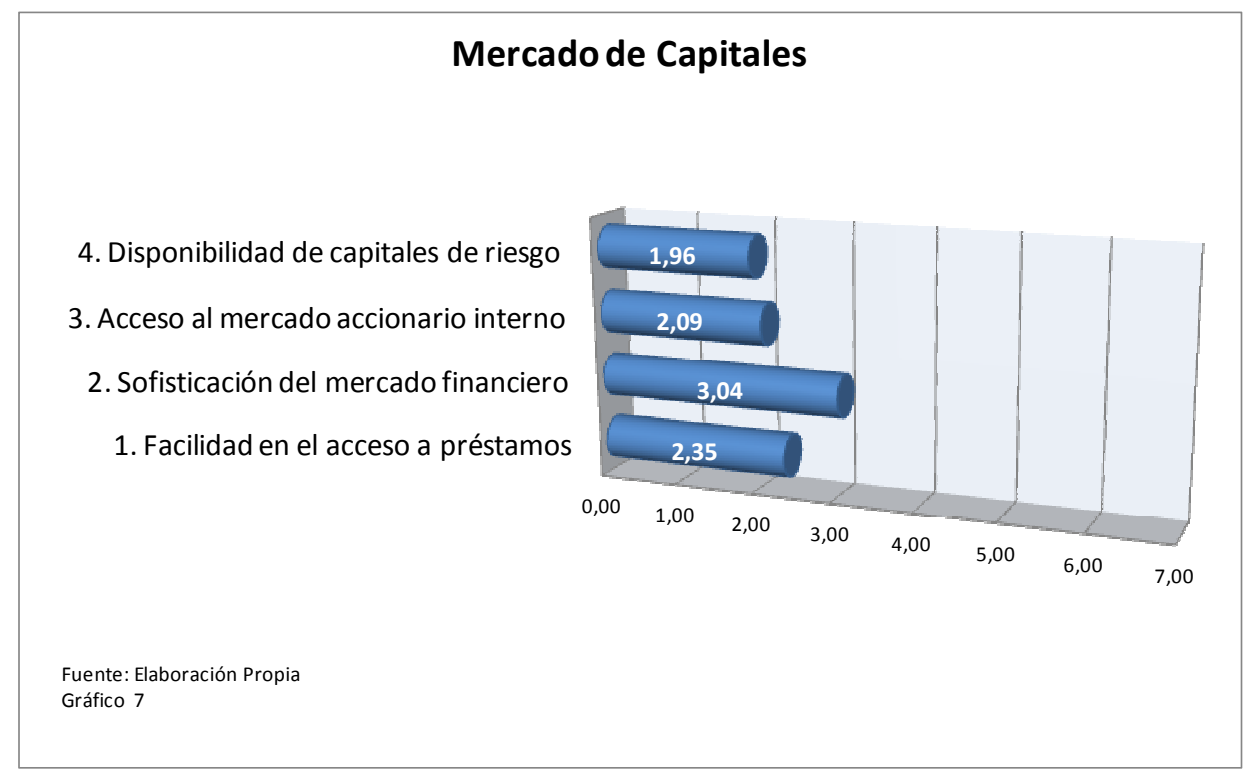

Como se señaló anteriormente, este factor es el peor calificado, obteniendo un puntaje bajo en todos los aspectos interrogados.

\section{B1. 4. Infraestructura tecnológica}

La investigación científica es otro de los recursos a considerar al momento de determinar las condiciones de los factores que afectan la competitividad. Las respuestas obtenidas al momento de evaluar este recurso se muestran en el siguiente gráfico: 


\section{Infraestructura tecnológica}

3. Colaboración en la investigación Universidad / Empresas

2. Calidad de los institutos de investigación científica

1. Disponibilidad de científicos e ingenieros

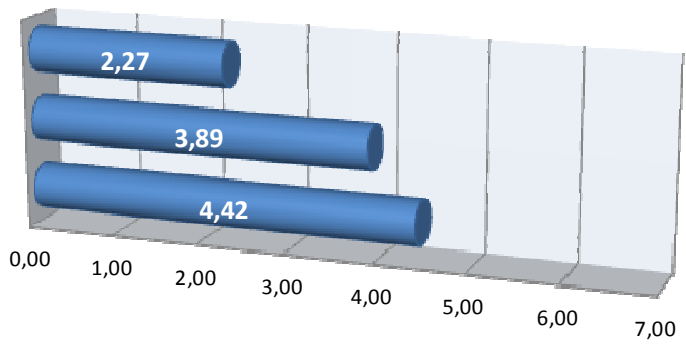

Fuente: Elaboración Propia

Gráfico 8

En el gráfico 8, puede destacarse la poca colaboración a las empresas por parte de las universidades en las actividades de investigación y desarrollo.

\section{B1. 5. Recursos Humanos}

Por último, la calidad de los recursos humanos fue jerarquizada del siguiente modo:

\section{Recursos Humanos}

2. Calidad de las escuelas de negocios

1. Calidad de las escuelas públicas

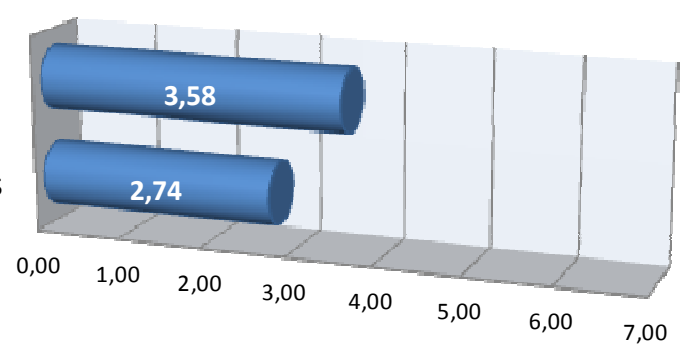

Fuente: Elaboración Propia Gráfico 9

Aquí se muestra que la calidad de las escuelas de negocios obtuvo un índice similar al general. 


\section{B2. Condiciones de la Demanda}

Tal como se menciona en el marco teórico, las naciones logran ventajas competitivas cuando su demanda interior informa anticipadamente a las empresas de nuevas necesidades a cubrir, presionando para que éstas innoven con mayor rapidez. La sofisticación de los compradores obliga a las empresas a responder a retos difíciles. Sin embargo, las empresas encuestadas en la región consideran que sus compradores son poco sofisticados, que las normas regulatorias son laxas donde no existe demasiada rigurosidad en las cuestiones ambientales y otros aspectos que pueden resumirse en el siguiente gráfico:

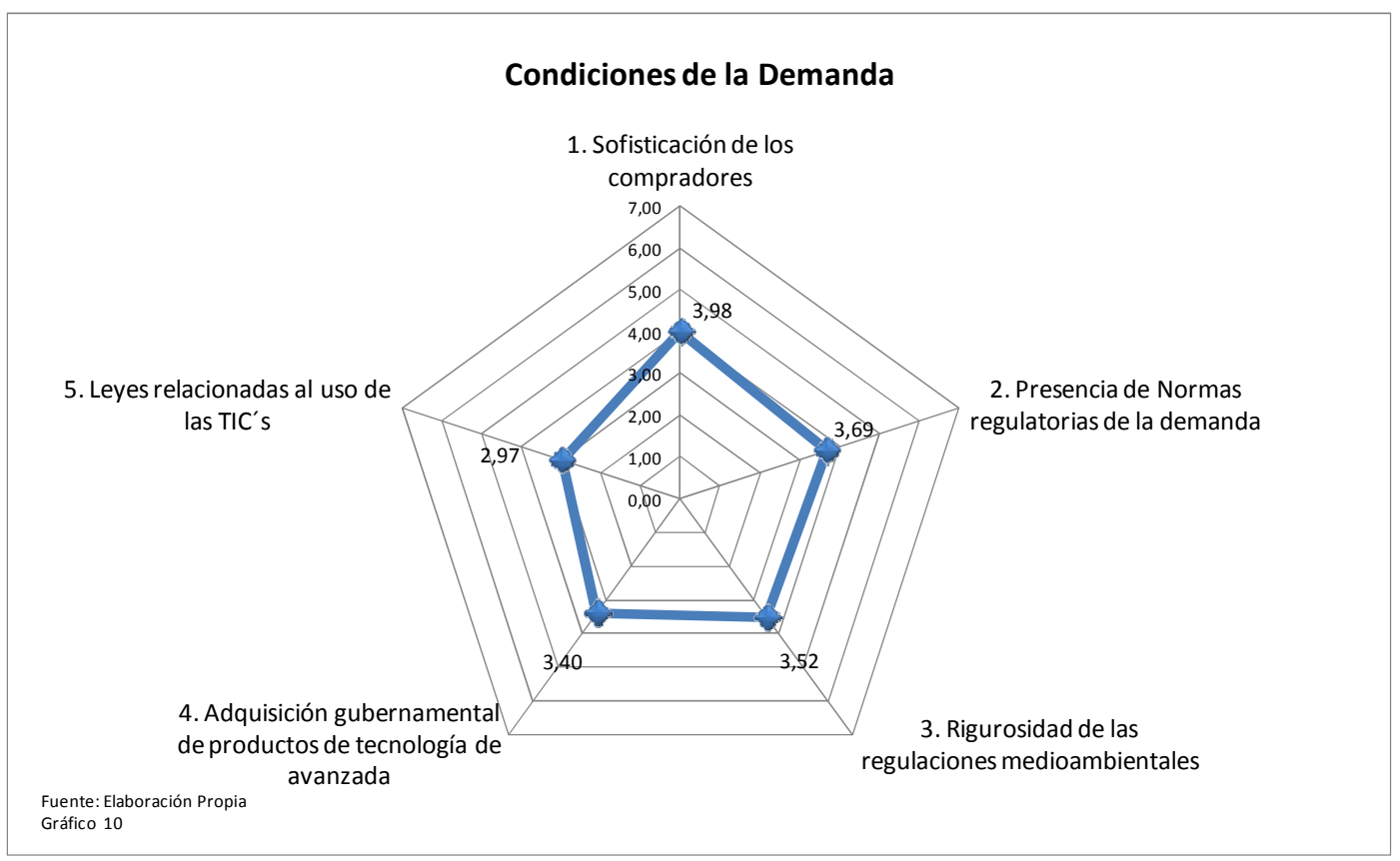

\section{B3. Industrias relacionadas y de apoyo}

Las industrias relacionadas constituyen una gran fuerza exterior a la empresa que favorece a la ventaja competitiva. El grado de colaboración de las empresas, la calidad y cantidad de los proveedores locales, el estado de desarrollo y colaboración de los agrupamientos, entre otros aspectos permiten evaluar esta importante variable que afecta a la ventaja competitiva de una 
empresa. A continuación se exponen los resultados correspondientes a este punto:

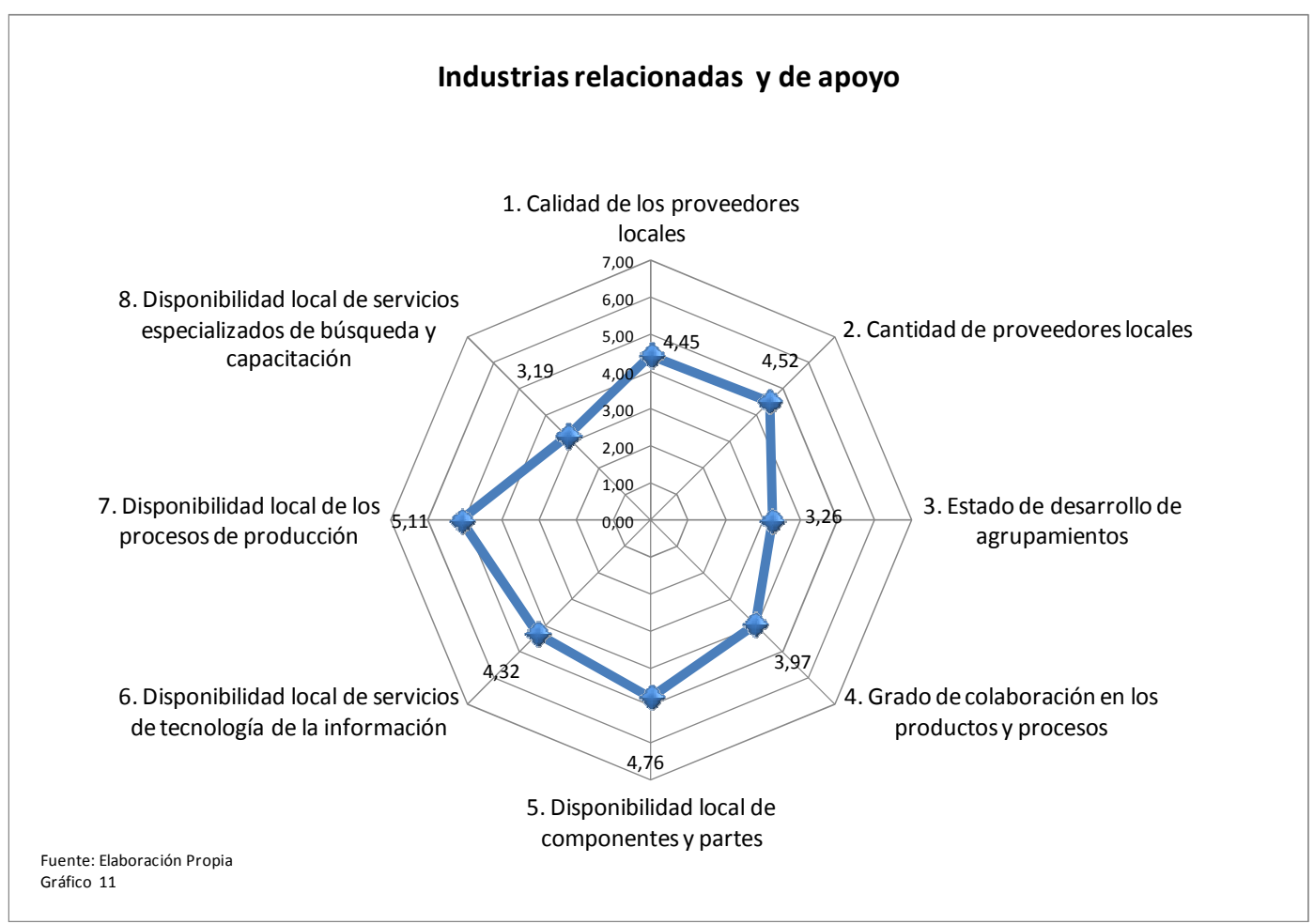

Puede visualizarse en el gráfico 11, que la disponibilidad local de los procesos de producción obtuvo un resultado relativamente importante, así como también, la disponibilidad local de componentes y partes.

\section{B4. Contexto para la Estrategia y Competencia de las empresas}

Las estrategias de las empresas deben responder y estar basadas en los intereses de la demanda local o extranjera. Las empresas de la región que participaron en esta investigación evaluaron su nivel de competencia e incentivos estatales como se refleja en el gráfico 12: 


\section{Contexto para la Estrategia y Competencia para las empresas}

4.2. Competencia

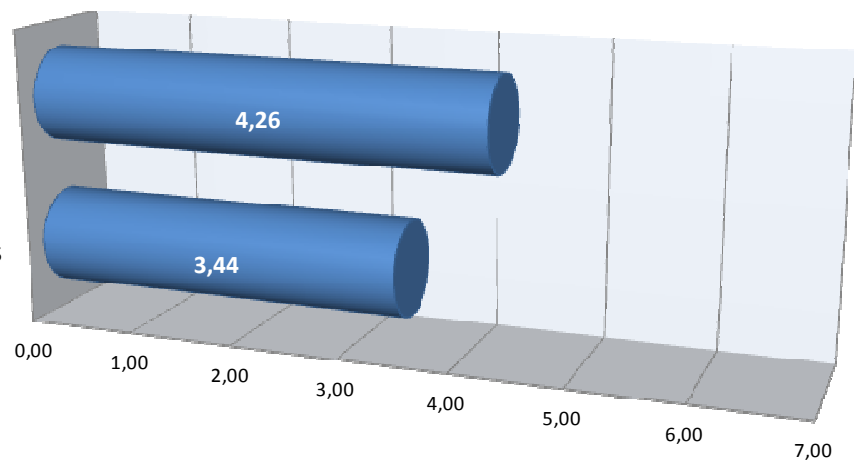

Fuente: Elaboración Propia

B.4.1. Incentivos

Gráfico 12

\section{B4. 1. Incentivo}

Observando de manera pormenorizada los resultados obtenidos para este punto se puede establecer que las empresas valoran los incentivos gubernamentales o internos de la siguiente manera:

\section{Incentivo}

4. Cooperación en las relaciones empleador-empleado

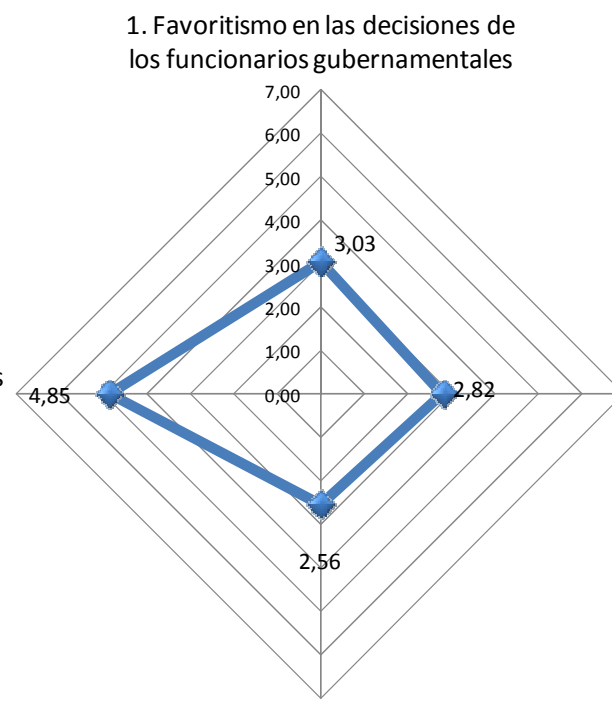

3. Eficacia de la junta directiva
2. Grado de distorsión de los subsidios del gobierno 


\section{B4. 2. Competencia}

Por último, queda avanzar sobre las respuestas que las empresas dieron con relación a los niveles de competencia en la región. El detalle se expresa a continuación:

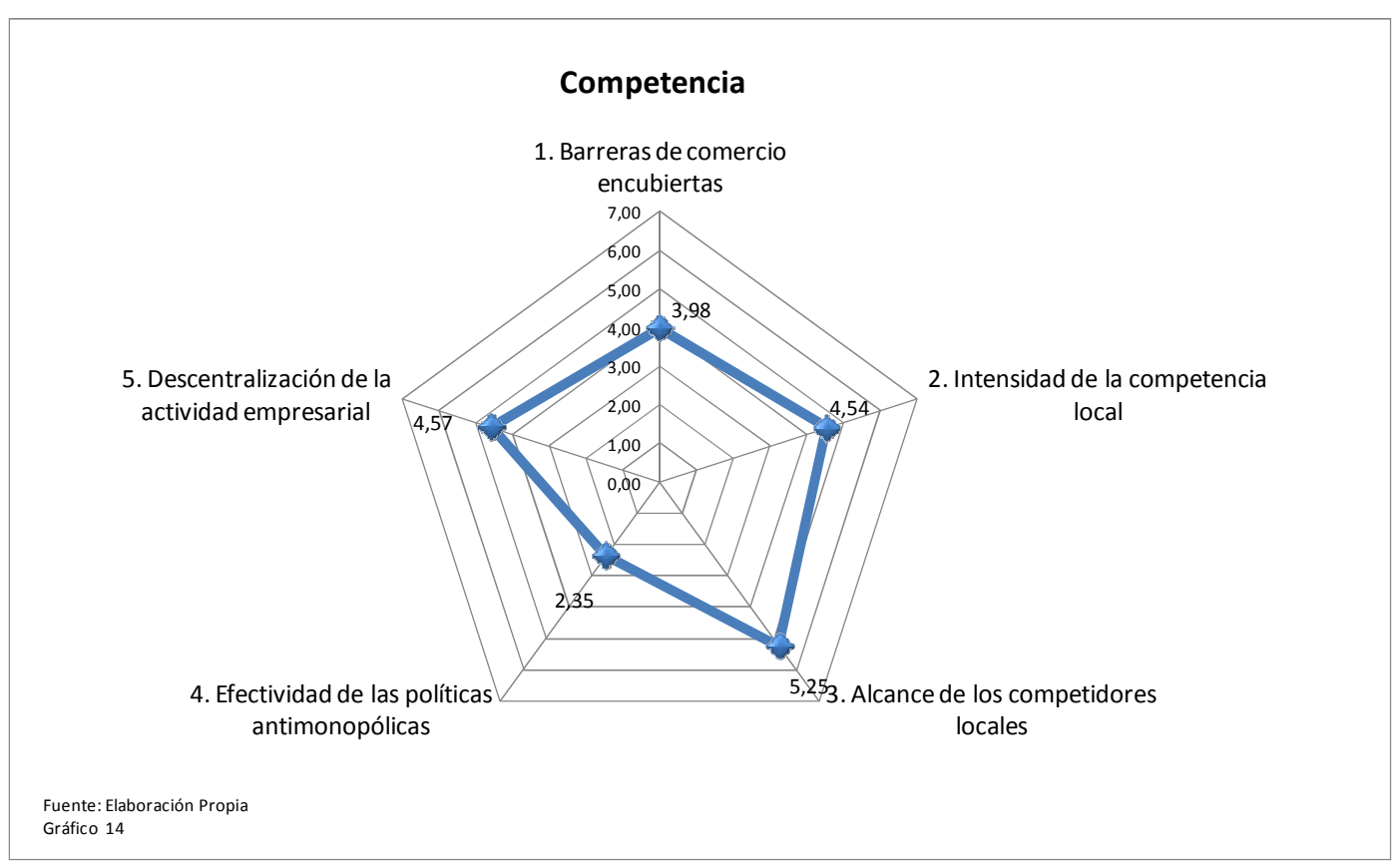

La competencia a nivel local se distingue por su intensidad, alcance y descentralización de la actividad empresarial.

\subsection{Análisis por sector}

Corresponde en esta sección, analizar los resultados obtenidos por sector. Por ello, se abordará el índice general obtenido en cada uno de los sectores encuestados: 


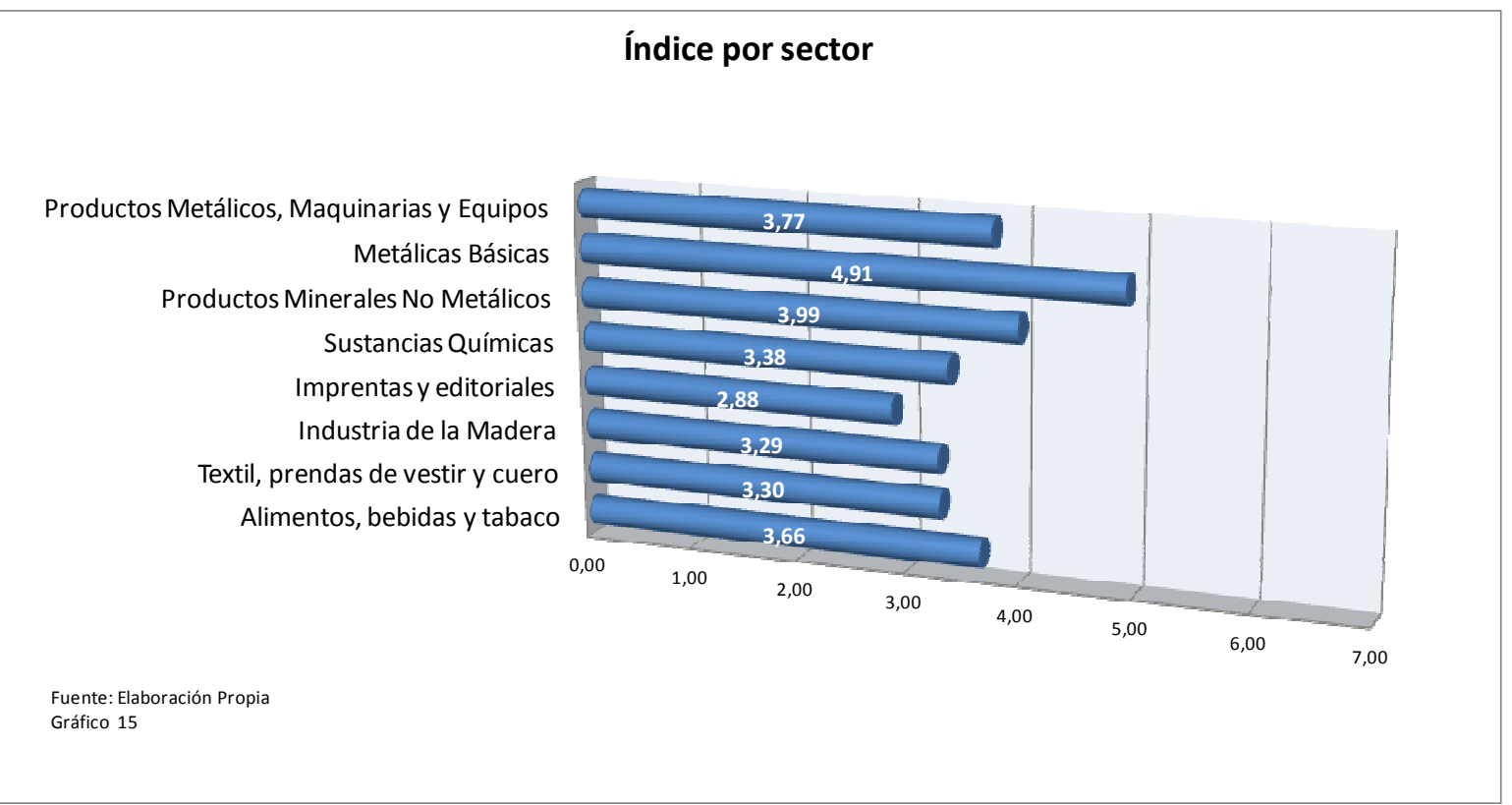

En el gráfico anterior se detalla que el sector Alimentos, bebidas y tabacos logró un índice de competitividad $(3,66)$ que se asemeja al índice de la región ya que la mayoría de las empresas que participaron de esta investigación pertenecen a este sector.

Por otro lado, Productos Minerales No Metálicos y Metálicas Básicas son las actividades más competitivas de la región. En el otro extremo, el sector Imprentas y editoriales obtuvo el índice más bajo $(2,88)$.

A continuación se mostrarán los resultados obtenidos en el apartado A. Operaciones y estrategias de las empresas, y B. Ambiente de negocios en cada sector: 


\section{Índice por sector - Operaciones y estrategias de las empresas}

Productos Metálicos, Maquinarias y Equipos Metálicas Básicas Productos Minerales No Metálicos Sustancias Químicas Imprentas y editoriales Industria de la Madera Textil, prendas de vestir y cuero

Alimentos, bebidas y tabaco

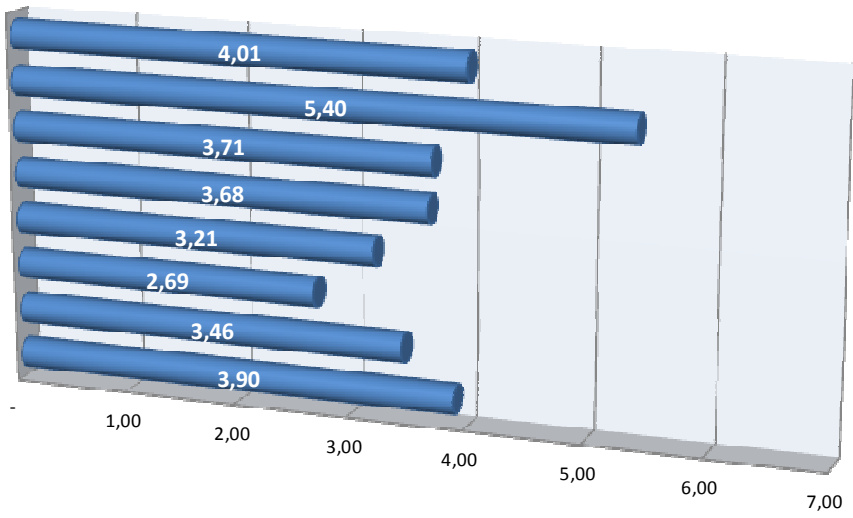

Fuente: Elaboración Propia Gráfico 16

\section{Índice por sector - Ambiente de Negocios}

Productos Metálicos, Maquinarias y Equipos Metálicas Básicas Productos Minerales No Metálicos Sustancias Químicas Imprentas y editoriales Industria de la Madera Textil, prendas de vestir y cuero Alimentos, bebidas y tabaco

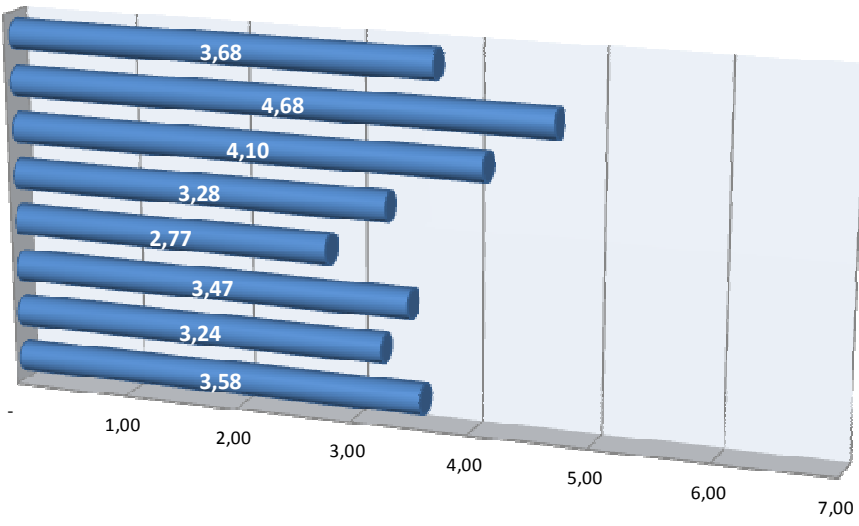

Fuente: Elaboración Propia Gráfico 17

Se observa que en ambos apartados se mantiene la misma tendencia, es decir, el sector Metálicas Básicas obtuvo un puntaje más elevado en ambos casos, siendo Imprentas y editoriales, el sector menos competitivo. El resto de los sectores alcanzaron un índice similar al índice general de toda la región. 


\subsection{Análisis comparativo con índices internacionales}

Tal como se mencionó en el punto 6.3. Técnicas de Recolección de Datos, se realizó un análisis comparativo con la encuesta del Foro Económico Mundial. $A$ tal efecto, se seleccionaron las preguntas comunes entre las utilizadas en el trabajo del Foro y las seleccionadas para este análisis.

En el Anexo 9.4 pueden observarse todos los resultados reprocesados por país o región, así como también, los subíndices e índices generales. A continuación se grafican los valores alcanzados:

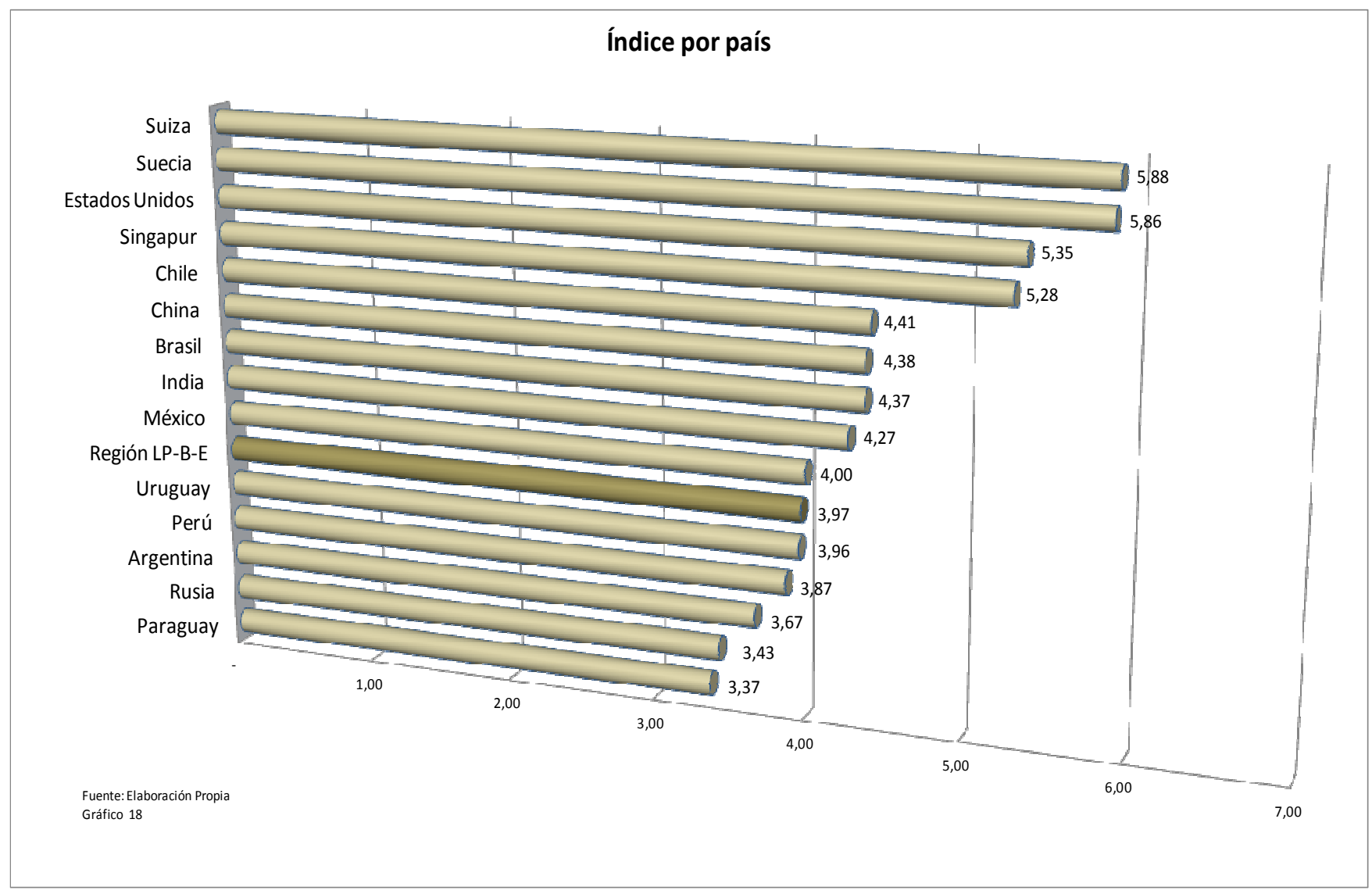

El cuadro anterior revela que la región La Plata, Berisso y Ensenada, obtuvo un índice de competitividad mayor al que posee la Argentina a nivel país, y resulta muy similar al alcanzado por Uruguay. También se observa que países como 
Paraguay, Rusia y Perú logran una competitividad menor respecto a la región seleccionada para esta investigación.

Por encima se encuentran potencias económicas como Suiza, Suecia, Estados Unidos, China y por otro lado, economías emergentes como India, Brasil y Chile.

A continuación se muestran los resultados obtenidos en el apartado $A$. Operaciones y estrategias de las empresas, y B. Ambiente de negocios en cada país o región:

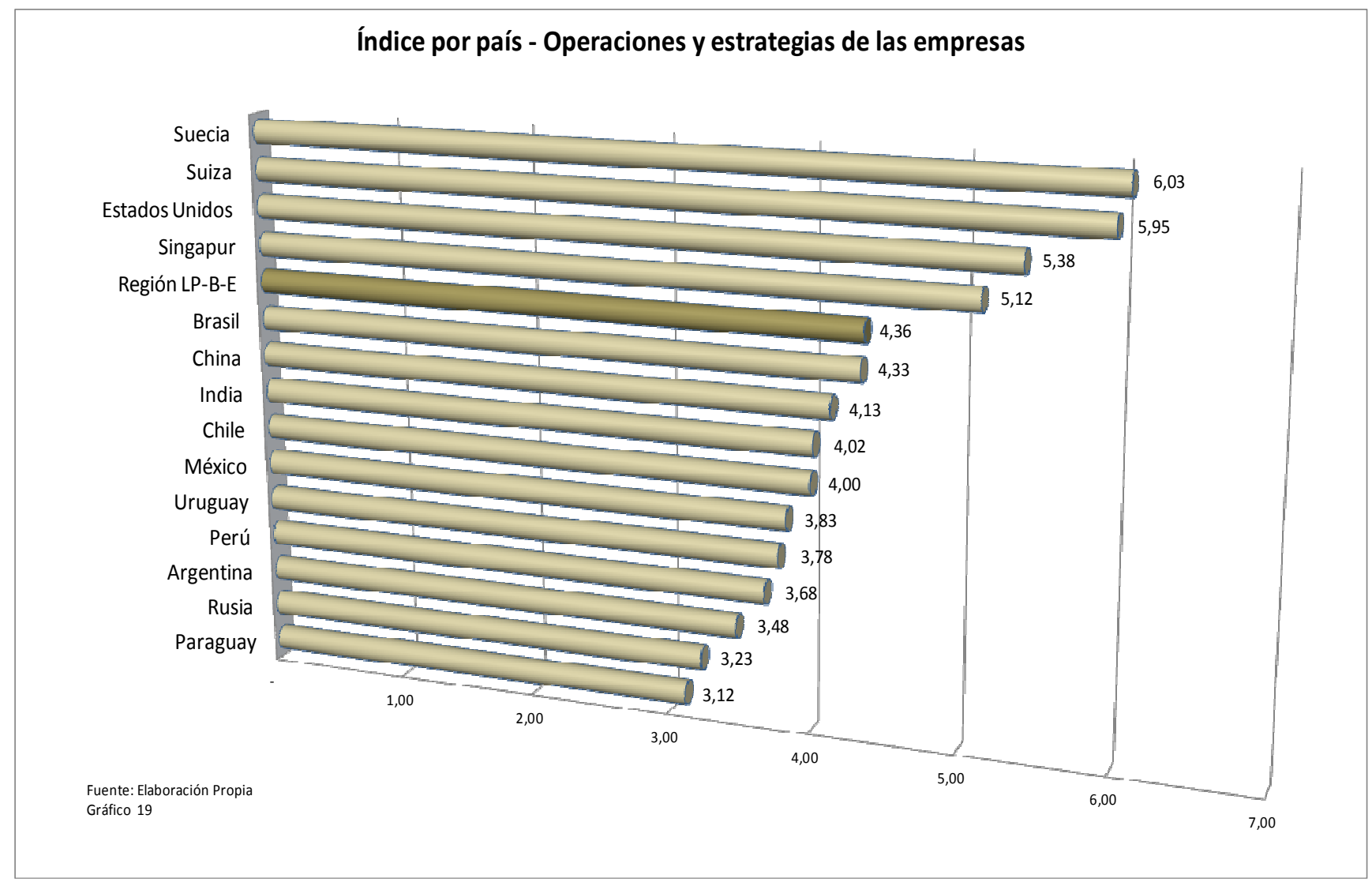

Los resultados que se muestran en el cuadro anterior revelan que los índices sufrieron algunas modificaciones, respecto del índice general. Por ejemplo, la región La Plata, Berisso y Ensenada, mejoró su posición, debido principalmente a que los empresarios consideran que se encuentran en una posición 
avanzada respecto a sus procesos y decisiones clave para encarar el negocio, comparado con el resto de la Argentina.

Al analizar los resultados del apartado B. Ambiente de Negocios se observa de manera clara que la región La Plata, Berisso y Ensenada obtuvo el menor puntaje comparado con el resto de los países seleccionados.

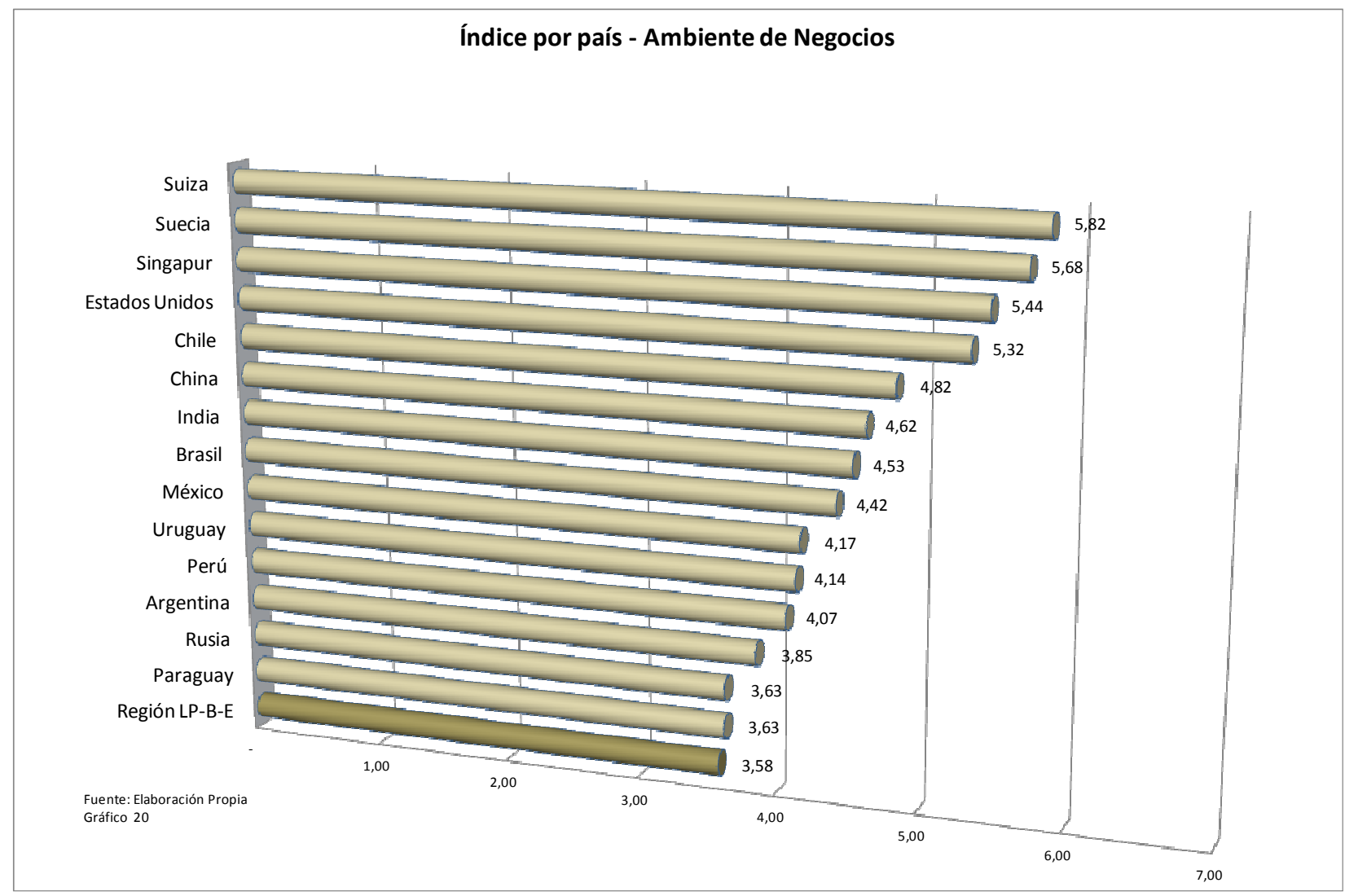

\subsection{Perfil de los respondentes}

Los perfiles se caracterizaron teniendo en cuenta los siguientes aspectos:

1. Tipo de negocio: Se establece cual es la línea de negocios que describe mejor a la empresa;

2. Sectores de negocios: Se establece el sector al cual pertenece la empresa; 
3. Porcentaje de exportación sobre el total de su facturación: Se establece la participación de las ventas a mercados extranjeros sobre el total de la facturación;

4. Posición en la empresa del respondente: Se determina cuál es el puesto que ocupa el encuestado en la empresa;

\section{Línea de Negocios:}

Tal como se observa en el gráfico siguiente, la mayoría de las empresas participantes son fabricantes de productos de consumo final.

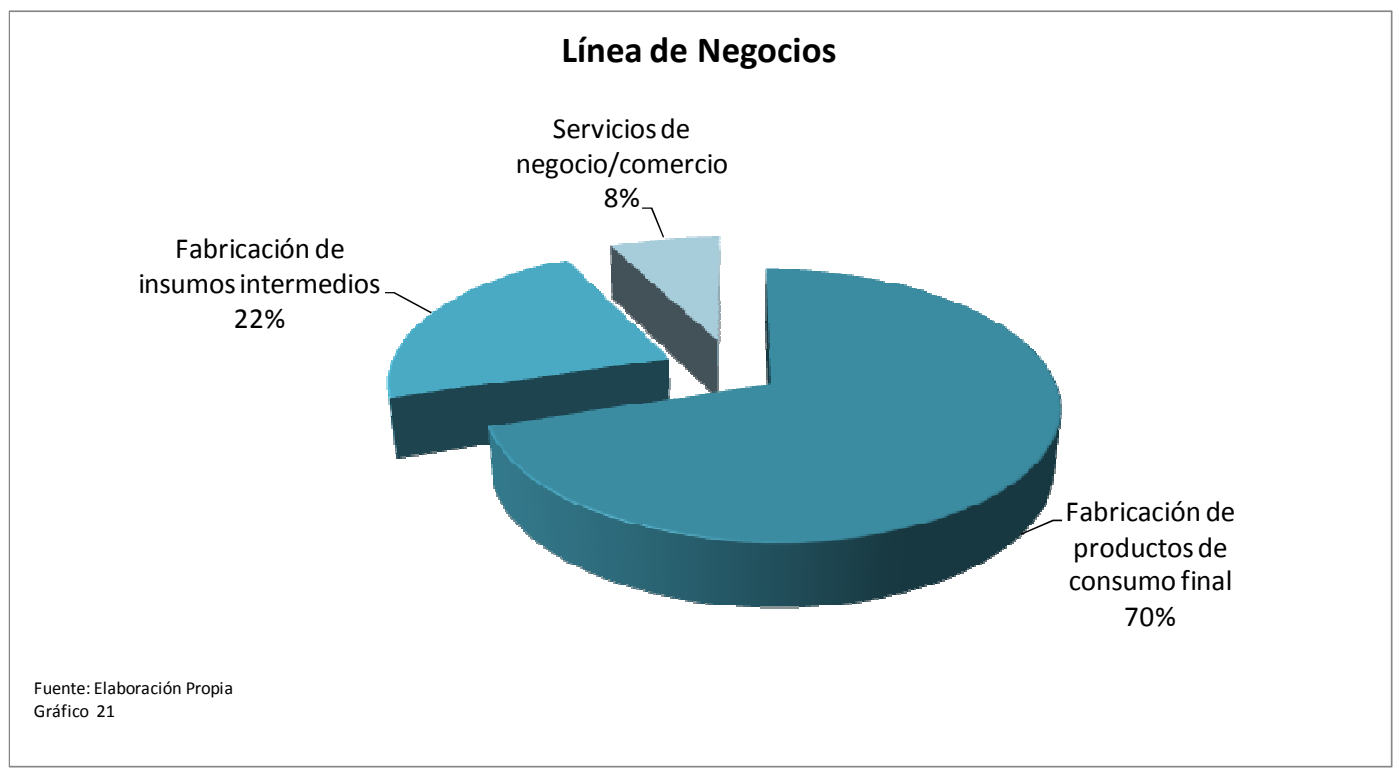

\section{Sector de negocios:}

El sector que se destaca dentro de las empresas participante de este proyecto es el Sector de Productos Alimenticios, bebidas y tabaco (33\%), seguido por los sectores Sustancias Químicas (16\%), Productos Metálicos, Maquinarias y Equipos (15\%); y Productos Minerales No Metálicos (13\%). En el siguiente gráfico se muestra en detalle el grado de participación de cada sector. 


\section{Cantidad de Encuestas logradas por Sector}

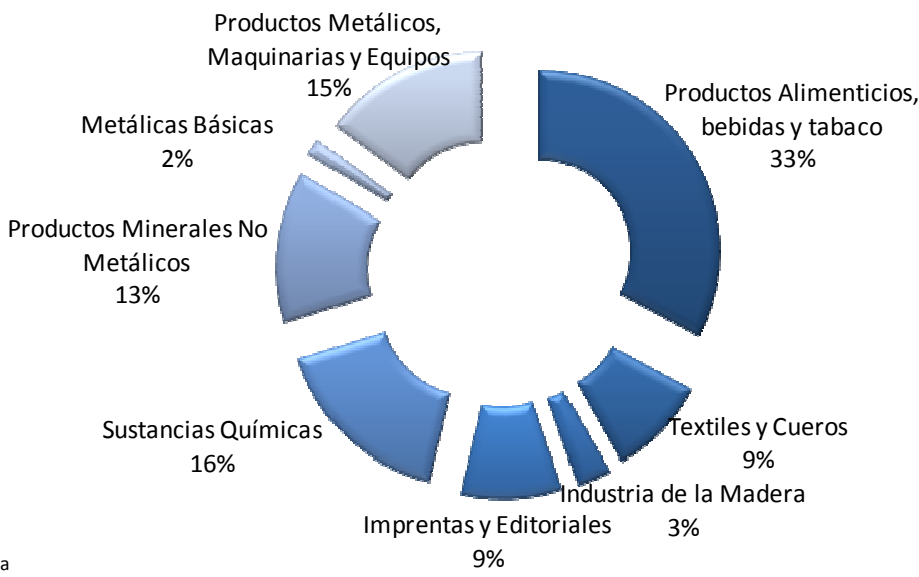

\section{Porcentaje de exportación sobre el total de su facturación:}

Como dato relevante puede ponerse de relieve que el $70 \%$ de las empresas encuestadas de la región La Plata, Berisso y Ensenada no exportan sus productos o servicios.

Del $30 \%$ restante, el $12 \%$ de las empresas exportan un porcentaje total de su facturación que se encuentra por debajo del diez por ciento.

\section{Exportaciones como \% de facturación}

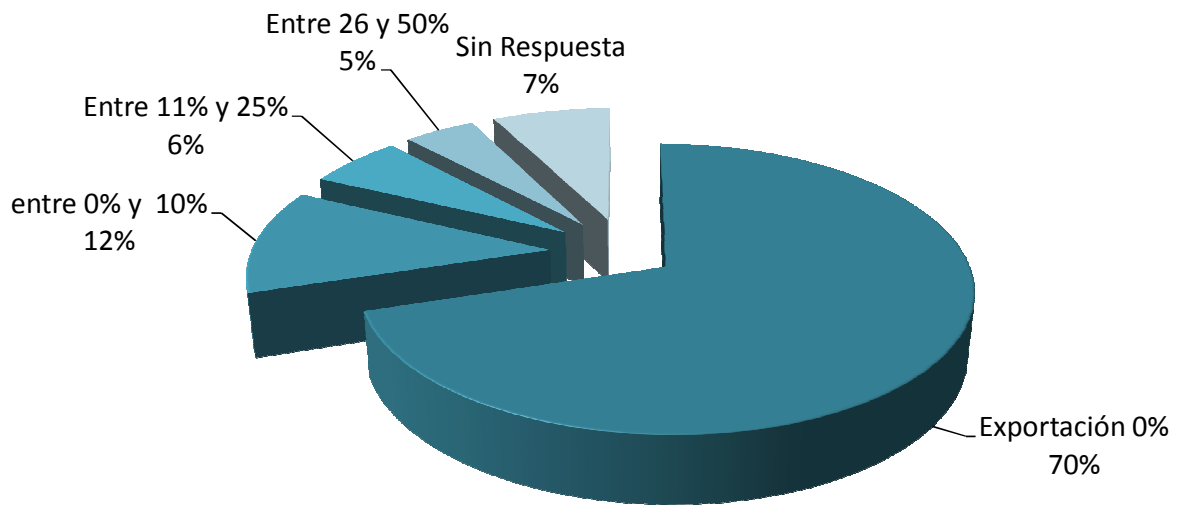

Fuente: Elaboración Propia Gráfico 23 


\section{Posición en la empresa del respondente:}

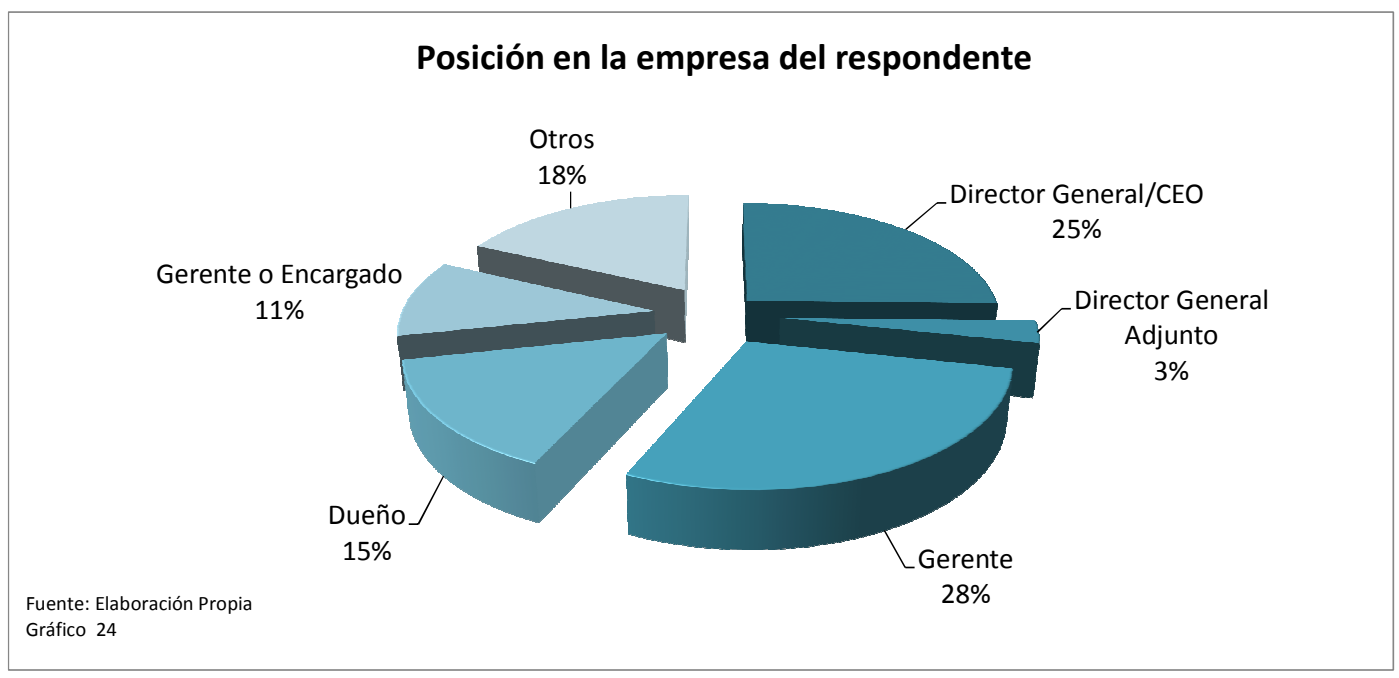

Por último, se observa a través del gráfico anterior que la mayoría de los entrevistados fueron personal jerárquico, lo que determina su alto conocimiento interno de los procesos, estrategias y funcionamiento general de la empresa. 


\section{Conclusiones}

En este trabajo se propuso identificar como primer objetivo las dimensiones y sectores o sub-sectores en los cuales se presentan las mayores oportunidades o debilidades de competitividad en el ámbito regional. Luego de analizar los resultados expuestos en la sección anterior, puede concluirse que la ventaja competitiva de las empresas de la región en el mercado internacional no se debe a productos y procesos únicos, ni tampoco a un bajo costo laboral. En general, dichas empresas desarrollan un producto estándar a un costo accesible, no pudiendo obtener una ventaja competitiva definida con el exterior. Esto se debe en gran medida a la débil apertura a los mercados internacionales. Sólo los sectores como Sustancias Químicas, Productos Minerales No Metálicos, y Metálicas Básicas tienen una ventaja competitiva orientada a productos desarrollados con mejor tecnología, profesionales capacitados y enfocados a las necesidades del consumidor. El resto de los sectores son por lo general medianas y pequeñas empresas familiares con marca propia, que utilizan tecnología estándar y están orientados al consumidor de la región.

A nivel general, las debilidades observadas en el recorte geográfico seleccionado residen en que las exportaciones a países limítrofes son escasas demostrado por el bajo puntaje obtenido (2). Además, las empresas basan principalmente sus incentivos en el salario, viendo lejana la posibilidad de reconocer a sus empleados a través de la entrega de acciones o bonos de la compañía, como una manera más completa de estimular su labor.

Como se mencionó anteriormente, otro punto a destacar es la débil apertura a los mercados internaciones $(2,32)$, teniendo en cuenta que las ventas de las empresas de la región primariamente son hacia el interior del país. Asimismo, el nivel de marketing que permite obtener un enfoque hacia el mercado es limitado (2,98 puntos).

Respecto a los recursos humanos, puede señalarse que al grado de profesionalismo de la gerencia de las empresas encuestadas es bajo, hecho 
que encuentra su razón de ser en que la mayoría de ellas son emprendimientos familiares y sus cargos directivos son ocupados por ellos. También se observa que las mismas invierten escasos recursos en capacitar y desarrollar a sus empleados.

Analizando cada sector en particular y según lo descrito en el apartado "Operaciones y Estrategias de las empresas", puede afirmarse que los sectores Imprentas y Editoriales e Industria de la Madera son los menos competitivos de acuerdo con el puntaje obtenido. Esto se debe a que, en el primero de los dos sectores antes mencionados, no tiene participación en el mercado exterior, ni agregan valor a sus productos. En el segundo caso, el nivel de comercialización es limitado, los productos no tienen un desarrollo en su diseño que les permita obtener una ventaja competitiva y, como se marcó en las debilidades del índice general, se trata de empresas familiares. Como consecuencia de ello, ambos sectores, recaen en un bajo nivel de capacitación de personal y, por consiguiente, baja capacidad de innovación.

En un repaso macro de los resultados que arrojaron los indicadores relacionados con el "Ambiente de Negocios" en el cual operan las empresas de la región, puede concluirse que el aspecto más débil es la condición en la que se encuentran los factores de la producción. En esta línea se hallan también las condiciones de los compradores de las empresas, que son poco exigentes y no presionan para que las empresas vendan productos con altos niveles de calidad.

Por último, los resultados obtenidos, tanto del contexto para la estrategia y competencia de las empresas, como el de las industrias relacionadas y de apoyo; fueron mejores aunque todavía les queda superar algunas metas dado que el flujo de información entres sectores afines y el intercambio técnico no es suficiente para acelerar la velocidad de innovación y mejora. Por otro lado, la falta de claridad en los objetivos de las empresas, debilitan su competitividad.

De una observación detallada emana que en los sectores Textil, prendas de vestir y cuero; Imprentas y Editoriales; y Sustancias Químicas; obtuvieron la 
menor puntuación relacionado con el Ambiente de Negocio ya que todos coinciden en que el mercado de capitales de la región tiene bajo grado de desarrollo. Por esto se entiende poco acceso al mercado crediticio; un mercado financiero poco sofisticado; imposibilidad de obtener fondos a través de un mercado accionario, y una baja disponibilidad de capitales de riesgo. Todas consideraron, también, que existe poco incentivo gubernamental para el desarrollo de sus actividades y volverlas competitivas.

En el caso de los sectores Textil, prendas de vestir y cuero; Imprentas y Editoriales; puede señalarse el bajo nivel de sofisticación de los compradores y las inexistentes normas regulatorias. En estos dos casos, a su vez, consideraron que existe un complejo entramado administrativo para llevar adelante sus emprendimientos.

Como segundo objetivo de trabajo, se evalúa la eficacia con que la economía regional utiliza su stock de recursos. Con relación a este ítem se puede concluir que existen dos motivos que producen la existencia de un índice que dista de ser el óptimo, provocando que la utilización de los recursos sea ineficaz. El primer motivo surge del Ambiente de Negocios, donde las empresas establecen que el nivel de recursos disponibles es escaso, y el segundo motivo surge de las estrategias de las empresas que deciden aprovechar ineficientemente los recursos que tienen a su disposición.

Repasando lo desarrollado en el Marco Teórico, los factores de producción son agrupados en cinco categorías básicas:

1. Recursos humanos;

2. Recursos físicos;

3. Recursos del conocimiento;

4. Recursos de capital;

5. Infraestructura.

Analizando cada uno de ellos, se puede afirmar que las empresas destacaron que la disponibilidad de científicos y la calidad de institutos de investigación científica, les permite una mejor utilización de la infraestructura tecnológica. 
También la infraestructura administrativa es la más ineficiente, ya que la protección de la propiedad intelectual es muy débil, y las regulaciones gubernamentales requieren mucho esfuerzo para poder ser cumplidas. Además iniciar un nuevo negocio implica que los trámites administrativos requeridos sean extremadamente difíciles y requieran demasiado tiempo.

Respecto a la infraestructura física y los recursos humanos, se remarca que son factores que representan una eficacia intermedia para las empresas de la región. Y se observa en los resultados que el mercado de capitales es el factor de mayor ineficiencia, hecho que también se destacó anteriormente por el escaso acceso al financiamiento.

Como tercer y último objetivo, se plantea la posibilidad de detectar las oportunidades para la mejora de la competitividad de la región. Una de ellas, es que si las empresas encuestadas generalmente enfocan sus esfuerzos en satisfacer al consumidor como principal objetivo, desarrollando un diseño y marca propia, a través de procesos de producción que utilizan tecnología eficiente; lograrán conseguir el valor agregado necesario para tener una mayor ventaja competitiva.

Como se señaló en las debilidades que tienen las empresas de la zona comprendida para este análisis, la mayoría de ellas no realizan exportaciones.

Esta flaqueza puede transformarse en una oportunidad que les permita aumentar sus niveles de ventas, por ejemplo, a países limítrofes, ampliando en algunos casos o creando en otros, nuevos mercados internacionales.

Además, el hecho de tratarse en su mayoría de empresas familiares dejan de lado la capacitación tanto del personal técnico como profesional, lo que deviene en una deficiencia a la hora de administrar. Por ende, lograr una mayor capacitación en los recursos humanos también puede convertirse en una ventaja competitiva. 
Siguiendo con el análisis, se puede destacar que resulta paradójico que los encuestados hayan mencionado como factor relevante la disponibilidad de recursos científicos y tecnológicos por parte de instituciones, y no lo capitalicen para la instrucción de su personal y la innovación de sus procesos. Pudiendo transformarse este aspecto en una oportunidad al momento de mejorar sus ventajas competitivas.

Las empresas destacaron que, en cuanto a la infraestructura física a su alcance, el acceso a Internet y las comunicaciones son las más desarrolladas.

Resulta evidente que, con el avance de la sociedad de la comunicación las empresas saquen provecho de esta valerosa herramienta para ampliar su horizonte competitivo. El mundo virtual se vuelve un campo extraordinario para fomentar estrategias relacionadas con el marketing, la publicidad, y las transacciones comerciales a distancia. En ese marco, este factor se vuelve una oportunidad -imprescindible- para ampliar sus negocios.

Como evaluación final puede afirmarse que, según el puntaje del índice general obtenido, se está en condiciones de asegurar que las empresas de la región La Plata, Berisso y Ensenada se encuentran en la mitad de camino para alcanzar una ventaja competitiva a nivel internacional obtenida por productos únicos, cuyos procesos de producción sean los más eficientes y sus diseños sean desarrollados localmente; donde sus recursos humanos se encuentren altamente capacitados, logrando así un alto grado de profesionalismo; y donde la innovación y la orientación hacia el consumidor sean prioridad dentro de sus estrategias.

Todas ellas inmersas en un ambiente de negocios al cual también le falta mucho por desarrollar; ya que el financiamiento y el acceso a capitales se encuentra restringido; la infraestructura física es ineficiente; existen restricciones y complicaciones para cumplimentar las regulaciones gubernamentales que le imponen a las empresas; acompañado por una demanda medianamente regulada; con compradores sofisticados y bien informados. 
En líneas generales, las empresas de la región consideran que las condiciones de los factores de producción son ineficientes, de baja calidad y poco desarrollados. Además, sostienen que sus compradores no demandan productos altamente sofisticados; que no existe regulación sobre el mercado y, por ende, sus consumidores están desprotegidos. Las empresas que desarrollan productos similares no se agrupan para transformar a su sector en una industria pujante. Todas estas falencias se agravan por la orientación de los subsidios gubernamentales a sostener artificialmente a sectores no competitivos, y quitando la posibilidad de generar incentivos en nichos productivos capaces de desarrollar ventajas competitivas. 


\section{Anexos}

\subsection{Encuesta sobre la visión sectorial de aspectos de competitividad empresarial regional.}

\section{A. Operaciones y estrategias de las empresas}

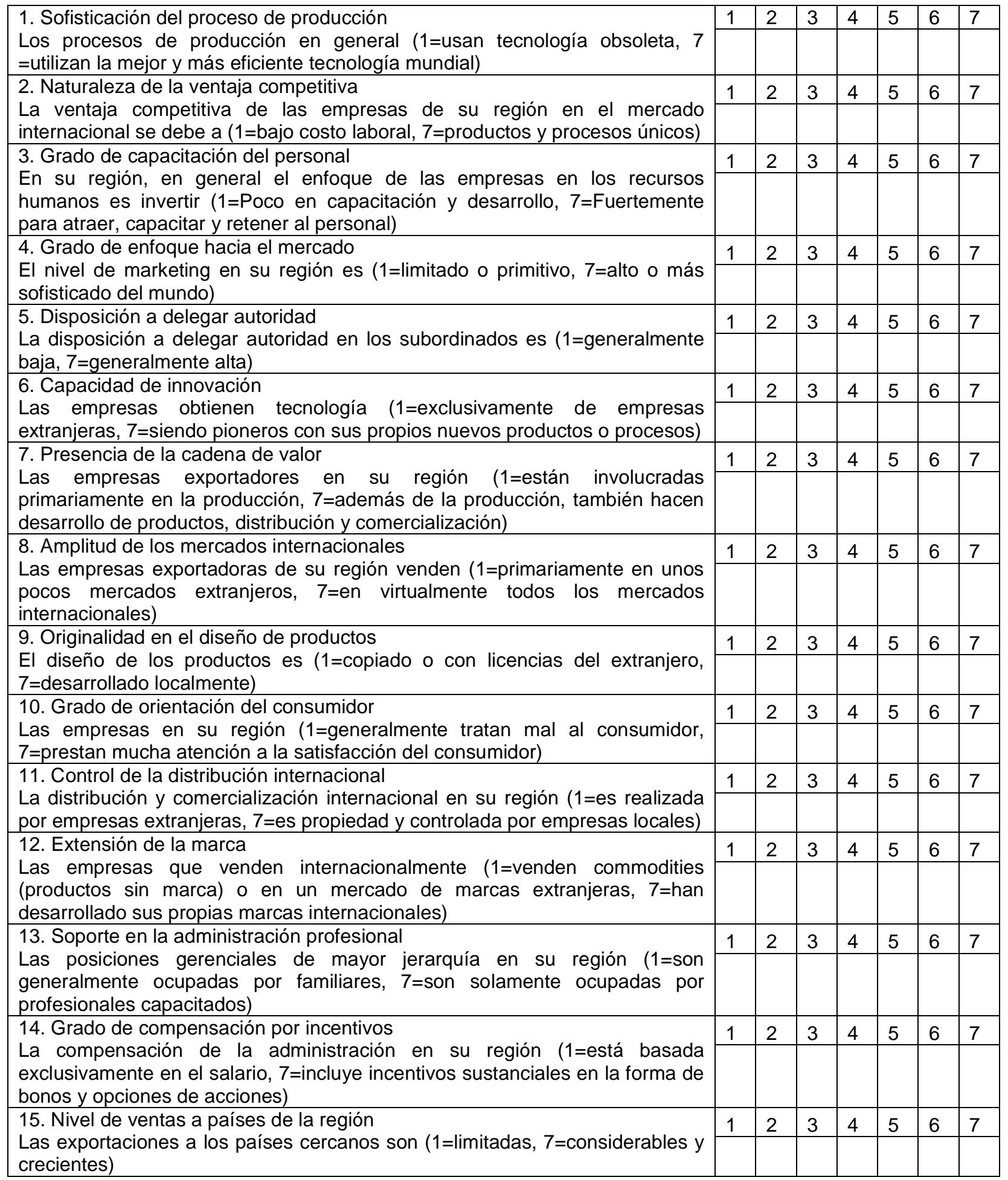


B. Ambiente de Negocios

B.1. Condiciones de los factores

B.1.1. Infraestructura física

\begin{tabular}{|c|c|c|c|c|c|c|c|}
\hline \multirow{2}{*}{$\begin{array}{l}\text { 1. Calidad de la infraestructura en general } \\
\text { La infraestructura general en su región es ( } 1=\text { poco desarrollada e ineficiente, } \\
7=\text { entre las mejores del mundo) }\end{array}$} & 1 & 2 & 3 & 4 & 5 & 6 & 7 \\
\hline & & & & & & & \\
\hline \multirow{2}{*}{$\begin{array}{l}\text { 2. Calidad de la infraestructura de las rutas } \\
\text { De acuerdo con la calidad de las rutas en su región (excepto autopistas), la } \\
\text { velocidad típica de manejo entre ciudades es ( } 1=10 \mathrm{Km} / \mathrm{hr}, 7=150 \mathrm{Km} / \mathrm{h})\end{array}$} & 1 & 2 & 3 & 4 & 5 & 6 & 7 \\
\hline & & & & & & & \\
\hline \multirow{2}{*}{$\begin{array}{l}\text { 3. Desarrollo de la infraestructura férrea } \\
\text { El ferrocarril en su región es (1=poco desarrollado, } 7=\text { extenso y eficiente } \\
\text { como los mejores del mundo) }\end{array}$} & 1 & 2 & 3 & 4 & 5 & 6 & \\
\hline & & & & & & & \\
\hline
\end{tabular}

B.1.1. Infraestructura física (Continuación)

\begin{tabular}{|c|c|c|c|c|c|c|c|}
\hline $\begin{array}{l}\text { 4. Calidad de la infraestructura de los puertos } \\
\text { Los servicios portuarios y las vías navegables interiores en su región son } \\
\text { (1=poco desarrollados, } 7=\text { extensos y eficientes como los mejores del mundo) }\end{array}$ & 1 & 2 & 3 & 4 & 5 & 6 & 7 \\
\hline $\begin{array}{l}\text { 5. Calidad de la infraestructura del transporte aéreo } \\
\text { El transporte aéreo en su región es ( } 1=\text { infrecuente e ineficiente, } 7=\text { extenso y } \\
\text { eficiente como los mejores del mundo) }\end{array}$ & 1 & 2 & 3 & 4 & 5 & 6 & 7 \\
\hline $\begin{array}{l}\text { 6. Calidad de la infraestructura de las comunicaciones } \\
\text { Nuevas líneas telefónicas para su negocio son ( } 1=\text { escasos y difíciles de } \\
\text { obtener, } 7=\text { =ampliamente disponibles y altamente confiables) }\end{array}$ & 1 & 2 & 3 & 4 & 5 & 6 & 7 \\
\hline $\begin{array}{l}\text { 7. Velocidad y costo de acceso a Internet } \\
\text { El acceso a Internet en su región es (1=lento y caro, } 2=\text { tan rápido y barato } \\
\text { como en el resto del mundo) }\end{array}$ & 1 & 2 & 3 & 4 & 5 & 6 & 7 \\
\hline
\end{tabular}

B.1.2. Infraestructura administrativa

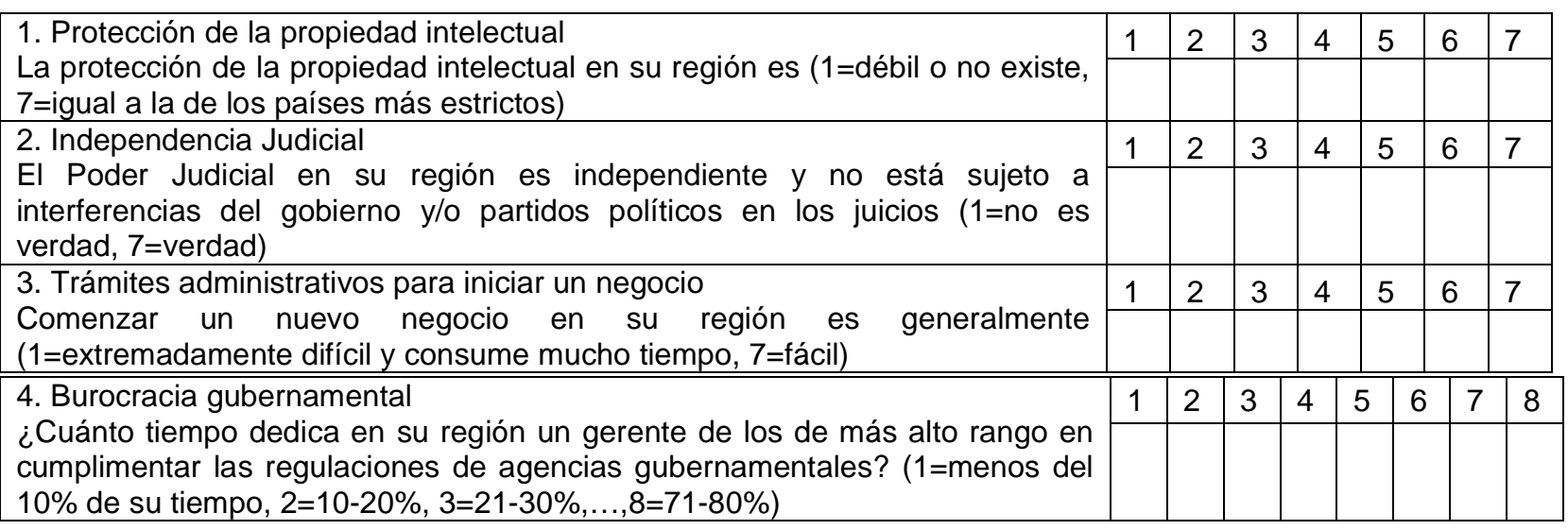

B.1.3. Recursos Humanos

\begin{tabular}{|l|l|l|l|l|l|l|l|}
\hline $\begin{array}{l}\text { 1. Calidad de las escuelas públicas } \\
\text { Las escuelas públicas (gratuitas) en su región son (1=de baja calidad, } 7=\text { igual } \\
\text { a las mejores del mundo) }\end{array}$ & 1 & 2 & 3 & 4 & 5 & 6 & 7 \\
\hline $\begin{array}{l}\text { 2. Calidad de las escuelas de negocios } \\
\text { Las escuelas de negocios en su región son (1=limitadas y de baja calidad, } \\
7=\text { fentre las mejores del mundo) }\end{array}$ & 1 & 2 & 3 & 4 & 5 & 6 & 7 \\
\hline
\end{tabular}

\section{B.1.4. Infraestructura Tecnológica}

\begin{tabular}{|l|l|l|l|l|l|l|l|}
\hline $\begin{array}{l}\text { 1. Disponibilidad de científicos e ingenieros } \\
\text { Los científicos e ingenieros en su región son (1=no existen o raros, }\end{array}$ & 1 & 2 & 3 & 4 & 5 & 6 & 7 \\
\hline 7=ampliamente disponibles) & & & & & & \\
\hline 2. Calidad de los institutos de investigación científica & 1 & 2 & 3 & 4 & 5 & 6 & 7 \\
\hline
\end{tabular}


Las instituciones de investigación científica en su región, tales como universidades o laboratorios del gobierno son ( $1=$ no existen, $7=$ los mejores en su disciplina)

3. Colaboración en la investigación Universidad / Empresas

En sus actividades de investigación y desarrollo, la colaboración de las empresas con las universidades locales es ( $1=$ mínima o no existe, $7=$ intensiva y progresiva)

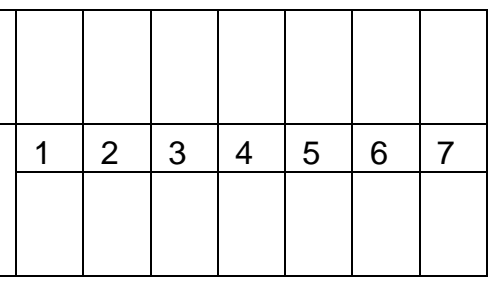

\section{B.1.5. Mercado de Capitales}

\begin{tabular}{|c|c|c|c|c|c|c|c|}
\hline \multirow{2}{*}{$\begin{array}{l}\text { 1. Facilidad en el acceso a préstamos } \\
\text { ¿Cuán fácil es obtener un préstamo en tu región con solamente un buen plan } \\
\text { de negocios y sin garantías? ( } 1=\text { imposible, } 7=\text { fácil })\end{array}$} & 1 & 2 & 3 & 4 & 5 & 6 & 7 \\
\hline & & & & & & & \\
\hline \multirow{2}{*}{$\begin{array}{l}\text { 2. Sofisticación del mercado financiero } \\
\text { El nivel de sofisticación del mercado financiero en su región es (1=menor que } \\
\text { el promedio internacional, } 7=\text { mayor que el promedio internacional) }\end{array}$} & 1 & 2 & 3 & 4 & 5 & 6 & 7 \\
\hline & & & & & & & \\
\hline \multirow{2}{*}{$\begin{array}{l}\text { 3. Acceso al mercado accionario interno } \\
\text { Obtener capital a través de la emisión de acciones en el mercado accionario } \\
\text { interno es ( } 1=\text { prácticamente imposible, } 7=\text { bastante posible para una buena } \\
\text { empresa) }\end{array}$} & 1 & 2 & 3 & 4 & 5 & 6 & 7 \\
\hline & & & & & & & \\
\hline \multirow{2}{*}{$\begin{array}{l}\text { 4. Disponibilidad de capitales de riesgo } \\
\text { Los emprendedores con proyectos innovadores pero riesgosos en su región, } \\
\text { generalmente pueden encontrar capital de riesgo disponible para invertir } \\
\text { ( } 1=\text { no es verdad, } 7=\text { es verdad) }\end{array}$} & 1 & 2 & 3 & 4 & 5 & 6 & \\
\hline & & & & & & & \\
\hline
\end{tabular}

\section{B.2. Condiciones de la Demanda}

\section{Sofisticación de los compradores}

Los compradores en su región son (1=poco sofisticados y eligen en función del precio más bajo, $7=$ inteligente, bien informado, demandante y comprador de productos innovadores)

2. Presencia de Normas regulatorias de la demanda

Las normas regulatorias -por ejemplo para productos, energía, seguridad,

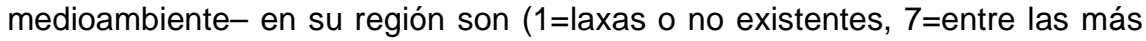
estrictas del mundo)

3. Rigurosidad de las regulaciones medioambientales

La rigurosidad de las regulaciones medioambientales globales en su región es (1=laxa comparada con la mayoría de los otros países, $7=$ entre las más estrictas del mundo)

4. Adquisición gubernamental de productos de tecnología de avanzada Las decisiones gubernamentales de adquisición de productos de tecnología avanzada están basadas en ( 1 =solamente precios, $7=$ =tecnología y fomento de la innovación)

5. Leyes relacionadas al uso de las TIC's (tecnologías de la información y comunicación)

Las leyes relacionadas al comercio electrónico, firma digital y protección al consumidor son ( $1=$ no existen, $7=$ bien desarrolladas y puestas en vigor)

\section{B.3. Industrias relacionadas y de apoyo}

\begin{tabular}{|l|l|l|l|l|l|l|l|}
\hline $\begin{array}{l}\text { 1. Calidad de los proveedores locales } \\
\text { Los proveedores del país en su región son (1=ineficientes y tienen poca } \\
\text { capacidad tecnológica, 7=internacionalmente competitivos y brindan } \\
\text { asistencia en el desarrollo de nuevos productos y procesos) }\end{array}$ & 1 & 2 & 3 & 4 & 5 & 6 & 7 \\
\hline $\begin{array}{l}\text { 2. Cantidad de proveedores locales } \\
\text { Los proveedores del país en su región son (1=prácticamente inexistentes, }\end{array}$ & 1 & 2 & 3 & 4 & 5 & 6 & 7 \\
$\begin{array}{l}\text { 7=numerosos y proveen los materiales, componentes, equipos y servicios } \\
\text { más importantes) }\end{array}$ & & & & & & \\
\hline $\begin{array}{l}\text { 3. Estado de desarrollo de agrupamientos con su región? (1=las } \\
\text { ¿Las agrupaciones empresarias son comunes en su } \\
\text { agrupaciones son limitadas y superficiales, 7=las agrupaciones son comunes }\end{array}$ & 1 & 2 & 3 & 4 & 5 & 6 & 7 \\
\hline
\end{tabular}




\begin{tabular}{|c|c|c|c|c|c|c|c|}
\hline e intensas) & & & & & & & \\
\hline 4. Grado de colaboración en los productos y procesos & 1 & 2 & 3 & 4 & 5 & 6 & 7 \\
\hline $\begin{array}{l}\text { El desarrollo de productos y procesos en su región es llevado a cabo } \\
\text { ( } 1=\text { dentro de las empresas o con proveedores extranjeros, } 7=\text { en colaboración } \\
\text { con proveedores locales, organizaciones de investigación de mercado) }\end{array}$ & & & & & & & \\
\hline 5. Disponibilidad local de componentes y partes & 1 & 2 & 3 & 4 & 5 & 6 & 7 \\
\hline $\begin{array}{l}\text { En su sector, los componentes y partes son ( } 1=\text { casi todos importados, } 7=\text { casi } \\
\text { siempre producidos localmente) }\end{array}$ & & & & & & & \\
\hline 6. Disponibilidad local de servicios de tecnología de la información & 1 & 2 & 3 & 4 & 5 & 6 & 7 \\
\hline $\begin{array}{l}\text { En su sector, los servicios especializados en tecnología de la información son } \\
\text { ( } 1=\text { no disponibles en la región, } 7=\text { disponibles por parte de instituciones } \\
\text { locales de clase mundial) }\end{array}$ & & & & & & & \\
\hline 7. Disponibilidad local de los procesos de producción & 1 & 2 & 3 & 4 & 5 & 6 & 7 \\
\hline $\begin{array}{l}\text { En su sector, los procesos de producción son (1=casi siempre importados, } \\
7=\text { casi siempre de origen del propio país) }\end{array}$ & & & & & & & \\
\hline 8. Disponibilidad local de servicios especializados de búsqueda y capacitación & 1 & 2 & 3 & 4 & 5 & 6 & 7 \\
\hline $\begin{array}{l}\text { En su sector, los servicios especializados de búsqueda y capacitación son } \\
\text { ( } 1=\text { no disponibles en su región, } 7=\text { disponibles por parte de instituciones } \\
\text { locales de clase mundial) }\end{array}$ & & & & & & & \\
\hline
\end{tabular}

\section{B.4. Contexto para la Estrategia y Competencia de las Empresas}

B.4.1. Incentivos

\begin{tabular}{|c|c|c|c|c|c|c|c|}
\hline \multirow{2}{*}{$\begin{array}{l}\text { 1. Favoritismo en las decisiones de los funcionarios gubernamentales } \\
\text { Ante las decisiones sobre políticas y contratos, los funcionarios del gobierno } \\
\text { ( } 1=\text { generalmente favorecen a empresas o individuos con llegada al gobierno, } \\
7=\text { son neutrales entre firmas e individuos) }\end{array}$} & 1 & 2 & 3 & 4 & 5 & 6 & 7 \\
\hline & & & & & & & \\
\hline \multirow{2}{*}{$\begin{array}{l}\text { 2. Grado de distorsión de los subsidios del gobierno } \\
\text { Los subsidios gubernamentales para las empresas en su región ( } 1=\text { sostienen } \\
\text { artificialmente a sectores no competitivos, } 7=\text { aumentan la productividad del } \\
\text { sector subsidiado) }\end{array}$} & 1 & 2 & 3 & 4 & 5 & 6 & 7 \\
\hline & & & & & & & \\
\hline \multirow{2}{*}{$\begin{array}{l}\text { 3. Eficacia de la junta directiva } \\
\text { Las juntas directivas en su región son ( } 1=\text { controlados por la gerencia, } \\
7=\text { poderosos y representantes de los accionistas) }\end{array}$} & 1 & 2 & 3 & 4 & 5 & 6 & 7 \\
\hline & & & & & & & \\
\hline \multirow{2}{*}{$\begin{array}{l}\text { 4. Cooperación en las relaciones empleador-empleado } \\
\text { Las relaciones empleador-empleado en su región son ( } 1=\text { generalmente } \\
\text { confrontativas, } 7=\text { generalmente cooperativas) }\end{array}$} & 1 & 2 & 3 & 4 & 5 & 6 & 7 \\
\hline & & & & & & & \\
\hline
\end{tabular}

\section{B.4.2. Competencia}

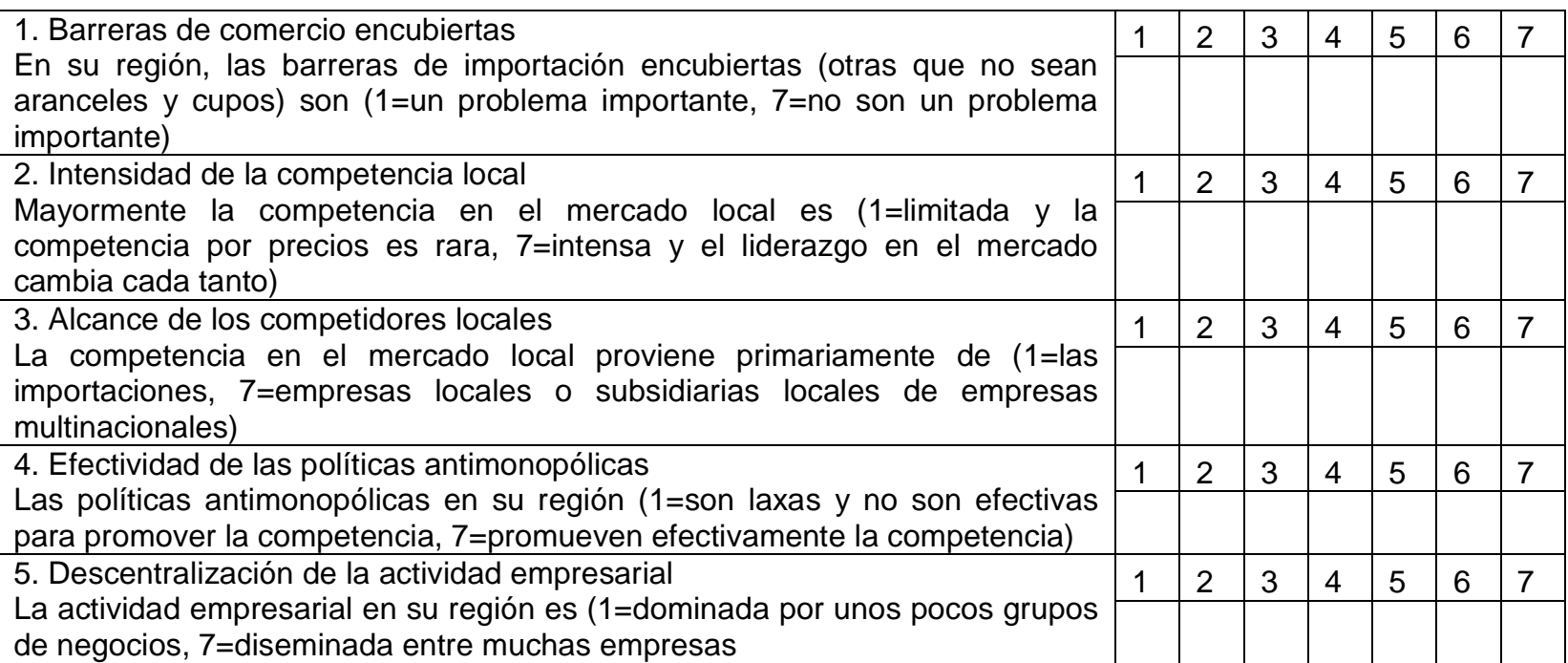




\section{Sobre su empresa}

¿Qué describe mejor su línea principal de negocio?

[1] $\square$ Fabricación de productos de consumo final

[2] $\square$ Fabricación de insumos intermedios

[3] $\square$ Servicios de negocio/comercio

[4] $\square$ Otros, por favor especificar

¿Cuál de los siguientes sectores describe mejor el negocio principal de su compañía (por favor elija sólo un sector)?

[1] $\square$ Alimentos, bebidas y tabaco $\quad$ [2] $\square$ Textil, prendas de vestir y cuero

[3] $\square$ Industria de la Madera

[4] $\square$ Imprentas y editoriales

[5] $\square$ Sustancias Químicas

[6] $\square$ Productos Minerales No Metálicos

[7] $\square$ Metálicas Básicas

$[8] \quad \square \quad$ Productos
Maquinarias y Equpos

Metálicos, [9] $\square$ Otro, especificar

Exportaciones como \% de facturación
[1] $\square 0 \%$
[2] $\square>0 \% \mathrm{y}<10 \%$
[3] $\square 10 \%-25 \%$
[4] $\square 26-50 \%$
[5] $\square 51-75 \%$
[6] $\square>75 \%$

¿Qué puesto describe mejor su posición en la empresa?

[1] $\square$ Director General/CEO

[2] $\square$ Director General Adjunto

[3] $\square$ Gerente

[4] $\square$ Otro 


\subsection{Respuestas procesadas. Resultados finales.}

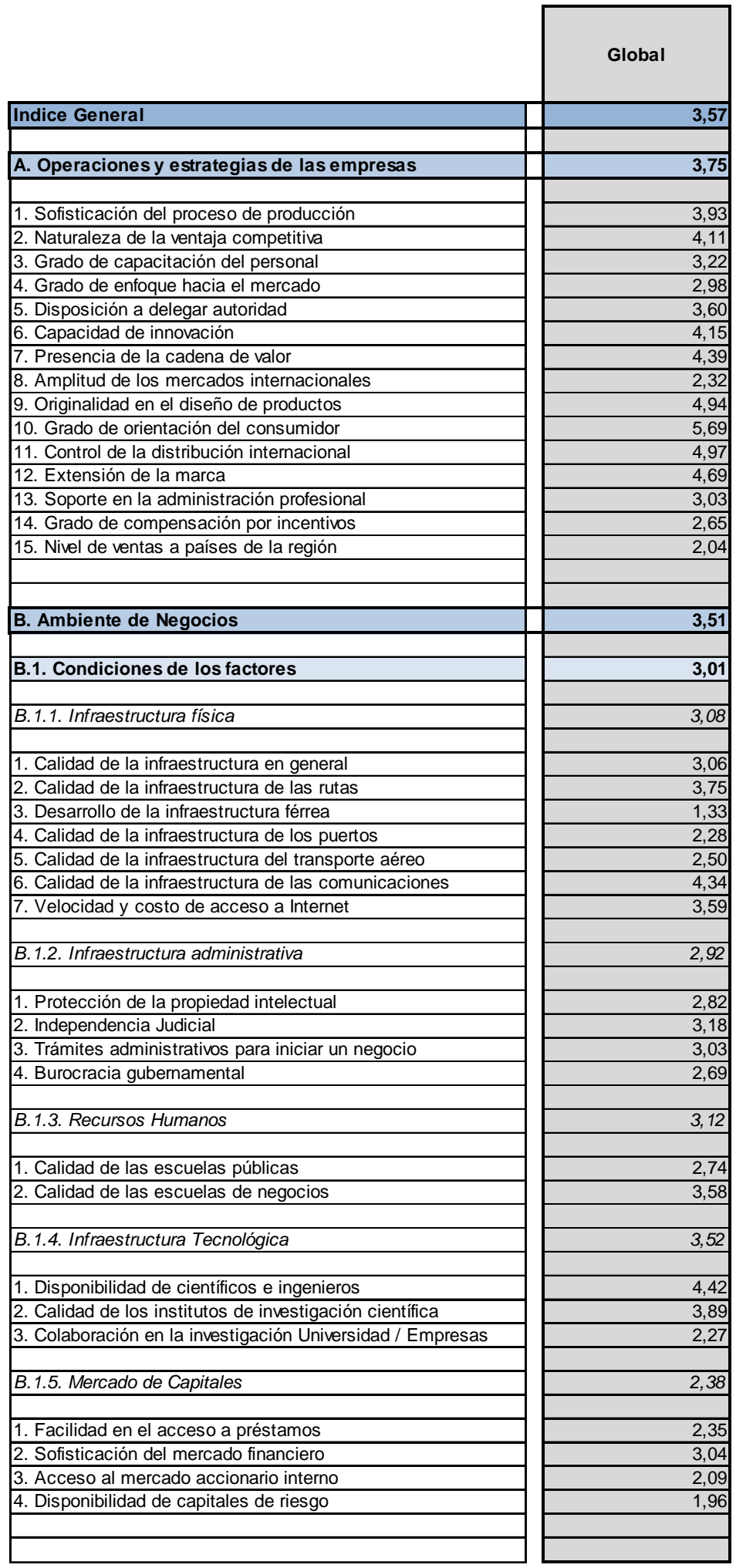




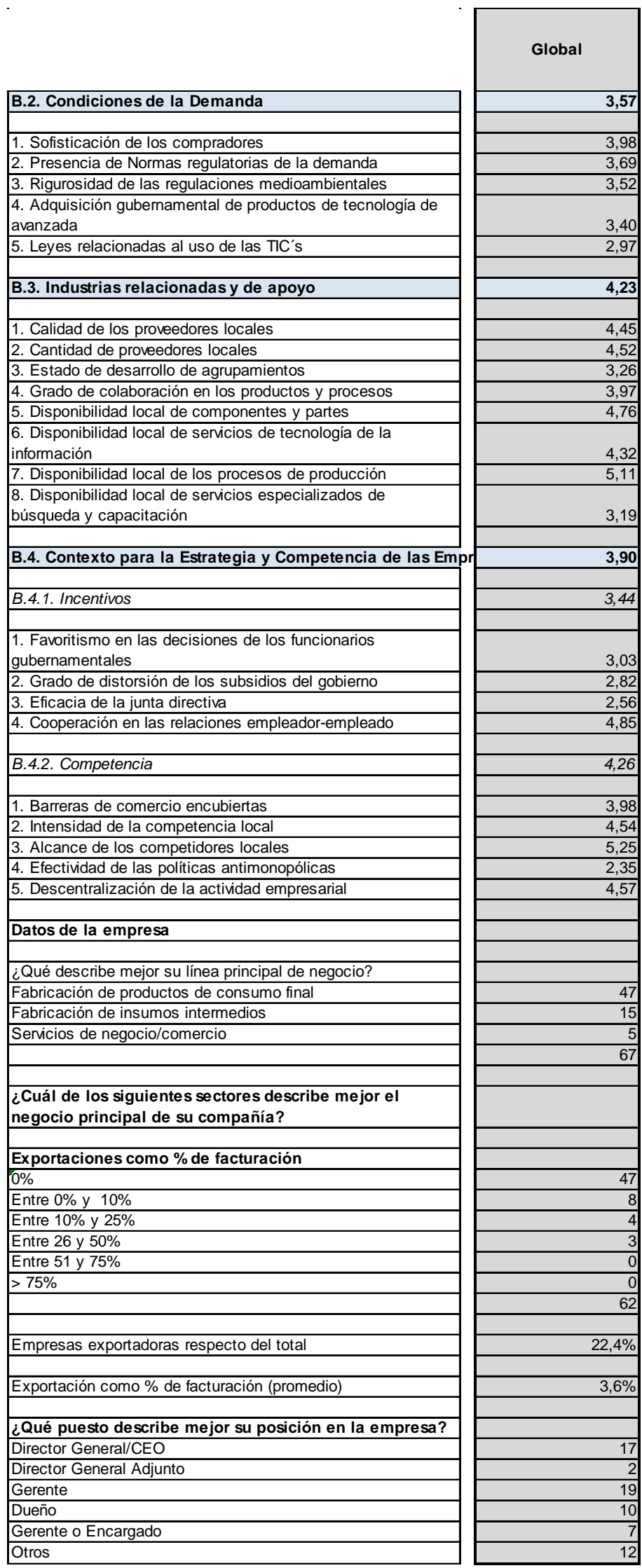




\begin{tabular}{|c|c|c|c|c|}
\hline & $\begin{array}{c}\text { Alimentos, } \\
\text { bebidas y tabaco }\end{array}$ & $\begin{array}{c}\text { Textil, prendas } \\
\text { de vestir y cuero }\end{array}$ & $\begin{array}{c}\text { Industria de la } \\
\text { Madera }\end{array}$ & $\begin{array}{l}\text { Imprentas y } \\
\text { editoriales }\end{array}$ \\
\hline Indice General & 3,66 & 3,30 & 3,29 & 2,88 \\
\hline A. Operaciones y estrategias de las empresas & 3,90 & 3,46 & 2,69 & 3,21 \\
\hline 1. Sofisticación del proceso de producción & 3,91 & 3,50 & 4,50 & 3,67 \\
\hline 2. Naturaleza de la ventaja competitiva & 3,37 & 3,67 & $\mathrm{Ns} / \mathrm{Nc}$ & 4,00 \\
\hline 3. Grado de capacitación del personal & 2,86 & 3,67 & 2,50 & 1,33 \\
\hline 4. Grado de enfoque hacia el mercado & 3,14 & 2,67 & 2,50 & 2,83 \\
\hline 5. Disposición a delegar autoridad & 3,91 & 3,67 & 3,00 & 2,83 \\
\hline 6. Capacidad de innovación & 5,59 & 3,80 & 2,00 & 1,20 \\
\hline 7. Presencia de la cadena de valor & 5,70 & 4,20 & $\mathrm{Ns} / \mathrm{Nc}$ & 2,33 \\
\hline 8. Amplitud de los mercados internacionales & 2,64 & 2,50 & $\mathrm{Ns} / \mathrm{Nc}$ & 1,33 \\
\hline 9. Originalidad en el diseño de productos & 6,19 & 4,17 & 2,50 & 5,50 \\
\hline 10. Grado de orientación del consumidor & 6,14 & 4,50 & 3,00 & 5,33 \\
\hline 11. Control de la distribución internacional & 4,63 & 4,00 & $\mathrm{Ns} / \mathrm{Nc}$ & 6,50 \\
\hline 12. Extensión de la marca & 5,33 & 3,00 & $\mathrm{Ns} / \mathrm{Nc}$ & 5,00 \\
\hline 13. Soporte en la administración profesional & 2,50 & 2,67 & 1,00 & 3,67 \\
\hline 14. Grado de compensación por incentivos & 2,05 & 3,00 & 3,00 & 2,67 \\
\hline 15. Nivel de ventas a países de la región & 1,40 & 2,25 & $\mathrm{Ns} / \mathrm{Nc}$ & 1,00 \\
\hline & & & & \\
\hline B. Ambiente de Negocios & 3,58 & 3,24 & 3,47 & 2,77 \\
\hline B.1. Condiciones de los factores & 2,67 & 3,09 & 3,12 & 2,63 \\
\hline B.1.1. Infraestructura física & 2,37 & 3,29 & 2,17 & 4,45 \\
\hline & & & & \\
\hline 1. Calidad de la infraestructura en general & 2,50 & 2,40 & 2,00 & 2,83 \\
\hline 2. Calidad de la infraestructura de las rutas & 3,59 & 4,00 & 4,00 & 4,33 \\
\hline 3. Desarrollo de la infraestructura férrea & 1,00 & 1,17 & 1,00 & 2,00 \\
\hline 4. Calidad de la infraestructura de los puertos & 1,61 & 1,67 & $\mathrm{Ns} / \mathrm{Nc}$ & $\mathrm{Ns} / \mathrm{Nc}$ \\
\hline 5. Calidad de la infraestructura del transporte aéreo & 1,50 & 3,00 & $\mathrm{Ns} / \mathrm{Nc}$ & $\mathrm{Ns} / \mathrm{Nc}$ \\
\hline 6. Calidad de la infraestructura de las comunicaciones & 3,16 & 5,00 & $\mathrm{Ns} / \mathrm{Nc}$ & 6,33 \\
\hline 7. Velocidad y costo de acceso a Internet & 2,95 & 4,67 & 2,00 & 4,67 \\
\hline B.1.2. Infraestructura administrativa & 2,83 & 2,38 & 2,89 & 2,35 \\
\hline & & & & \\
\hline 1. Protección de la propiedad intelectual & 2,39 & 2,83 & 4,00 & 1,50 \\
\hline 2. Independencia Judicial & 3,76 & 1,67 & 4,00 & 1,83 \\
\hline 3. Trámites administrativos para iniciar un negocio & 3,33 & 2,17 & $\mathrm{Ns} / \mathrm{Nc}$ & 2,33 \\
\hline 4. Burocracia gubernamental & 1,99 & 2,83 & 1,79 & 3,71 \\
\hline B.1.3. Recursos Humanos & 2,63 & 3,27 & 2,67 & 2,00 \\
\hline & & & & \\
\hline 1. Calidad de las escuelas públicas & 2,23 & 3,00 & 1,50 & 2,33 \\
\hline 2. Calidad de las escuelas de negocios & 3,19 & 3,60 & 5,00 & 1,60 \\
\hline B.1.4. Infraestructura Tecnológica & 2,86 & 4,44 & 6,50 & 2,72 \\
\hline & & & & \\
\hline 1. Disponibilidad de científicos e ingenieros & 3,76 & 4,67 & 6,00 & 3,83 \\
\hline 2. Calidad de los institutos de investigación científica & 3,31 & 5,17 & 7,00 & 2,17 \\
\hline 3. Colaboración en la investigación Universidad / Empresas & 1,62 & 3,50 & 7,00 & 2,17 \\
\hline B.1.5. Mercado de Capitales & 2,98 & 2,06 & 2,00 & 1,36 \\
\hline & & & & \\
\hline 1. Facilidad en el acceso a préstamos & 3,33 & 1,83 & 3,00 & 1,50 \\
\hline 2. Sofisticación del mercado financiero & 4,00 & 2,50 & 2,00 & 1,67 \\
\hline 3. Acceso al mercado accionario interno & 2,29 & 1,50 & 1,00 & 1,00 \\
\hline 4. Disponibilidad de capitales de riesgo & 1,93 & 2,25 & 1,00 & 1,17 \\
\hline
\end{tabular}




\begin{tabular}{|c|c|c|c|c|}
\hline & $\begin{array}{l}\text { Alimentos, } \\
\text { bebidas y tabaco }\end{array}$ & $\begin{array}{l}\text { Textil, prendas } \\
\text { de vestir y cuero }\end{array}$ & $\begin{array}{c}\text { Industria de la } \\
\text { Madera }\end{array}$ & $\begin{array}{l}\text { Imprentas y } \\
\text { editoriales }\end{array}$ \\
\hline B.2. Condiciones de la Demanda & 3,29 & 3,18 & 3,43 & 2,38 \\
\hline & & & & \\
\hline 1. Sofisticación de los compradores & 4,10 & 3,83 & 3,50 & 3,50 \\
\hline 2. Presencia de Normas regulatorias de la demanda & 2,65 & 3,83 & 3,00 & 2,20 \\
\hline 3. Rigurosidad de las regulaciones medioambientales & 2,68 & 3,17 & 4,00 & 2,20 \\
\hline $\begin{array}{l}\text { 4. Adquisición gubernamental de productos de tecnología de } \\
\text { avanzada }\end{array}$ & 4,13 & 2,40 & $\mathrm{Ns} / \mathrm{Nc}$ & 1,75 \\
\hline 5. Leyes relacionadas al uso de las TIC's & 2,85 & 2,40 & 3,00 & 1,75 \\
\hline B.3. Industrias relacionadas y de apoyo & 4,60 & 3,55 & 3,92 & 2,76 \\
\hline & & & & \\
\hline 1. Calidad de los proveedores locales & 4,77 & 3,20 & 3,50 & 5,00 \\
\hline 2. Cantidad de proveedores locales & 4,77 & 3,40 & 4,00 & 4,00 \\
\hline 3. Estado de desarrollo de agrupamientos & 2,90 & 3,00 & 3,50 & 2,17 \\
\hline 4. Grado de colaboración en los productos y procesos & 4,64 & 2,60 & 5,00 & 1,75 \\
\hline 5. Disponibilidad local de componentes y partes & 6,32 & 3,80 & 4,50 & 1,17 \\
\hline $\begin{array}{l}\text { 6. Disponibilidad local de servicios de tecnología de la } \\
\text { información }\end{array}$ & 3,69 & 4,60 & 4,00 & 4,50 \\
\hline 7. Disponibilidad local de los procesos de producción & 6,43 & 4,83 & 4,50 & 2,00 \\
\hline $\begin{array}{l}\text { 8. Disponibilidad local de servicios especializados de } \\
\text { búsqueda y capacitación }\end{array}$ & 2,65 & 2,60 & 2,00 & 1,17 \\
\hline B.4. Contexto para la Estrategia y Competencia de las Em & 4,74 & 3,36 & 3,70 & 3,33 \\
\hline B.4.1. Incentivos & 4,15 & 2,74 & 3,67 & 2,59 \\
\hline $\begin{array}{l}\text { 1. Favoritismo en las decisiones de los funcionarios } \\
\text { gubernamentales }\end{array}$ & 3,45 & 2,40 & 1,00 & 2,17 \\
\hline 2. Grado de distorsión de los subsidios del gobierno & 3,71 & 2,00 & $\mathrm{Ns} / \mathrm{Nc}$ & 2,33 \\
\hline 3. Eficacia de la junta directiva & 3,10 & 2,67 & $\mathrm{Ns} / \mathrm{Nc}$ & 3,00 \\
\hline 4. Cooperación en las relaciones empleador-empleado & 5,73 & 3,67 & 5,00 & 3,00 \\
\hline B.4.2. Competencia & 5,19 & 3,84 & 3,71 & 3,81 \\
\hline & & & & \\
\hline 1. Barreras de comercio encubiertas & 6,33 & 4,60 & $\mathrm{Ns} / \mathrm{Nc}$ & 3,00 \\
\hline 2. Intensidad de la competencia local & 5,14 & 4,00 & 3,50 & 3,83 \\
\hline 3. Alcance de los competidores locales & 6,86 & 4,17 & 4,50 & 4,60 \\
\hline 4. Efectividad de las políticas antimonopólicas & 1,72 & 1,67 & 1,00 & 2,40 \\
\hline 5. Descentralización de la actividad empresarial & 5,57 & 3,80 & 4,50 & 4,83 \\
\hline Datos de la empresa & & & & \\
\hline & & & & \\
\hline ¿Qué describe mejor su línea principal de negocio? & & & & \\
\hline Fabricación de productos de consumo final & 20 & 6 & 1 & 5 \\
\hline Fabricación de insumos intermedios & 2 & 0 & 0 & 0 \\
\hline Servicios de negocio/comercio & 0 & 0 & 1 & 1 \\
\hline & 22 & 6 & 2 & 6 \\
\hline & & & & \\
\hline $\begin{array}{l}\text { ¿Cuál de los siguientes sectores describe mejor el } \\
\text { negocio principal de su compañía? }\end{array}$ & 22 & 6 & 2 & 6 \\
\hline & & & & \\
\hline Exportaciones como \% de facturación & & & & \\
\hline $0 \%$ & 20 & 5 & 2 & 3 \\
\hline Entre $0 \%$ y $10 \%$ & 1 & 0 & 0 & 0 \\
\hline Entre $10 \%$ y $25 \%$ & 0 & 1 & 0 & 0 \\
\hline Entre 26 y $50 \%$ & 1 & 0 & 0 & 0 \\
\hline Entre 51 y $75 \%$ & 0 & 0 & 0 & 0 \\
\hline$>75 \%$ & 0 & 0 & 0 & 0 \\
\hline & 22 & 6 & 2 & 3 \\
\hline & & & & \\
\hline Empresas exportadoras respecto del total & $9,1 \%$ & $16,7 \%$ & $0,0 \%$ & $0,0 \%$ \\
\hline Exportación como \% de facturación (promedio) & $2,0 \%$ & $2.9 \%$ & $0,0 \%$ & $0,0 \%$ \\
\hline & & & & \\
\hline ¿Qué puesto describe mejor su posición en la empresa? & & & & \\
\hline Director General/CEO & 2 & 2 & 0 & 4 \\
\hline \begin{tabular}{|l|} 
Director General Adjunto \\
\end{tabular} & 0 & 0 & 1 & 0 \\
\hline Gerente & 4 & 2 & 0 & 1 \\
\hline Dueño & 5 & 1 & 1 & 1 \\
\hline Gerente o Encargado & 3 & 1 & 0 & 0 \\
\hline Otros & 8 & 0 & 0 & 0 \\
\hline
\end{tabular}




\begin{tabular}{|c|c|c|c|c|}
\hline & $\begin{array}{c}\text { Sustancias } \\
\text { Químicas }\end{array}$ & $\begin{array}{c}\text { Productos } \\
\text { Minerales No } \\
\text { Metálicos }\end{array}$ & $\begin{array}{l}\text { Metálicas } \\
\text { Básicas }\end{array}$ & $\begin{array}{c}\text { Productos } \\
\text { Metálicos, } \\
\text { Maquinarias y } \\
\text { Equipos }\end{array}$ \\
\hline Indice General & 3,38 & 3,99 & 4,91 & 3,77 \\
\hline A. Operaciones y estrategias de las empresas & 3,68 & 3,71 & 5,40 & 4,01 \\
\hline 1 Sofisticación del proceso de producción & 382 & 433 & 400 & 400 \\
\hline 2. Naturaleza de la ventaja competitiva & 4,50 & 5,75 & 7,00 & 3,89 \\
\hline 3. Grado de capacitación del personal & 3,91 & 2,89 & 5,00 & 4,40 \\
\hline 4. Grado de enfoque hacia el mercado & 3,00 & 3,13 & 5,00 & 2,67 \\
\hline 5. Disposición a delegar autoridad & 4,00 & 3,22 & 5,00 & 3,20 \\
\hline 6. Capacidad de innovación & 3,20 & 3,33 & 7,00 & 4,22 \\
\hline 7. Presencia de la cadena de valor & 4,18 & 4,00 & 7,00 & 3,71 \\
\hline 8. Amplitud de los mercados internacionales & 2,00 & 1,00 & 1,00 & 4,00 \\
\hline 9. Originalidad en el diseño de productos & 2,80 & 4,67 & 7,00 & 5,11 \\
\hline 10. Grado de orientación del consumidor & 5,00 & 6,38 & 7,00 & 6,00 \\
\hline 11. Control de la distribución internacional & 4,60 & 5,50 & 7,00 & 5,75 \\
\hline 12. Extensión de la marca & 4,56 & 4,00 & 7,00 & 5,00 \\
\hline 13. Soporte en la administración profesional & 4,36 & 2,22 & 5,00 & 3,50 \\
\hline 14. Grado de compensación por incentivos & 2,91 & 2,56 & 6,00 & 3,10 \\
\hline 15. Nivel de ventas a países de la región & 2,45 & 2,20 & 1,00 & 2,88 \\
\hline & & & & \\
\hline B. Ambiente de Negocios & 3,28 & 4,10 & 4,68 & 3,68 \\
\hline B.1. Condiciones de los factores & 3,03 & 3,41 & 4,24 & 3,49 \\
\hline B11 Infraestructura física & 3,13 & 3.65 & 4.50 & 359 \\
\hline B.1.1. Infraestructura fisica & & & 4,50 & 3,59 \\
\hline 1. Calidad de la infraestructura en general & 3,18 & 3,44 & 6,00 & 4,20 \\
\hline 2. Calidad de la infraestructura de las rutas & 3,64 & 3,50 & 4,00 & 4,00 \\
\hline 3. Desarrollo de la infraestructura férrea & 1,27 & 1,00 & $\mathrm{Ns} / \mathrm{Nc}$ & 2,20 \\
\hline 4. Calidad de la infraestructura de los puertos & 2,36 & 4,60 & $\mathrm{Ns} / \mathrm{Nc}$ & 2,44 \\
\hline 5. Calidad de la infraestructura del transporte aéreo & 2,45 & 2,50 & $\mathrm{Ns} / \mathrm{Nc}$ & 4,44 \\
\hline 6. Calidad de la infraestructura de las comunicaciones & 4,55 & 5,00 & 7,00 & 3,90 \\
\hline 7. Velocidad y costo de acceso a Internet & 4,45 & 2,71 & 1,00 & 3,90 \\
\hline B.1.2. Infraestructura administrativa & 3,14 & 3,09 & 2,62 & 3,49 \\
\hline & & & & \\
\hline 1. Protección de la propiedad intelectual & 2,90 & 2,67 & 2,00 & 5,00 \\
\hline 2. Independencia Judicial & 2,73 & 4,33 & $\mathrm{Ns} / \mathrm{Nc}$ & 3,60 \\
\hline 3. Trámites administrativos para iniciar un negocio & 2,64 & 2,44 & 4,00 & 4,20 \\
\hline 4. Burocracia gubernamental & 4,27 & 3,19 & 1,86 & 1,61 \\
\hline B.1.3. Recursos Humanos & 3,43 & 3,73 & 3,50 & 3,89 \\
\hline & & & & \\
\hline 1. Calidad de las escuelas públicas & 2,55 & 2,75 & 1,00 & 4,60 \\
\hline 2. Calidad de las escuelas de negocios & 4,40 & 4,86 & 6,00 & 3,00 \\
\hline B.1.4. Infraestructura Tecnológica & 3,69 & 4,19 & 6,00 & 3,43 \\
\hline 1. Disponibilidad de científicos e ingenieros & 4,73 & 4,86 & 6,00 & 4,90 \\
\hline 2. Calidad de los institutos de investigación científica & 4,09 & 5,67 & 7,00 & 3,20 \\
\hline 3. Colaboración en la investigación Universidad / Empresas & 2,10 & 2,50 & 5,00 & 2,20 \\
\hline B.1.5. Mercado de Capitales & 2,07 & 1,00 & $N s / N c$ & 3,00 \\
\hline & & & & \\
\hline 1. Facilidad en el acceso a préstamos & 1,64 & 1,00 & $\mathrm{Ns} / \mathrm{Nc}$ & 2,78 \\
\hline 2. Sofisticación del mercado financiero & 3,00 & 1,00 & $\mathrm{Ns} / \mathrm{Nc}$ & 3,25 \\
\hline 3. Acceso al mercado accionario interno & 2,09 & $\mathrm{Ns} / \mathrm{Nc}$ & $\mathrm{Ns} / \mathrm{Nc}$ & 3,33 \\
\hline 4. Disponibilidad de capitales de riesgo & 1,55 & 1,00 & $\mathrm{Ns} / \mathrm{Nc}$ & 3,00 \\
\hline & & & & \\
\hline
\end{tabular}




\begin{tabular}{|c|c|c|c|c|}
\hline & $\begin{array}{l}\text { Sustancias } \\
\text { Químicas }\end{array}$ & $\begin{array}{c}\text { Productos } \\
\text { Minerales No } \\
\text { Metálicos }\end{array}$ & $\begin{array}{l}\text { Metálicas } \\
\text { Básicas }\end{array}$ & $\begin{array}{c}\text { Productos } \\
\text { Metálicos, } \\
\text { Maquinarias y } \\
\text { Equipos }\end{array}$ \\
\hline B.2. Condiciones de la Demanda & 3,79 & 4,58 & 6,20 & 3,81 \\
\hline 1 Soficticación de los compradorec & 418 & 300 & 700 & 450 \\
\hline 2. Presencia de Normas regulatorias de la demanda & 4,36 & 5,38 & 5,00 & $\frac{4,50}{4,50}$ \\
\hline 3. Rigurosidad de las regulaciones medioambientales & 4,27 & 5,13 & 6,00 & 3,50 \\
\hline 4. Adquisición gubernamental de productos de tecnología de avanzada & 2,36 & 6,75 & 7,00 & 2,50 \\
\hline 5. Leyes relacionadas al uso de las TIC's & 3,75 & 3,20 & 6,00 & 2,50 \\
\hline B.3. Industrias relacionadas y de apoyo & 3,89 & 4,87 & 5,67 & 4,43 \\
\hline 1. Calidad de los proveedores locales & 4,09 & 4,67 & 4,00 & 4,50 \\
\hline 2. Cantidad de proveedores locales & 4,09 & 5,33 & 5,00 & 4,60 \\
\hline 3. Estado de desarrollo de agrupamientos & 3,73 & 3,25 & $\mathrm{Ns} / \mathrm{Nc}$ & 4,20 \\
\hline 4. Grado de colaboración en los productos y procesos & 3,80 & 3,67 & 6,00 & 4,22 \\
\hline 5. Disponibilidad local de componentes y partes & 3,45 & 5,67 & 7,00 & 4,40 \\
\hline 6. Disponibilidad local de servicios de tecnología de la información & 4,00 & 5,29 & 5,00 & 4,50 \\
\hline 7. Disponibilidad local de los procesos de producción & 4,00 & 5,89 & 7,00 & 4,80 \\
\hline $\begin{array}{l}\text { 8. Disponibilidad local de servicios especializados de búsqueda y } \\
\text { capacitación }\end{array}$ & 4,00 & 5,14 & $\mathrm{Ns} / \mathrm{Nc}$ & 4,14 \\
\hline B.4. Contexto para la Estrategia y Competencia de las Empresas & 3,05 & 4,31 & 3,78 & 3,37 \\
\hline B.4.1. Incentivos & 2,60 & 3,82 & 6,50 & 3,03 \\
\hline 1. Favoritismo en las decisiones de los funcionarios gubernamentales & 2,45 & 4,00 & 6,00 & 2,89 \\
\hline 2. Grado de distorsión de los subsidios del gobierno & 1,82 & 3,75 & 6,00 & 1,90 \\
\hline 3. Eficacia de la junta directiva & 3,43 & 1,56 & 7,00 & 1,67 \\
\hline 4. Cooperación en las relaciones empleador-empleado & 3,00 & 6,00 & 7,00 & 5,50 \\
\hline B.4.2. Competencia & 3,38 & 4,68 & 1,60 & 3,71 \\
\hline 1. Barreras de comercio encubiertas & 2,18 & 2,50 & 1,00 & 2,83 \\
\hline 2. Intensidad de la competencia local & 4,27 & 5,11 & $\begin{array}{ll}1,00 \\
1,00\end{array}$ & 4,33 \\
\hline 3. Alcance de los competidores locales & 4,64 & 5,44 & 1,00 & 3,90 \\
\hline 4. Efectividad de las políticas antimonopólicas & 2,91 & 4,00 & 4,00 & 3,00 \\
\hline 5. Descentralización de la actividad empresarial & 2,91 & 5,56 & 1,00 & 3,88 \\
\hline Datos de la empresa & & & & \\
\hline \begin{tabular}{|l} 
¿ Oué describe meior sulínea princinal de neaccio? \\
\end{tabular} & & & & \\
\hline ¿abricación de productos de consumo final & 3 & 4 & 1 & 7 \\
\hline Fabricación de insumos intermedios & 7 & 5 & 0 & 1 \\
\hline Servicios de negocio/comercio & 1 & 0 & 0 & 2 \\
\hline & 11 & 9 & 1 & 10 \\
\hline $\begin{array}{l}\text { ¿Cuál de los siguientes sectores describe mejor el negocio } \\
\text { principal de su compañía? }\end{array}$ & 11 & 9 & 1 & 10 \\
\hline Exportaciones como \% de facturación & & & & \\
\hline $0 \%$ & 4 & 5 & 0 & 8 \\
\hline Entre $0 \%$ y $10 \%$ & 2 & 4 & 1 & 0 \\
\hline Entre $10 \%$ y $25 \%$ & 2 & 0 & 0 & 1 \\
\hline Entre 26 y $50 \%$ & 1 & 0 & 0 & 1 \\
\hline Entre 51 y $75 \%$ & 0 & 0 & 0 & 0 \\
\hline$>75 \%$ & 0 & 0 & 0 & 0 \\
\hline & 9 & 9 & 1 & 10 \\
\hline Empresas exportadoras respecto del total & $45,5 \%$ & $44,4 \%$ & $100,0 \%$ & $20,0 \%$ \\
\hline & & & & \\
\hline Exportación como \% de facturación (promedio) & $9,2 \%$ & $2,2 \%$ & $5,0 \%$ & $5,6 \%$ \\
\hline ¿Qué puesto describe mejor su posición en la empresa? & & & & \\
\hline Director General/CEO & 3 & 2 & 0 & 4 \\
\hline Director General Adjunto & 0 & $\overline{0}$ & 1 & $\overline{0}$ \\
\hline Gerente & 7 & 5 & 0 & 0 \\
\hline Dueño & 1 & 0 & 0 & 1 \\
\hline Gerente o Encargado & 0 & 2 & 0 & 1 \\
\hline Otros & 0 & 0 & 0 & 4 \\
\hline
\end{tabular}

\subsection{Encuesta de Competitividad Adaptada para la comparación con índices internacionales.}




\begin{tabular}{|c|c|}
\hline INDICE GENERAL & $\begin{array}{c}\text { Preguntas } \\
\text { Coincidentes } \\
\end{array}$ \\
\hline \multicolumn{2}{|l|}{ A. Operaciones y estrategias de las empresas } \\
\hline \multicolumn{2}{|l|}{ 1. Sofisticación del proceso de producción } \\
\hline \multicolumn{2}{|l|}{ 2. Naturaleza de la ventaja competitiva } \\
\hline \multicolumn{2}{|l|}{ 3. Grado de capacitación del personal } \\
\hline \multicolumn{2}{|l|}{ 4. Grado de enfoque hacia el mercado } \\
\hline \multicolumn{2}{|l|}{ 5. Disposición a delegar autoridad } \\
\hline \multirow{2}{*}{\multicolumn{2}{|c|}{ 6. Capacidad de innovación }} \\
\hline & 7. Presencia de la cadena de valor \\
\hline \multicolumn{2}{|l|}{ 8. Amplitud de los mercados internacionales } \\
\hline \multicolumn{2}{|l|}{ 9. Originalidad en el diseño de productos } \\
\hline \multirow{2}{*}{\multicolumn{2}{|c|}{ 10. Grado de orientación del consumidor }} \\
\hline 11. Control de la distribución internacional & \\
\hline 12. Extensión de la marca & \\
\hline 13. Soporte en la administración profesional & \\
\hline 14. Grado de compensación por incentivos & \\
\hline 15. Nivel de ventas a países de la región & \\
\hline B. Ambiente de Negocios & \\
\hline B.1. Condiciones de los factores & \\
\hline B.1.1. Infraestructura física & \\
\hline & \\
\hline 1. Calidad de la infraestructura en general & \\
\hline 2. Calidad de la infraestructura de las rutas & \\
\hline 3. Desarrollo de la infraestructura férrea & \\
\hline 4. Calidad de la infraestructura de los puertos & \\
\hline 5. Calidad de la infraestructura del transporte aéreo & \\
\hline 6. Calidad de la infraestructura de las comunicaciones & \\
\hline 7. Velocidad y costo de acceso a Internet & \\
\hline B.1.2. Infraestructura administrativa & \\
\hline 1. Protección de la propiedad intelectual & \\
\hline 2. Independencia Judicial & \\
\hline 3. Trámites administrativos para iniciar un negocio & \\
\hline 4. Burocracia gubernamental & \\
\hline B.1.3. Recursos Humanos & \\
\hline 1. Calidad de las escuelas públicas & \\
\hline 2. Calidad de las escuelas de negocios & \\
\hline B.1.4. Infraestructura Tecnológica & \\
\hline 1. Disponibilidad de científicos e ingenieros & \\
\hline 2. Calidad de los institutos de investigación científica & \\
\hline 3. Colaboración en la investigación Universidad / Empresas & \\
\hline B.1.5. Mercado de Capitales & \\
\hline 1. Facilidad en el acceso a préstamos & \\
\hline 2. Sofisticación del mercado financiero & \\
\hline 3. Acceso al mercado accionario interno & \\
\hline 4. Disponibilidad de capitales de riesgo & \\
\hline B.2. Condiciones de la Demanda & \\
\hline 1. Sofisticación de los compradores & \\
\hline 2. Presencia de Normas regulatorias de la demanda & \\
\hline 3. Rigurosidad de las regulaciones medioambientales & \\
\hline 4. Adquisición gubernamental de productos de tecnología de avanzada & \\
\hline 5. Leyes relacionadas al uso de las TIC's & \\
\hline B.3. Industrias relacionadas y de apoyo & \\
\hline 1. Calidad de los proveedores locales & \\
\hline 2. Cantidad de proveedores locales & \\
\hline 3. Estado de desarrollo de agrupamientos & \\
\hline 4. Grado de colaboración en los productos y procesos & \\
\hline 5. Disponibilidad local de componentes y partes & \\
\hline 6. Disponibilidad local de servicios de tecnología de la información & \\
\hline 7. Disponibilidad local de los procesos de producción & \\
\hline 8. Disponibilidad local de servicios especializados de búsqueda y capacitación & \\
\hline B.4. Contexto para la Estrategia y Competencia de las Empresas & \\
\hline B.4.1. Incentivos & \\
\hline 1. Favoritismo en las decisiones de los funcionarios gubernamentales & \\
\hline 2. Grado de distorsión de los subsidios del gobierno & \\
\hline 3. Eficacia de la junta directiva & \\
\hline 4. Cooperación en las relaciones empleador-empleado & \\
\hline B.4.2. Competencia & \\
\hline 1. Barreras de comercio encubiertas & \\
\hline 2. Intensidad de la competencia local & \\
\hline 3. Alcance de los competidores locales & \\
\hline 4. Efectividad de las políticas antimonopólicas & \\
\hline 5. Descentralización de la actividad empresarial & \\
\hline
\end{tabular}

\subsection{Resultados de las respuestas adaptadas.}




\begin{tabular}{|c|c|c|c|c|c|}
\hline & $\begin{array}{l}\text { Argentina } \\
\quad\left(85^{\circ}\right)\end{array}$ & $\begin{array}{l}\text { Región La } \\
\text { Plata, Berisso } \\
\text { y Ensenada }\end{array}$ & Suiza $\left(1^{\circ}\right)$ & Singapur $\left(2^{\circ}\right)$ & Suecia $\left(3^{\circ}\right)$ \\
\hline Indice General & 3,67 & 3,97 & 5,88 & 5,28 & 5,86 \\
\hline A. Operaciones y estrategias de las empresas & 3,48 & 4,36 & 5,95 & 5,12 & 6,03 \\
\hline \multirow{7}{*}{$\begin{array}{l}\text { 1. Sofisticación del proceso de producción } \\
\text { 2. Naturaleza de la ventaja competitiva } \\
\text { 5. Disposición a delegar autoridad } \\
\text { 6. Capacidad de innovación } \\
\text { 10. Grado de orientación del consumidor } \\
\text { 12. Extensión de la marca }\end{array}$} & 39 & 393 & 64 & 56 & \\
\hline & $\begin{array}{l}3, y \\
2,4\end{array}$ & $\begin{array}{l}3,93 \\
4,11\end{array}$ & $\begin{array}{l}0,4 \\
6,4\end{array}$ & $\frac{5,6}{5,5}$ & $\frac{6,3}{5,8}$ \\
\hline & 3,6 & 3,60 & 5,3 & 4,6 & 6,3 \\
\hline & 2,9 & 4,15 & 5,8 & 4,3 & 5,7 \\
\hline & 3,8 & 5,69 & 6,0 & 5,4 & 6,0 \\
\hline & 4,3 & 4,69 & 5,8 & 5,3 & 6,1 \\
\hline & & & & & \\
\hline B. Ambiente de Negocios & 3,85 & 3,58 & 5,82 & 5,44 & 5,68 \\
\hline B.1. Condiciones de los factores & 3,31 & 3,00 & $\overline{5,84}$ & 5,80 & $\overline{5,64}$ \\
\hline \multirow[t]{2}{*}{ B.1.1. Infraestructura física } & 3,18 & 2,61 & 6,32 & 6,50 & 5,82 \\
\hline & & & & & \\
\hline \multirow{5}{*}{$\begin{array}{l}\text { 1. Calidad de la infraestructura en general } \\
\text { 2. Calidad de la infraestructura de las rutas } \\
\text { 3. Desarrollo de la infraestructura férrea } \\
\text { 4. Calidad de la infraestructura de los puertos } \\
\text { 5. Calidad de la infraestructura del transporte aéreo }\end{array}$} & 3,5 & 3,18 & 6,7 & 6,6 & 6,1 \\
\hline & 3,2 & 3,75 & 6,4 & 6,5 & 5,7 \\
\hline & 2,0 & 1,33 & 6,8 & 5,7 & 5,0 \\
\hline & 3,7 & 2,28 & 5,2 & 6,8 & 6,0 \\
\hline & 3,5 & 2,50 & 6,5 & 6,9 & 6,3 \\
\hline \multirow[t]{2}{*}{ B.1.2. Infraestructura administrativa } & 2,70 & 3,00 & 6,40 & 6,00 & 6,35 \\
\hline & & & & & \\
\hline \multirow{2}{*}{$\begin{array}{l}\text { 1. Protección de la propiedad intelectual } \\
\text { 2. Independencia Judicial }\end{array}$} & 2,8 & 2,82 & 6,4 & 6,4 & 6,2 \\
\hline & 2,6 & 3,18 & 6,4 & 5,6 & 6,5 \\
\hline \multirow[t]{2}{*}{ B.1.3. Recursos Humanos } & 4,10 & 3,16 & 5,95 & 5,85 & 5,30 \\
\hline & & & & & \\
\hline \multirow{2}{*}{$\begin{array}{l}\text { 1. Calidad de las escuelas públicas } \\
\text { 2. Calidad de las escuelas de negocios }\end{array}$} & 3,1 & 2,74 & 5,9 & 6,1 & 5,1 \\
\hline & 5,1 & 3,58 & 6,0 & 5,6 & 5,5 \\
\hline \multirow[t]{2}{*}{ B. 1.4. Infraestructura Tecnológica } & 4,03 & 3,53 & 5,73 & 5,43 & 5,70 \\
\hline & & & & & \\
\hline \multirow{3}{*}{$\begin{array}{l}\text { 1. Disponibilidad de científicos e ingenieros } \\
\text { 2. Calidad de los institutos de investigación científica } \\
\text { 3. Colaboración en la investigación Universidad / Empresas }\end{array}$} & 4,0 & 4,42 & 5,1 & 5,3 & 5,6 \\
\hline & 4,2 & 3,89 & $\overline{6,3}$ & 5,5 & 6,0 \\
\hline & 3,9 & 2,27 & 5,8 & 5,5 & 5,5 \\
\hline \multirow[t]{2}{*}{ B.1.5. Mercado de Capitales } & 2,55 & 2,70 & 4,80 & 5,20 & 5,05 \\
\hline & & & & & \\
\hline \multirow{3}{*}{$\begin{array}{l}\text { 1. Facilidad en el acceso a préstamos } \\
\text { 2. Sofisticación del mercado financiero }\end{array}$} & 1,8 & 2,35 & 3,7 & 4,6 & 4,5 \\
\hline & 3,3 & 3,04 & 5,9 & 5,8 & 5,6 \\
\hline & & & & & \\
\hline B.2. Condiciones de la Demanda & 4,15 & 3,69 & 5,95 & 5,45 & 5,90 \\
\hline \multirow{3}{*}{$\begin{array}{l}\text { 1. Sofisticación de los compradores } \\
\text { 4. Adquisición gubernamental de productos de tecnología de avanzada }\end{array}$} & & & & & \\
\hline & 3,5 & 3,98 & 5,2 & 4,6 & 4,9 \\
\hline & 4,8 & 3,40 & 6,7 & 6,3 & 6,9 \\
\hline B.3. Industrias relacionadas y de apoyo & 4,10 & 4,08 & 5,67 & 5,07 & 5,50 \\
\hline \multirow{4}{*}{$\begin{array}{l}\text { 1. Calidad de los proveedores locales } \\
\text { 2. Cantidad de proveedores locales } \\
\text { 3. Estado de desarrollo de agrupamientos }\end{array}$} & & & & & \\
\hline & 4,3 & 4,45 & 6,2 & 5,1 & 6,0 \\
\hline & 4,5 & 4,52 & 5,7 & 4,9 & 5,4 \\
\hline & 3,5 & 3,26 & 5,1 & 5,2 & 5,1 \\
\hline B.4. Contexto para la Estrategia y Competencia de las Empresas & 3,18 & 3,55 & $\overline{5,15}$ & 5,63 & 5,85 \\
\hline \multirow{3}{*}{ B.4.1. Incentivos } & & & & & \\
\hline & 3,07 & 3,48 & 5,43 & 5,70 & 5,80 \\
\hline & & & & & \\
\hline \multirow{3}{*}{$\begin{array}{l}\text { 1. Favoritismo en las decisiones de los funcionarios gubernamentales } \\
\text { 3. Eficacia de la junta directiva } \\
\text { 4. Cooperación en las relaciones empleador-empleado }\end{array}$} & 1,8 & 3,03 & 4,9 & 5,4 & $\overline{5,8}$ \\
\hline & 4,1 & 2,56 & 5,3 & 5,6 & 5,9 \\
\hline & 3,3 & 4,85 & 6,1 & 6,1 & 5,7 \\
\hline \multirow{3}{*}{ B.4.2. Competencia } & & & & & \\
\hline & 3,30 & 3,62 & 4,87 & 5,57 & 5,90 \\
\hline & & & & & \\
\hline \multirow{3}{*}{$\begin{array}{l}\text { 1. Barreras de comercio encubiertas } \\
\text { 2. Intensidad de la competencia local } \\
\text { 4. Efectividad de las políticas antimonopólicas }\end{array}$} & 2,5 & 3,98 & 4,2 & 6,1 & 6,1 \\
\hline & 4,3 & 4,54 & 5,5 & 5,4 & 5,8 \\
\hline & 3,1 & 2,35 & 4,9 & 5,2 & 5,8 \\
\hline
\end{tabular}




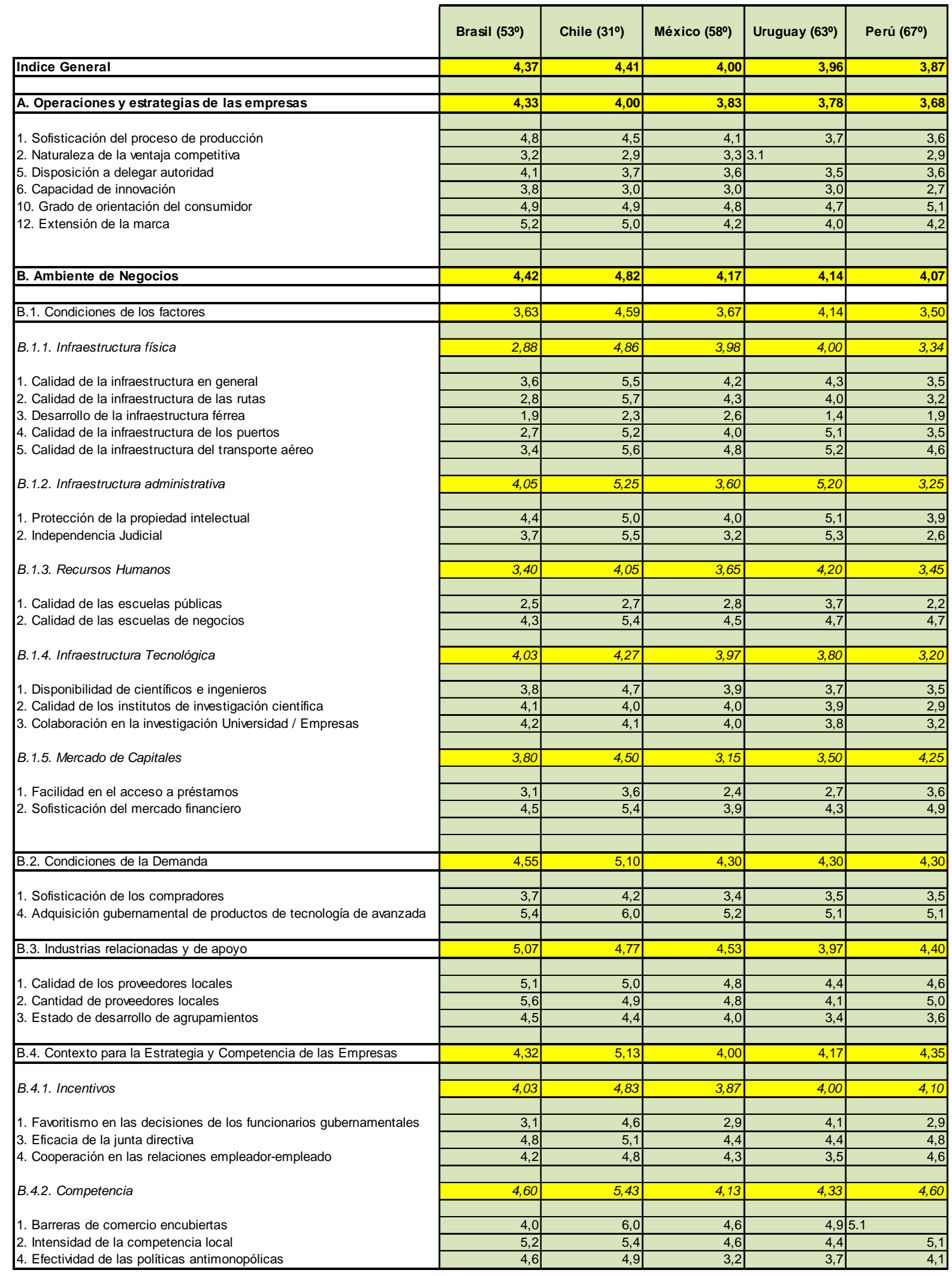




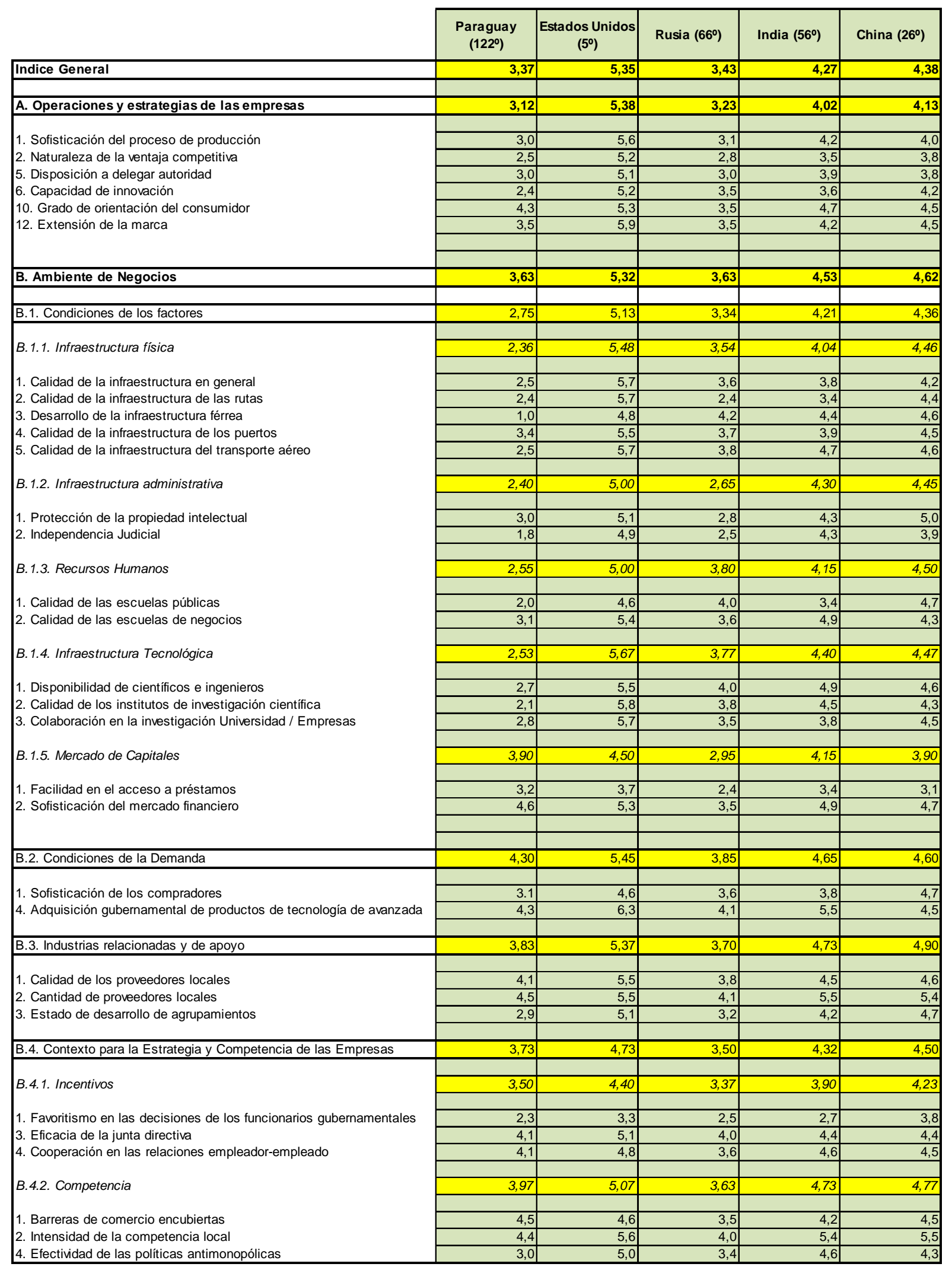




\section{Bibliografía}

- Aghón, Gabriel; Alburquerque, Francisco y Cortés, Patricia (2001) "Desarrollo Económico Local y Descentralización en América Latina: un análisis comparativo", Santiago de Chile, CEPAL / GTZ.

- Buitelaar, Rudolf M. (2000) "¿Cómo crear competitividad colectiva?” Unidad de Industria. División de Desarrollo Productivo y Empresarial.

- Cortés Conde, Roberto (1998) Progreso y declinación de la economía argentina, Buenos Aires, Fondo de Cultura Económica.

- Deming, Edwards (1989) Calidad, productividad y competitividad: la salida de la crisis, Madrid, Ediciones Díaz de Santos.

- Elster, Jon. 1989 The Cement of Society, Cambridge University Press.

- Elster, Jon. 1997 Egonomics, Madrid, Editorial Gedisa.

- Grondona, Mariano (1999) Hacia una teoría del desarrollo. Las condiciones culturales del desarrollo económico, Buenos Aires, Ariel-Planeta

- Harrison, Lawrence (1999) El sueño panamericano, Buenos Aires, Ariel.

- Harrison, Lawrence E. \& Huntington, Samuel P. (2001) La cultura es lo que importa, Editorial Planeta.

- Harrison, Lawrence E. (1991) El subdesarrollo es un estado de la mente, Costa Rica, Libro Libre

- Hofstede, Geert (1999) Culturas y organizaciones: el software mental, la cooperación internacional y su importancia para la supervivencia, Madrid, Editorial Alianza.

- Inglehart, Ronald (1997) Modernization and Postmodernization. Cultural, economic and political change in 43 societies, Princeton, Princeton University Press.

- Klaus Schwab (2011) The Global Competitiveness Report 2011-2012, World Economic Forum ISBN-13: 978-92-95044-74-6 en www.weforum.org/gcr

- Lipset, Seymour Martin y Lenz, Gabriel Salman (2001) La corrupción, la cultura y los mercados, en Huntington, Samuel y Harrison, Lawrence (Ed.): La cultura es lo que importa, Buenos Aires, Planeta-Ariel. 
- Llach, Juan J. (1999) "El crecimiento económico regional: el papel de los clusters basados en los recursos naturales".

- Naciones Unidas, Programa de Desarrollo

http://hdr.undp.org/reports/global/2002/en/indicator/indicator.cfm?File=index. $\underline{\mathrm{html}}$

- Neffa, Julio César (2000) "Qué hacer para mejorar la competitividad de las PyME argentinas". Asociación Trabajo y Sociedad. PIETTE CONICET.

- Porter, Michael (1993) La ventaja competitiva de las naciones, Buenos Aires, Vergara.

- Salvaris, Mike (2000) Community and social indicators: How citizens can measure progress. An overview of social and community indicator projects in Australia and internationally, Hawthorn (Australia), Institute for Social Research - Swinburne University of Technology en http://www.sisr.net/programcsp/published/com_socind.PDF 